\title{
Design and Synthesis of Imidazoline Derivatives Active on Glucose Homeostasis in a Rat Model of Type II Diabetes. 2. Syntheses and Biological Activities of 1,4-Dialkyl-, 1,4-Dibenzyl, and 1-Benzyl-4-alkyl-2-(4',5'-dihydro-1'H- imidazol-2'-yl)piperazines and I sosteric Analogues of I midazoline
}

\begin{abstract}
Gaëlle Le Bihan, ${ }^{\S, \nabla}$ Frédéric Rondu, ${ }^{\S, \nabla}$ Agnès Pelé-Tounian, ${ }^{\ddagger}$ Xuan Wang, ${ }^{\S} \ddagger$ Sandrine Lidy, ${ }^{\S}$ Estéra Touboul, ${ }^{\S}$ Aazdine Lamouri, ${ }^{\S}$ Georges Dive, ${ }^{\perp}$ J ack Huet, ${ }^{\S}$ Bruno Pfeiffer, ${ }^{\dagger}$ Pierre Renard, † Béatrice Guardiola-Lemaître," Domi nique Manéchez," Luc Pénicaud, $\diamond$ Alain Ktorza, ${ }^{\ddagger}$ and J ean-J acques Godfroid*,§

Laboratoire de Pharmacochimi e Moléculaire et Systèmes Membranaires, EA 2381, and Laboratoi re de Physi opathol ogie de la Nutrition, CNRS ESA 7059, Université Paris 7-Denis Diderot, 2, place J ussieu, 75251 Paris Cedex 05, France, ADIR, 1, rue Carle Hébert, and IRI Servier, 6, place des Pléiades, 92415 Courbevoie Cedex, France, Centre d'I ngénierie des Protéines, Institut de Chimie, Université de Liège, Belgium, and UPRESA, CNRS 5018/-UPS, Toulouse, France
\end{abstract}

Received October 5, 1998

\begin{abstract}
Piperazine derivatives have been identified as new antidiabetic compounds. Structure-activity relationship studies in a series of 1-benzyl-4-alkyl-2-(4',5'-dihydro-1' $\mathrm{H}$-imidazol-2'-yl)piperazines

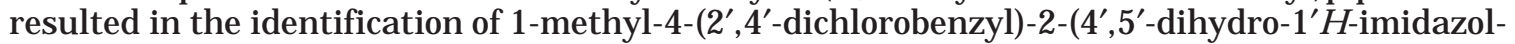
2'-yl)piperazine, PMS 812 (S-21663), as a highly potent antidiabetic agent on a rat model of diabetes, mediated by an important increase of insulin secretion independently of $\alpha_{2}$ adrenoceptor blockage. These studies were extended to find additional compounds in these series with improved properties. In such a way, substitution of both piperazine $\mathrm{N}$ atoms was first optimized by using various alkyl, branched or not, and benzyl groups. Second, some modifications of the imidazoline ring and its replacement by isosteric heterocycles were carried out, proceeding from PMS 812, to evaluate their influence on the antidiabetic activity. The importance of the distance between the imidazol ine ring and the piperazine skel eton was studied third. Finally, the influence of the N-benzyl moiety was also analyzed compared to a direct $\mathrm{N}$-phenyl substitution. The pharmacological evaluation was performed in vivo using glucose tolerance tests on a rat model of type II diabetes. The most active compounds were 1,4-dii sopropyl-2-(4',5'-di hydro-1'H-imidazol-2'-yl)piperazine (41a), PMS 847 (S-22068), and 1,4diisobutyl-2-(4',5'-dihydro-1'H-imidazol-2'-yl)piperazine (41b), PMS 889 (S-22575), which strongly improved glucose tolerance without any side event or hypoglycemic effect. More particularly, PMS 847 proved to be as potent after po $(100 \mu \mathrm{mol} / \mathrm{kg})$ as after ip administration and appears as a good candidate for clinical investigations.
\end{abstract}

\section{Introduction}

Non-insulin-dependent diabetes mellitus (NIDDM) is one of the most common chronic and dangerous diseases with a preval ence of $4 \%$ in the Western world's population. Despite large efforts to discover new antidiabetic drugs, only two classes of oral hypoglycemic agents (sulfonylureas and biguanides) are available for the treatment of NIDDM, and for both of them, a residual insulin secretion is necessary for activity. Sulfonylureas, such as tolbutamide and gliclazide, are hypoglycemic

\footnotetext{
* To whom correspondence should be adressed. E-mail: godfroid@ paris7.jussieu.fr.

§ Université of Paris 7-Denis Diderot-EA 2381.

¥ Université of Paris 7-Denis Diderot-CNRS ESA 7059.

† ADIR.

"IRI Servier.

$\perp$ Université of Liège.

$\diamond$ UPRESA, CNRS 5018/-UPS

$\nabla$ These authors contributed equally to this work.
}

compounds which stimulate insulin secretion via a wellknown mechanism. ${ }^{1}$ But a major drawback of sulfonylurea-based therapies is the occurrence of severe hypoglycemia. Biguanides (particularly metformine) act mainly by decreasing gluconeogenesis and increasing peripheral utilization of glucose. ${ }^{2-5}$ Among the most promising therapeutic approaches, imidazol ine derivatives such as midaglizole, ${ }^{6,7}$ deriglidole, ${ }^{8,10}$ and efaroxan ${ }^{11}$ were reported to be antihyperglycemic agents.

In the past few years evidence occurred that the insulin-secreting potency of imidazoline derivatives was not correlated with their $\alpha_{2}$ antagonistic properties, ${ }^{12,13}$ and it has been proposed that some of these compounds could interact with imidazol ine preferring binding sites (I-PBS). ${ }^{14,15}$

In a previous paper, ${ }^{16}$ we described the syntheses and pharmaceutical evaluation of new antihyperglycemic 1,4-disubstituted-2-(4', 5'-dihydro-1'H-imidazol-2'-yl)- 


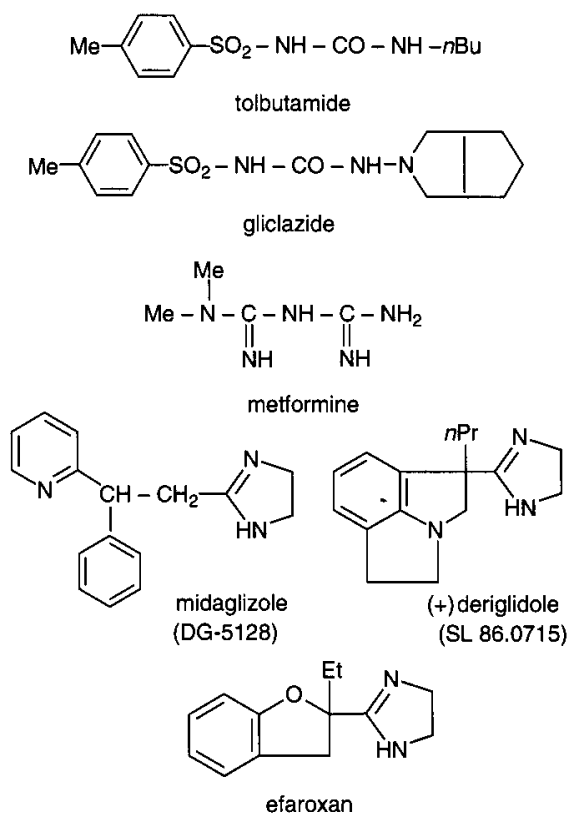

piperazines having the following general formula:

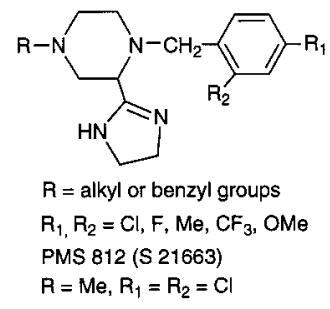

These compounds proved to be potent antihyperglycemic agents in glucose tolerance tests using a rat model of type II diabetes obtained by iv single injection of a low dose (35 mg/kg) of streptozotocin (STZ rats). The structure-activity relationships obtained within this first series showed that good potency was reached when $\mathrm{R}$ is a short linear or branched alkyl chain and the phenyl ring is substituted with halogens (more particularly chlorine atoms). One of the most active compounds was 1-(2',4'-dichlorobenzyl)-4-methyl-2-(4',5'-dihydro-1'Himidazol-2'-yl)piperazine, PMS 812 (S-21663). Diabetic rats treated with such compounds, especially PMS 812, exhibited similar glycemia as nondiabetic control rats. ${ }^{16,17}$ None of the compounds of this series presented a potent affinity for adrenoreceptors and I-PBS. ${ }^{16}$ M oreover PMS 812 was considered as a very efficient glucose-independent insulin secretagogue acting through a novel imidazol ine site, linked to $\mathrm{K}^{+}$channels, and distinct from $\mathrm{I}_{1}$ - and $\mathrm{I}_{2}$-PBS. ${ }^{18}$

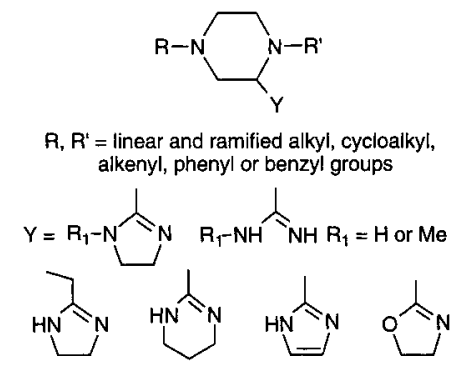

In the continuation of this previous work, ${ }^{16}$ we report here the synthesis and the biological evaluation of 1,4- dialkyl-, 1,4-dibenzyl-, and 1-alkyl-4-benzyl(or phenyl)2-(4',5'-dihydro-1'H-imidazol-2'-yl)piperazine derivatives. Pharmacomodulation was also performed on the imidazoline moiety itself which was substituted by a methyl or replaced by isosteric groups such as oxazoline, tetrahydropyrimidine, or amidine. All these compounds were evaluated in vivo for their antidiabetic activity using glucose tolerance tests. In vitro binding experiments were performed on selected compounds and showed the same negative results as observed in the previous study. ${ }^{16}$

\section{Chemistry}

The 2-(4',5'-dihydro-1'H-imidazol-2'-yl)- (41a-q, 42 , and 60-63), 2-(4',5'-dihydro- $1^{\prime}, 3^{\prime}$-oxaxazol-2'-yl)- (50), and 2-(4',5'-dihydro-1'H-imidazol-2'-yl)- (59) piperazines were prepared from the corresponding esters synthesized according to pathways described in Schemes 1-4.

Scheme 1 describes the synthesis of the major part of the 1,4-alkylated and 1,4-benzylated ester derivatives. Alkylation of ethyl piperazine-2-carboxylate (1) 1$)^{16}$ with 2 equiv of alkyl or allyl halides in refluxing acetone or acetonitrile afforded the disubstituted compounds $\mathbf{2} \mathbf{a}-$ g. In the case of chloro or bromo derivatives, the yields of $\mathbf{2}$ were improved by addition of catalytic amounts of $\mathrm{KI} .{ }^{19}$ Selective alkylation in position 1 needed the use of a protective group in position 4, i.e., triphenylmethyl which was introduced by treating $\mathbf{1}$ at $-10^{\circ} \mathrm{C}$ with 1 equiv of trityl chloride. Ethyl 4-tritylpiperazine-2-carboxylate (3) ${ }^{16}$ was then alkylated into 5 and the trityl group removed under acidic conditions leading to $\mathbf{6}$. Reductive alkylation ${ }^{20}$ of $\mathbf{6}$ afforded the ethyl 1-alkyl4-methyl piperazi ne-2-carboxylate (7). Monosubstitution of $\mathbf{1}$ in position 4 was performed in conditions depending on the halide derivative. Ethyl 4-alkylpiperazine-2carboxylates $\mathbf{4}$ were achieved in refluxing acetone with alkyl halides and at room temperature with allyl and benzyl chlorides. In all cases a mixture of 4-monosubstituted and 1,4-disubstituted piperazine derivatives was obtained, but the components were easily separated by column chromatography on silica gel. No 1-Nmonosubstituted compound was detected, and this can be explained by the steric hindrance due to the substituent in position 2 . This effect disappears probably by change of piperazine conformation after 4-N-alkylation.

When $\mathrm{R}$ is a phenyl or a dicyclopropylmethyl group and $\mathrm{R}^{\prime}$ a methyl or a dicyclopropylmethyl moiety, the corresponding $\mathrm{N}, \mathrm{N}^{\prime}$-disubstituted ethylenediamine was prepared before cyclization into the piperazine ring as seen in Schemes 2 and 3. In Scheme 2, reductive alkylation of commercial $\mathrm{N}$-benzylaminoethanol afforded $\mathbf{9}$ which was converted to chloride $\mathbf{1 0}$ by treatment with thionyl chloride. The amine 11, easily purified by distillation, was then obtained in good yield using an excess of ammonia (30 times more). Prolonged heating ( 14 days) at $80^{\circ} \mathrm{C}$ of $\mathbf{1 1}$ or ethylenediamine with dicyclopropyl ketone was required to produce the imine $\mathbf{1 3}$ or diimine 14. After sodium borohydride reduction (and catalytic debenzylation of compound 15), the resulting amines 16 and $\mathbf{1 7}$ reacted with ethyl 2,3dibromopropionate to give 1-dicyclopropylmethyl-4methyl (18) and 1,4-bis(dicycl opropylmethyl) (19) ester intermediates. Two isomers could be expected from the 
Scheme 1. Synthesis of Alkyl and Benzyl Ester Intermediates $\mathbf{2} \mathbf{a}-\mathbf{g}, \mathbf{7} \mathbf{a}-\mathbf{d}$, and $\mathbf{8} \mathbf{a}-\mathbf{c}^{\mathbf{a}}$

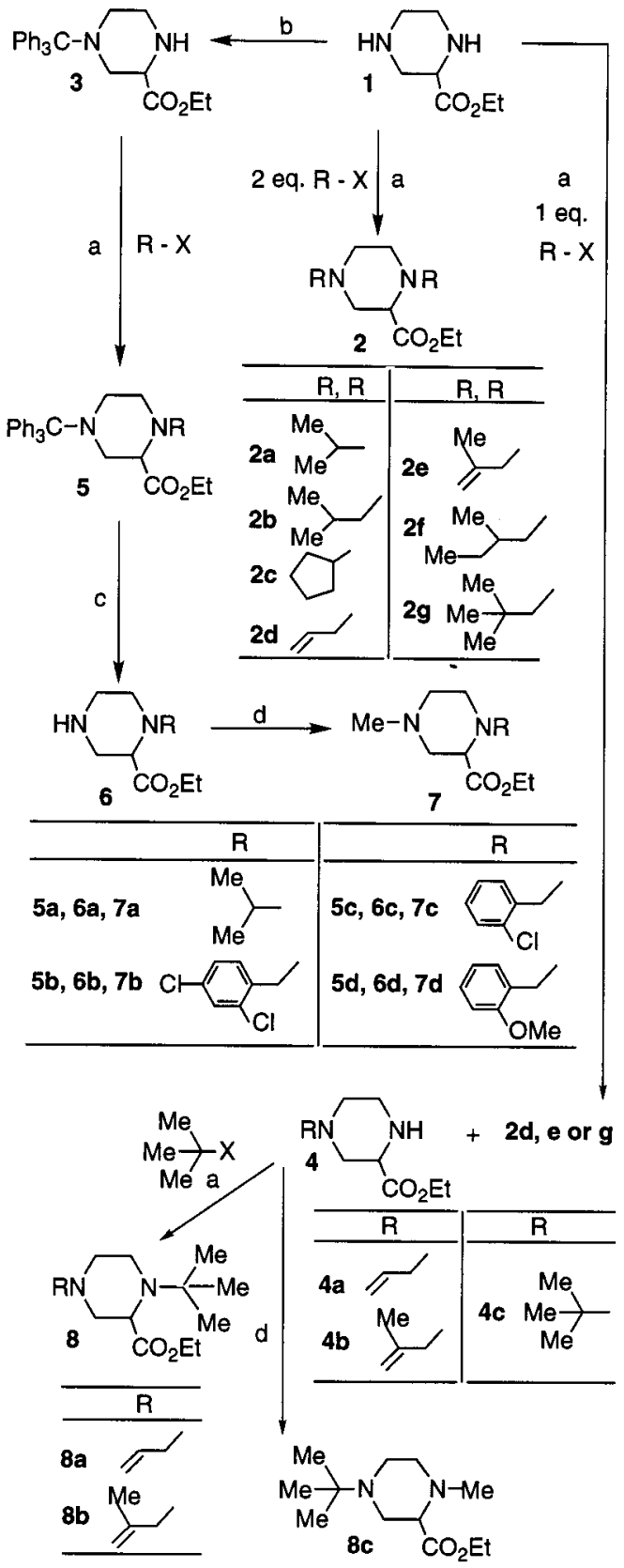

a (a) $\mathrm{MeCN}$ or $\mathrm{Me}_{2} \mathrm{CO}, \mathrm{K}_{2} \mathrm{CO}_{3}, \mathrm{KI}$; (b) $\mathrm{Ph}_{3} \mathrm{C}-\mathrm{Cl}, \mathrm{NEt}_{3}, \mathrm{CH}_{2} \mathrm{Cl}_{2}$, $-10^{\circ} \mathrm{C}$; (c) $\mathrm{HCl}, \mathrm{Me}_{2} \mathrm{CO}$ then $\mathrm{Na}_{2} \mathrm{CO}_{3}$; (d) $\mathrm{HCO}_{2} \mathrm{H}, \mathrm{HCHO}, \mathrm{MeOH}$.

condensation of amine 17. Only the isomer 18 was isolated. The reaction is a type II NS. The first attack comes from the nonbulky nitrogen on C3 bromide of ethyl 2,3-dibromopropionate. If the methyl group is replaced by a more bulky substituent such as an isopropyl group, the cyclization provided two regioisomers, ${ }^{21}$ suggesting that steric control plays a major role in determining the high selectivity.

N-Phenyl-substituted esters 24, 29, and 35 were prepared using the corresponding 1-phenyl-4-al kylethylenediamines 23, 28, and $\mathbf{3 4}$. These diamines were synthesized by three different pathways described in Scheme 3. In method $A$, reaction of aniline with 0.5 equiv of benzoyl chloride followed by alkylation of the resulting amide $\mathbf{2 0}$ with 2-chloro-1-N-methyl-N-benzylaminoethane gave compound $\mathbf{2 1}$. Both protecting groups
Scheme 2. Synthesis of Dicyclopropylmethyl Ester Intermediates 18 and $19^{\mathrm{a}}$

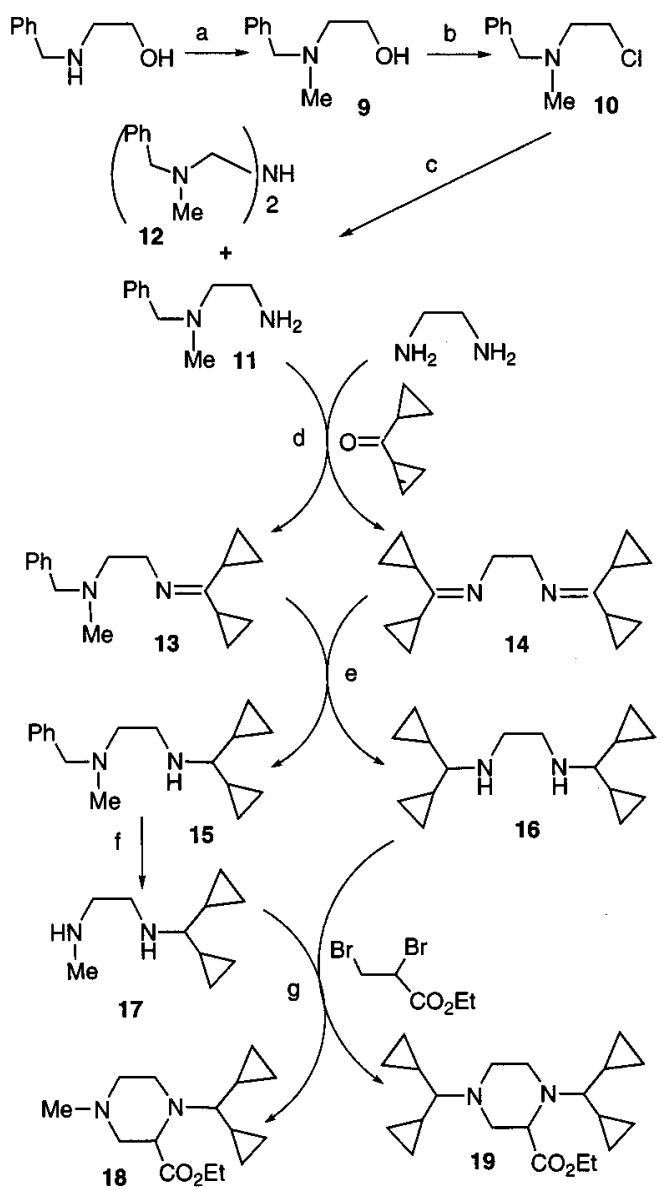

a (a) $\mathrm{HCO}_{2} \mathrm{H}, \mathrm{HCHO}, \mathrm{MeOH}$ then $\mathrm{Na}_{2} \mathrm{CO}_{3}$; (b) $\mathrm{SOCl}_{2}$; (c) $\mathrm{NH}_{3}$, $\mathrm{H}_{2} \mathrm{O}$; (d) $\mathrm{C}_{6} \mathrm{H}_{6}$; (e) $\mathrm{NaBH}_{4}, \mathrm{MeOH}$; (f) $\mathrm{H}_{2}, \mathrm{Pd} / \mathrm{C}, \mathrm{EtOH}$; (g) $\mathrm{C}_{6} \mathrm{H}_{6}$, $\mathrm{NEt}_{3}, 80^{\circ} \mathrm{C}$.

were successively removed (i) by heating in acidic medium to give $\mathbf{2 2}$ and (ii) then by catalytic hydrogenolysis at room temperature leading to 23 . If the mixture was warmed at $50^{\circ} \mathrm{C}$ or treated under pressure (40 psi), the phenyl group was cl eaved too. The diamine 28 could not be prepared by this method, because of the cleavage of the $\mathrm{N}$-isopropyl bond in strong acidic conditions, but according to method $\mathrm{B}$. The $\mathrm{N}$-protection of $\mathrm{N}$-phenylethanolamine was selectively performed in good yield using 0.5 equiv of benzyl chloride to afford 25. This alcohol was converted into the corresponding tosylate $\mathbf{2 6}$ which reacted with isopropylamine to provide compound $\mathbf{2 7}$. Benzyl protecting group was then removed by catalytic hydrogenolysis at room temperature affording 28. Because of the sensibility to hydrogenolysis of the chloro substituent (Scheme 3, methods $A$ and $B$, step d), another protocol was used (method C) for preparing diamine 34. 2-Chloroaniline was acylated by benzoyl chloride and the resulting amide $\mathbf{3 0}$ al kylated with chloroacetonitrile to give 31. Catalytic hydrogenation of the nitrile in the presence of Raney nickel in acetic anhydride afforded the diamide $\mathbf{3 2}$ which was alkylated. Acidic hydrolysis of compound $\mathbf{3 3}$ provided the diamine 34. Cyclization of the diamines $\mathbf{2 3}, \mathbf{2 8}$, and 34 with ethyl 2,3-dibromopropionate was difficult be cause of the low nucleophilicity of the nitrogen substituted with the aromatic ring. Anyway, the two possible regi oi somers were obtained. The ratio of the esters, 24a: 
Scheme 3. Synthesis of 1-Aryl-4-alkyl Ester I ntermediates $\mathbf{2 4 a}, \mathbf{b}, \mathbf{2 9 a}, \mathbf{b}$, and $\mathbf{3 5 a} \mathbf{a}, \mathbf{b}^{\mathbf{a}}$

Method A

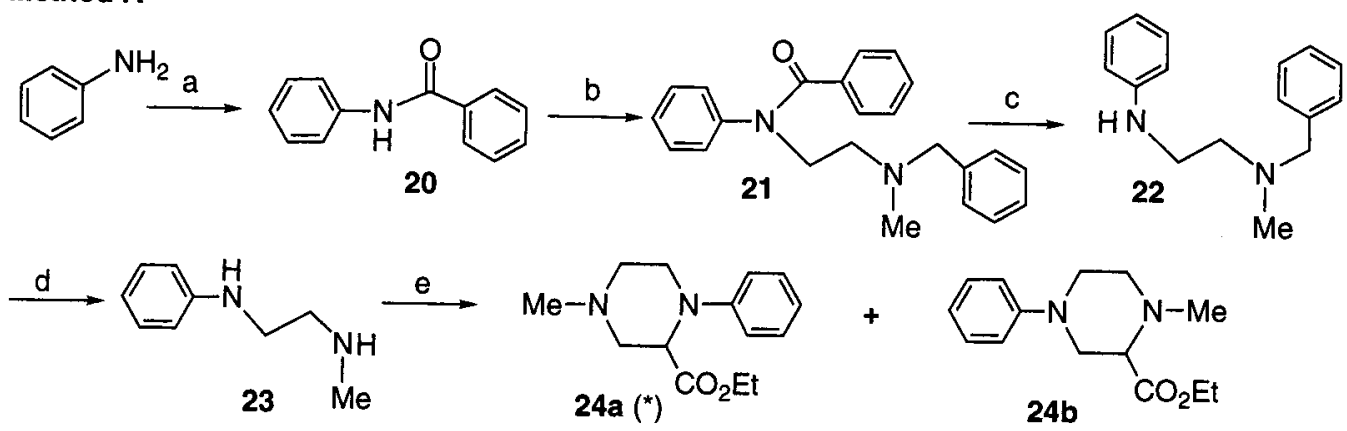

Method B<smiles>CC(C)NCCN(Cc1ccccc1)c1ccccc1</smiles><smiles>CCOC(=O)C1CN(C(C)C)CCN1c1ccccc1</smiles>

Method C<smiles>CC(=O)NCCN(C(=O)c1ccccc1)c1ccc(C)c(C(=O)N(CC#N)c2ccc(I)cc2C(=O)c2ccccc2)c1</smiles>

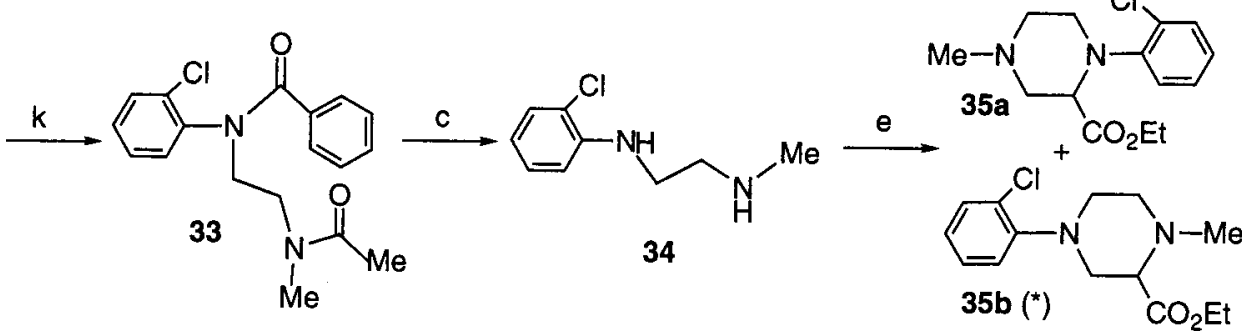

a (a) 0.5 equiv of Ph-COCl, $\mathrm{CH}_{2} \mathrm{Cl}_{2}$; (b) (1) $\mathrm{NaH}, \mathrm{DMF}, 60^{\circ} \mathrm{C}$, (2) $\mathrm{Bzl}-\mathrm{N}(\mathrm{Me}) \mathrm{CH}_{2}-\mathrm{CH}_{2}-\mathrm{Cl}$; (c) $6 \mathrm{~N} \mathrm{HCl}, \mathrm{EtOH} / \mathrm{H}_{2} \mathrm{O}$; (d) $\mathrm{H}_{2}, \mathrm{Pd} / \mathrm{C}$, EtOH (e) $\mathrm{Br}-\mathrm{CH}_{2} \mathrm{CHBr}_{-} \mathrm{CO}_{2}-\mathrm{Et}$; (f) 0.5 equiv of $\mathrm{Bzl}-\mathrm{Cl}, \mathrm{rt}, \mathrm{C}_{6} \mathrm{H}_{6}$; (g) $\mathrm{Ts}-\mathrm{Cl}, \mathrm{NEt}_{3}, \mathrm{CHCl}_{3}, \mathrm{O}^{\circ} \mathrm{C}$; (h) $\mathrm{Me}_{2} \mathrm{CHNH}_{2}, \mathrm{CH}_{2} \mathrm{Cl}_{2}$; (i) (1) $\mathrm{NaH}$, DMF, rt, (2) $\mathrm{Cl}_{-} \mathrm{CH}_{2}-\mathrm{CN}$; (j) Raney Ni, (MeCO) ${ }_{2} \mathrm{O}, \mathrm{H}_{2} 40$ psi; (k) (1) NaH, DMF, rt, (2) Mel. *I solated and purified for further syntheses.

24b (4:1), 29a:29b (7:3), and 35a:35b (1:9), depended on the structure of the starting diamine. Only compounds 24a, 29a, 29b, and 35b were isolated pure, the percentage of minor isomer being determined by ${ }^{1} \mathrm{H}$ NMR.

The preparation of ethyl piperazin-2-ylacetate (40) is described in Scheme 4. Ethyl 1,4-dibenzylpiperazine-2carboxylate ${ }^{16}$ was first reduced by $\mathrm{AlLiH}_{4}$ to afford the intermediate 36. This alcohol was treated with thionyl chloride to give chloride $\mathbf{3 7}$ which was then substituted by $\mathrm{CN}^{-}$. Hydrolysis of the nitrile function of $\mathbf{3 8}$ by $\mathrm{H}_{2-}$ $\mathrm{SO}_{4}$ in $\mathrm{EtOH}$ afforded the corresponding ethyl 1,4dibenzyl pi perazin-2-ylacetate (39). I ts debenzylation led to the key intermediate $\mathbf{4 0}$ which could be treated as described in Scheme 1 to provide compounds $40 \mathbf{a}-\mathbf{c}$.

Imidazoline analogues were prepared according to Neef general procedure ${ }^{22}$ with a minor modification ${ }^{16}$ (Scheme 5). Reaction of esters with ethylenediamine in the presence of an excess of $\mathrm{Al}\left(\mathrm{CH}_{3}\right)_{3}$ provided the imidazoline ring (41a-q, 60-63). N-Methylethylene diamine afforded the corresponding derivative 42 . The tetrahydropyrimidine $\mathbf{4 3}$ was prepared from 1,3-diaminopropane.

Both enantiomers of imidazol ine derivative 41a were tentatively prepared from (2R)- and (2S)-(1'R, 2'S, 5'Rmenthoxycarbonyl)piperazines obtained according to Aebischer et al. ${ }^{23}$ These diastereoisomers were alkylated with isopropyl iodide and the resulting esters converted into the optically active imidazolines as described in Scheme 5. U nfortunately these enantiomers were slowly racemized in solution. ${ }^{21} \mathrm{~F}$ or this reason, no further investigation was performed on separation of enantiomers in these series (see Conclusion).

The synthetic strategy for preparing the oxazol ine $\mathbf{5 0}$ is illustrated in Scheme 6. Compound $\mathbf{4 6}$ was prepared first by $\mathrm{N}$-benzylation of ethanolamine, then protection 
Scheme 4. Synthesis of Key Ester Intermediates 39 and $40 \mathbf{a}-\mathbf{c}^{\mathrm{a}}$
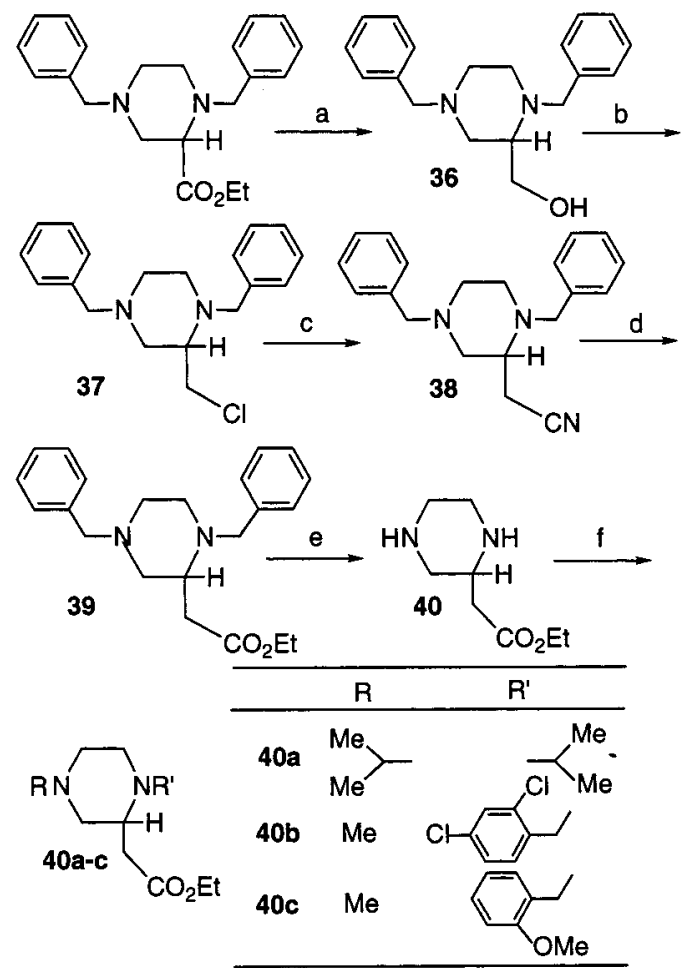

a (a) $\mathrm{AlLiH}_{4}, \mathrm{THF}$; (b) $\mathrm{SOCl}_{2}, \mathrm{CHCl}_{3}$; (c) $\mathrm{KCN}, \mathrm{EtOH}, \mathrm{H}_{2} \mathrm{O}$; (d) $\mathrm{H}_{2} \mathrm{SO}_{4}$, EtOH, $\mathrm{H}_{2} \mathrm{O}$; (e) $\mathrm{H}_{2}, \mathrm{Pd} / \mathrm{C}$, EtOH, $\mathrm{HCl}$; (f) 40a-c were prepared as for $\mathbf{2 a}, \mathbf{7 b}$, and $\mathbf{7 d}$, respectively (Scheme 1).

Scheme 5. Syntheses of Final I midazolines 41a-q, 42, and 60-63 and Tetrahydropyrimidine 43

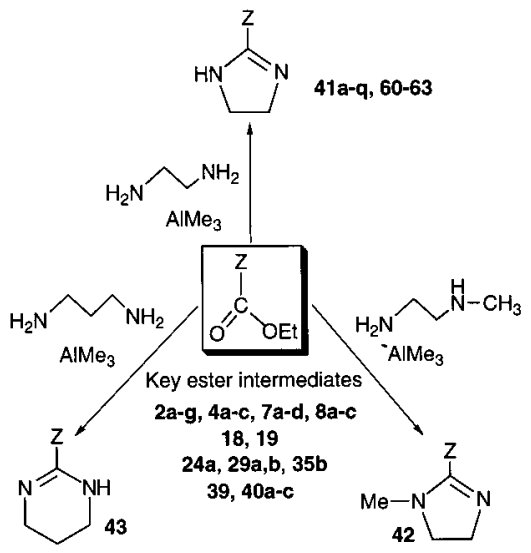

of the alcohol $\mathbf{4 4}$ using dihydropyran, and finally removal of both benzyl protecting groups of the substituted ethanolamine $\mathbf{4 5}$. Condensation of the amine $\mathbf{4 6}$ with ester 7c in the presence of $\mathrm{Al}\left(\mathrm{CH}_{3}\right)_{3}$ afforded the amide 47. After removal of the THP protecting group, the resulting alcohol $\mathbf{4 8}$ was converted into the corresponding chloride $\mathbf{4 9}$. I ts cyclization in the presence of $\mathrm{NaOH}$ gave the oxazol ine anal ogue $\mathbf{5 0}$.

The synthesis of the amidines $\mathbf{5 2 a}, \mathbf{5 2} \mathbf{b}$, and $\mathbf{5 6}$ (Scheme 7) started from the cyanopi perazines $\mathbf{5 1}$ or $\mathbf{5 5}$ prepared by cyclization of $\mathrm{N}, \mathrm{N}^{\prime}$-disubstituted ethylenediamine and 2,3-dibromopropionitrile in refluxing benzene. According to Garigipati's method, ${ }^{24}$ the ami dines $\mathbf{5 2 a}, \mathbf{5 2 b}$ and $\mathbf{5 6}$ were obtained from nitriles by addition of methylchloroaluminum ami des ${ }^{25}$ generated from tri-
Scheme 6. Synthesis of Oxazoline Analogue 50
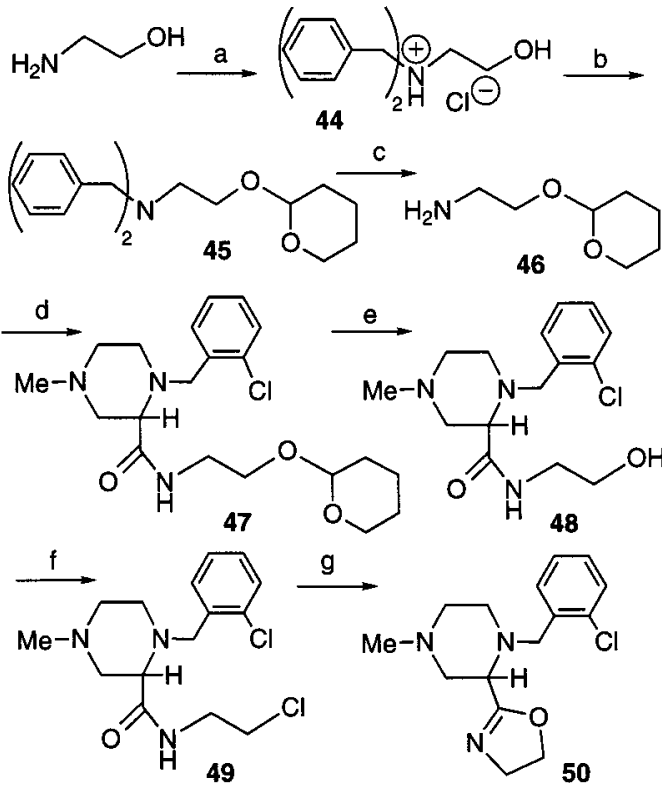

a (a) (1) 2 equiv of $\mathrm{C}_{6} \mathrm{H}_{5} \mathrm{CH}_{2} \mathrm{Cl}, \mathrm{NEt}_{3}$, (2) $\mathrm{HCl}$; (b) $\mathrm{DHP}, \mathrm{CH}_{2} \mathrm{Cl}_{2}$ then $\mathrm{Na}_{2} \mathrm{CO}_{3}$; (c) $\mathrm{H}_{2}, \mathrm{Pd} / \mathrm{C}, \mathrm{EtOH}$; (d) 7c, AlMe , toluene; (e) $\mathrm{HCl}$, $\mathrm{MeOH}$ then $\mathrm{Na}_{2} \mathrm{CO}_{3}$; (f) $\mathrm{SOCl}_{2}, \mathrm{CHCl}_{3}$ then $\mathrm{Na}_{2} \mathrm{CO}_{3}$; (g) $\mathrm{NaOH}$.

Scheme 7. Syntheses of Amidine 52a and Methylamidines $\mathbf{5 2 b}$ and $\mathbf{5 6}^{\mathrm{a}}$

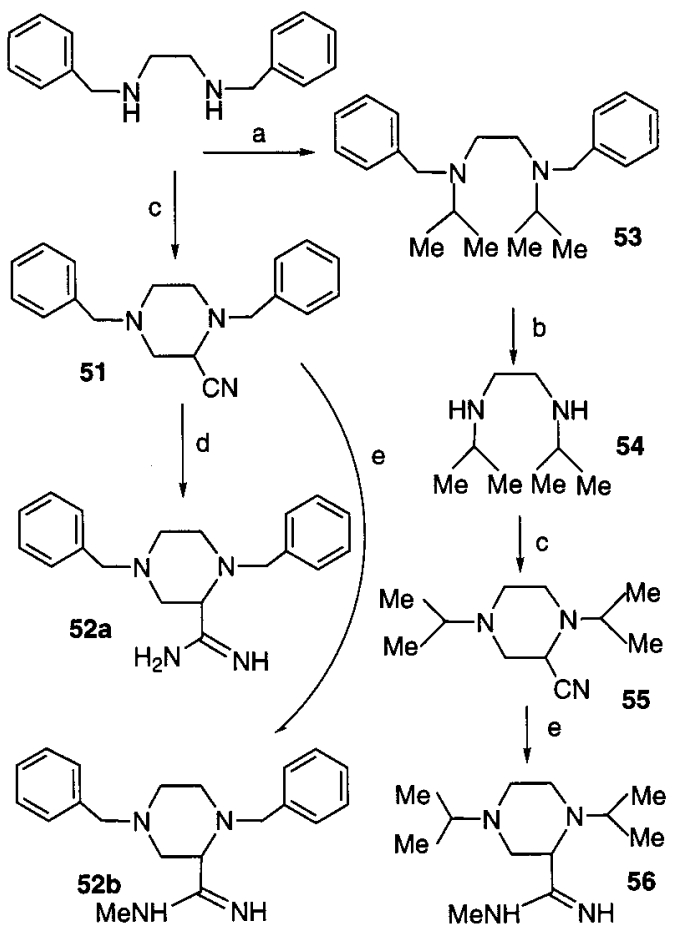

a (a) $\mathrm{Me}_{2} \mathrm{CH}-\mathrm{I}, \mathrm{K}_{2} \mathrm{CO}_{3}, \mathrm{KI}$; (b) $\mathrm{H}_{2}, \mathrm{Pd} / \mathrm{C}, \mathrm{EtOH}$; (c) $\mathrm{Br}-\mathrm{CH}_{2} \mathrm{CH}(\mathrm{Br}$ )$\mathrm{CN}, \mathrm{C}_{6} \mathrm{H}_{6}, \mathrm{NEt}_{3}$; (d) $\mathrm{AlMe}_{3}, \mathrm{NH}_{4} \mathrm{Cl}, \mathrm{C}_{6} \mathrm{H}_{5} \mathrm{Me}$; (e) $\mathrm{AlMe}_{3}, \mathrm{CH}_{3}-\mathrm{NH}_{2}$, $\mathrm{HCl}$, toluene.

methylaluminum and ammonium chloride or methylamine hydrochloride.

The first step of the imidazole anal ogue 59 synthesis (Scheme 8) was the reduction of ethyl 1-(2',4'-dichlorobenzyl)-4-methyl piperazine-2-carboxylate into the alcohol 57. ${ }^{16}$ Subsequent oxidation into aldehyde 58 under Swern's conditions ${ }^{26}$ and then reaction with ammonia and glyoxal ${ }^{27}$ gave the final product. 
Scheme 8. Preparation of I midazole Analogue 59a
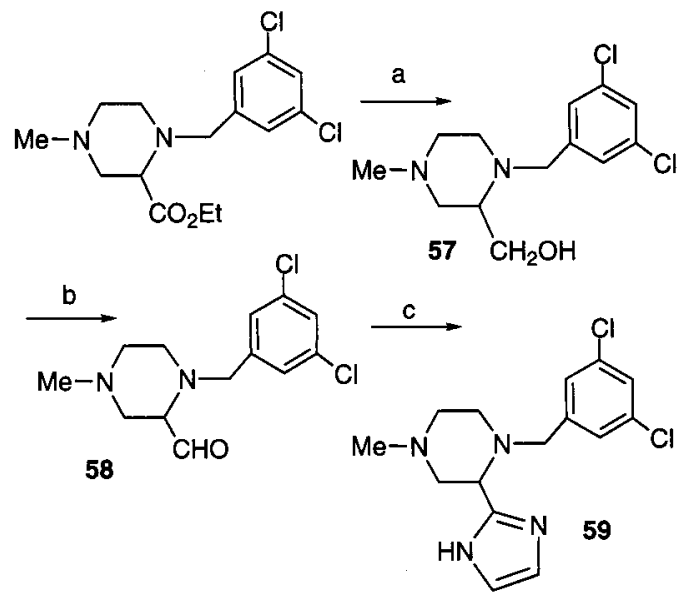

a (a) $\mathrm{LiAlH}_{4}, \mathrm{THF}$; (b) trifluoroacetic anhydride, DMSO, $\mathrm{Et}_{3} \mathrm{~N}$, $\mathrm{CH}_{2} \mathrm{Cl}_{2}, \mathrm{~N}_{2}$ atm; (c) glyoxal, $\mathrm{NH}_{3}, \mathrm{MeOH}$.

Significance and Validity of Pharmacological Parameters. As previously described, ${ }^{16}$ antidiabetic properties of all the synthesized compounds were evaluated in vivo by their ability to improve the glucose tolerance during intravenous glucose tests (IVGTT) performed on a rat model of mild diabetes. ${ }^{28}$ This model presents moderate basal hyperglycemia, glucose intolerance, and impairment of the glucose-induced insulin secretion which are the main features in patients with NIDDM. IVGTT were carried out after a single ip administration of $100 \mu \mathrm{mol} / \mathrm{kg}$ of each synthesized molecule, and glucose tolerance was evaluated according to three parameters: (i) $\mathrm{G}_{30}$, which is the glycemic value at $30 \mathrm{~min}$ after glucose administration, (ii) $\Delta \mathrm{G}$, which represents the increase of glycemia over the baseline integrated over a period of $30 \mathrm{~min}$ following the glucose load, and (iii) K, which is the rate of glucose disappearance between 5 and 30 min after glucose administration.

To correct for the slight variations that appeared when glucose tolerance tests were performed with different control diabetic rats, we expressed the results as a percentage $\left(\Delta G^{*}\right)$ of variation of $\Delta G$ between treated and untreated diabetic rats:

$$
\Delta G^{*}=\left|\frac{\Delta G_{\text {treated STZ rats }}-\Delta G_{\text {untreated STZ rats }}}{\Delta G_{\text {untreated STZ rats }}-\Delta G_{\text {control rats }}}\right| \times 100
$$

In the same way, we defined $\mathrm{G}_{30}$ * and $\mathrm{K}^{*}$. To be considered as effective antidiabetics, compounds must induce high percentages of variation for $\Delta G^{*}, K^{*}$, and $\mathrm{G}_{30} *$. Results around $100 \%$ or more indicate that the parameters for the treated diabetic animals are close to those obtained with nondiabetic control animals. Among these three parameters, $G_{30}$ which is obtained via a direct measurement, is considered as the most relevant when the compounds are tested po.

\section{Results and Discussion}

Within this new series, the first synthesized and evaluated compounds were symmetrically substituted on both piperazine nitrogen atoms by branched alkyl or cycloalkyl chains.

The compounds $\mathbf{4 1 a}, \mathbf{4 1 b}$, and $\mathbf{4 1 f}$, respectively substituted by two isopropyl, isobutyl, or 2-methylbutyl groups, show potent effects on glycemia with values similar to those of nondiabetic control rats. As in our first paper, ${ }^{16}$ this correlates very well with their effects on $\Delta \mathrm{G}^{*}$ and $\mathrm{G}_{30} *$ with values around $100 \%$ (Table 1 ). Their effect on the $K$ parameter is also very significant but less potent, since $K *$ values remain between $47 \%$ for compound $\mathbf{4 1 a}$ and $82 \%$ for compound $\mathbf{4 1 f}$. The derivatives $\mathbf{4 1}$ and $\mathbf{4 1 g}$, substituted by two cycl opentyl and neopentyl groups, are clearly less active on $\Delta G(\Delta G$ $*=58 \%$ and $54 \%$, respectively) than their isobutyl (compound 41b, $\Delta \mathrm{G} *=141 \%$ ) and 2-methylbutyl (compound 41f, $\Delta \mathrm{G}^{*}=104 \%$ ) anal ogues, probably due to problems of steric hindrance. Concerning the compound 41c, there is a slight discrepancy between the effects on $\Delta G$ and $K$ which is rather moderate and the effect on $\mathrm{G}_{30}$ which is very high $\left(\mathrm{G}_{30} *=103 \%\right)$. Compound 4lh, substituted by two dicyclopropylmethyl groups, was slightly less active on $\Delta \mathrm{G}(\Delta \mathrm{G} *=24 \%)$. This is not surprising if cyclopropyl molecular orbitals are considered to have a partial $\pi$ character so that compound $\mathbf{4 l h}$ is comparable in some respects with the dibenzyl-substituted imidazol inyl piperazines which were found inactive in our first paper. ${ }^{16}$ Replacement of the two isobutyl moi eties (compound $\mathbf{4 1 b}$ ) by two 2-methyl2-propenyl substituents (compound $\mathbf{4 1 e}$ ) has no deleterious effect on the three parameters which are all around $100 \%$. This is not the case for the diallylsubstituted compound 41d which is almost inactive $\left(\Delta \mathrm{G}^{*}=19 \%, \mathrm{G}_{30} *=30 \%, \mathrm{~K}^{*}=35 \%\right)$.

Unsymmetrically substituted compounds (Table 1) were then prepared and evaluated. The compounds 41l and $41 \mathrm{~m}, 4$-methyl and respectively 1-isobutyl and 1-dicyclopropylmethyl substituted, are equipotent with values around $100 \%$ for $\Delta G^{*}$ and around $50 \%$ for $\mathrm{G}_{30} *$ and $\mathrm{K}^{*}$. It is noteworthy that compound $\mathbf{4 1} \mathbf{m}$ is much more potent than its inactive symmetrically substituted anal ogue $\mathbf{4 1 h}$, while compound $\mathbf{4 1 l}$ is only slightly less active than its analogue $\mathbf{4 1 b}$ but much more potent than compound 41k ( $\left.\Delta \mathrm{G}^{*}=40 \%, \mathrm{G}_{30} *=21 \%, \mathrm{~K}^{*}=42 \%\right)$, for which the methyl and isobutyl substituents have been inverted. Surprisingly, while compound 41i, 1-isobutyl, 4-allyl remains very potent $\left(\Delta \mathrm{G}^{*}=115 \%\right)$, its 4-propenyl analogue $\mathbf{4 1 j}$ is clearly less active $\left(\Delta \mathrm{G}^{*}=\right.$ $53 \%$ ). When compared to symmetrically substituted compounds 41d and 4le, the results are inverted. Compounds bearing a phenyl or a 2-chlorophenyl group were finally synthesized and evaluated (compounds 41n, 410, 41p, 41q). All of them proved to be inactive on $\Delta \mathrm{G}$ so that a phenyl substitution seems to be unfavorable. An expected $\mathrm{pK}_{\mathrm{a}}$ variation cannot be taken into account. In our first paper, ${ }^{16}$ we clearly demonstrated that the protonation center at physiological $\mathrm{pH}$ in such series was the imidazoline ring $\left(\mathrm{pK}_{\mathrm{a}} \sim 9.5\right)$ and not the pi perazine one $\left(\mathrm{pK}_{a} \sim 5.5\right)$. Consequently this negative effect should be due to a decrease of flexibility of these molecules. Moreover, concerning compound 410, significant unexplainable discrepancies can be noticed concerning the effects on $\Delta G$ and those on $K$ and $G_{30}$. It is noteworthy that the 2-chlorobenzyl analogue of compound 41p, PMS 774, is very potent $\left(\Delta \mathrm{G}^{*}=81 \%\right.$, $\left.\mathrm{K}^{*}=98 \%, \mathrm{G}_{30} *=103 \%\right) .{ }^{16}$

In a second step, chemical modulations on the imidazoline pharmacophore itself were performed (Table 2). Insertion of a methylene spacer between the piperazine and imidazoline rings results in a very clear 
Table 1. Variation of the Glycemia Parameters after ip Administration of $100 \mu \mathrm{mol} / \mathrm{kg}$ of 1,4-Disubstituted-2(4',5'-dihydro-1'H-imidazol-2'-yl)pi perazines to STZ Ratsa

41

a Three-month-old male Wistar rats $(250 \mathrm{~g})$ treated with $35 \mathrm{mg} /$ $\mathrm{kg}$ iv of streptozotocin. ${ }^{\mathrm{b}} \Delta \mathrm{G}$, incremental glycemia values over baseline integrated over $30 \mathrm{~min}$ after glucose $(0.5 \mathrm{~g} / \mathrm{kg} \mathrm{iv})$ administration. ${ }^{c} \mathrm{G}_{30}$, glycemia value $30 \mathrm{~min}$ after glucose administration. ${ }^{d} \mathrm{~K}$, rate of glucose disappearance between 5 and $30 \mathrm{~min}$ after glucose administration.All results (asterisk) are expressed as the percent of variation of the parameters between treated rats (with an ip administration of $100 \mu \mathrm{mol} / \mathrm{kg}$ of the tested compound) and untreated rats. Number of treated rats for each compound included between 4 and 8 ( \pm SEM).
Table 2. Variation of the Glycemia Parameters after ip Administration of $100 \mu \mathrm{mol} / \mathrm{kg}$ of Substituted I midazolines, Tetrahydropyrimidine, Oxazoline, Amidines, Imidazole, and 2-Methylimidazoline to STZ Rats ${ }^{a}$

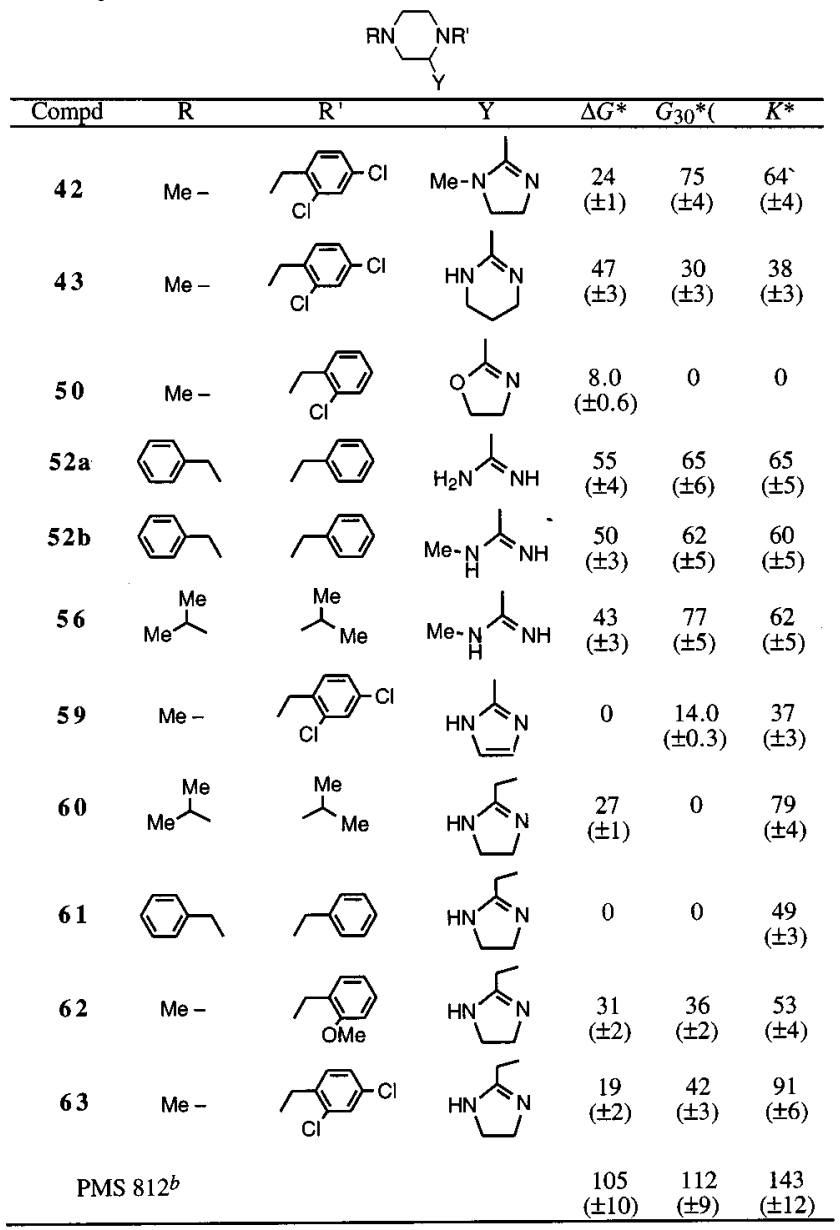

a See footnotes of Table 1. ' See formula in Introduction, PMS 812 or S-21663.

decrease of hypoglycemic properties for three of the four synthesized derivatives $(\mathbf{6 0}, \mathbf{6 2}$, and $\mathbf{6 3})$. Concerning the fourth compound, the dibenzyl derivative $\mathbf{6 1}$, a moderate but clear effect on $\Delta \mathrm{G}^{*}$ is observed, while its analogue without the methylene spacer was totally inactive. ${ }^{16} \mathrm{It}$ can be postulated that introduction of a spacer gives more flexibility to this bulky molecule and consequently allows a better access to a hypothetic imidazoline binding site. Substitution of the imidazoline ring by a methyl in position 1 (compound 42) leads to a poorly active compound $\left(\Delta \mathrm{G}^{*}=24 \%\right)$ as compared to its very potent nonmethylated analogue PMS 812 (S-21663) $(\Delta G *=105 \%)$. Replacement of the imidazoline by an imidazole (compound 59) or an oxazol ine (compound 50) induces a total loss of activity. However only a partial decrease in activity is observed for the tetrahydropyrimidine analogue $\mathbf{4 3}\left(\Delta \mathrm{G}^{*}=47 \%\right)$ as compared to PMS $812\left(\Delta G^{*}=105 \%\right)$. The results obtained with amidine and $\mathrm{N}$-methylamidine are more contrasted. The $\mathrm{N}$ methylamidino diisopropyl compound $\mathbf{5 6}$ is clearly less potent $\left(\Delta \mathrm{G}^{*}=43 \%\right)$ than its imidazol ine counterpart 4la $\left(\Delta \mathrm{G}^{*}=138 \%\right)$, and the amidino $52 \mathrm{a}\left(\Delta \mathrm{G}^{*}=55 \%\right)$ and $\mathrm{N}$-methylamidino 52b $\left(\Delta \mathrm{G}^{*}=50 \%\right)$ dibenzyl derivatives are moderately active, while their imidazoline anal ogue is totally inactive. ${ }^{16}$ 
Due to their good activity via ip administration, compounds 41a, 41b, 41e, 41f, and 41i were selected to be tested via po administration at $100 \mu \mathrm{mol} / \mathrm{kg}$ (Table 3). Among these five derivatives, only compounds 41 a and $\mathbf{4 1 \mathbf { b }}$ proved to be active via po administration with significant effects on $\mathrm{G}_{30} *$ (respectively $73 \%$ and $66 \%$ ). This could be explained by the poor bioavailability of the other compounds with (i) perhaps problems of metabolism for the unsaturated compounds $\mathbf{4 1 e}$ and $\mathbf{4 1 i}$, despite their isolipophilicity $(\log P=1.45$ and 1.30, respectively) with the congener $\mathbf{4 1 a}$, or (ii) a too high hydrophobicity for compound 41 f $(\log P=3.22$ ) as compared to 1.15 and 2.18 for compounds $\mathbf{4 1 a}$ and $\mathbf{4 1 b}$, respectively (cf. Table 3 and Experimental Section for calculations). It seems that the range of lipophilicity required for a good bioavailability of these compounds is included between 2.2 and 1.1 units of $\log P$ approximately. Moreover, the log $\mathrm{P}$ value of PMS 812, a very potent in vivo antihyperglycemic compound, ${ }^{16,17}$ was equal to 2.21 .

Compound 4la was then selected for further pharmacological studies and first evaluated for its capacity to stimulate the secretion of insulin during IVGTT. Surprisingly and unlike the substituted benzylpiperazine derivative PMS 812,16-18 compound 41a, PMS 847 (S-22068), has a poor stimulating effect on insulin secretion. 30

The in vitro binding experiments performed with these compounds demonstrated that they were clearly devoid of any affinity for the $I_{1}$ and $I_{2}$ binding sites as well as for the $\alpha_{2}$ adrenoreceptor $\left(K_{1} \geq 10^{-5} \mathrm{M}\right)$. This is in agreement with an increasing number of studies showing that $\alpha_{2}$ adrenergic antagonists are able to stimulate insulin secretion independently of $\alpha_{2}$ and $I_{1}$ $I_{2}$ blockage. ${ }^{16,17,28,29,31-38}$

\section{Conclusion}

In conclusion, 29 new imidazoline derivatives were synthesized and evaluated ( $100 \mu \mathrm{mol} / \mathrm{kg}$ via ip administration) for their antidiabetic properties in glucose tolerance tests. Seven of them (compounds 41a, 41b, 41e, 41f, 41i, 411, and 41m) have a potent effect on the glucose tolerance via ip administration, and 2 of them (compounds 41a and 41b) were also found active after po administration $(100 \mu \mathrm{mol} / \mathrm{kg})$. Surprisingly, compound 41a (PMS 847, S-22068) ${ }^{30}$ has no effect on insulin secretion and is devoid of any affinity either for the $I_{1}$ and $I_{2}$ imidazoline binding sites or for the $\alpha_{2}$ adrenoreceptors. This compound undergoes current complementary studies in order to investigate its possible mechanism of action. Concurrently, the structureactivity relationships that have been established with this present work and the previous one ${ }^{16}$ show unambiguously that an unsubstituted imidazoline ring is a required pharmacophore for potent antihyperglycemic properties. All attempts to substitute it or to replace it by imidazole, tetrahydropyrimidine, oxazoline, or amidine result in a clear decrease or a total loss of activity. This could be an argument for the involvement of specific and still unknown imidazoline binding sites in the regulation of glucose homeostasis.

Finally it is noteworthy that a spontaneous slow racemization at the chiral carbon 2 is observed in such molecules (cf. compound 41a, see Chemi stry). This is a
Table 3. Variation of the Glycemia Parameters after po Administration of $100 \mu \mathrm{mol} / \mathrm{kg}$ of 1,4-Disubstituted-2 $\left(4^{\prime}, 5^{\prime}\right.$-dihydro- $\mathbf{I}^{\prime} \mathrm{H}$-imidazol-2'-yl)piperazines to STZ Rats and Partition Coefficient ${ }^{\mathrm{a}}$

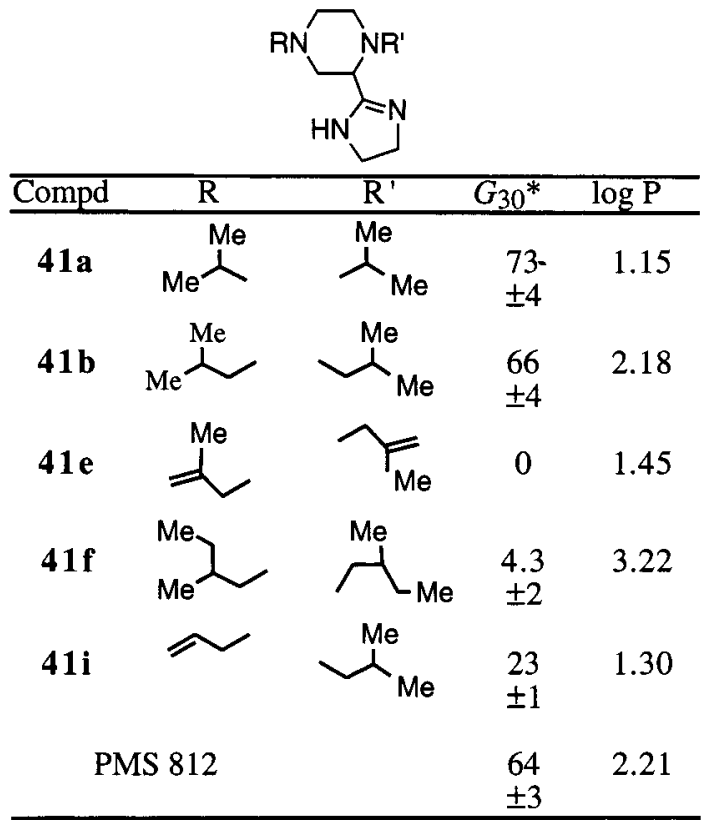

a See footnotes of Table 1 and Experimental Section for calculation of $\log P$.

consequence of a hydrogen transfer to the imidazoline ring inducing an intermediate tautomeric form. It is reasonable to suspect that such a phenomenon takes place in vivo. If their exceptional conformational flexibility is taken into account, ${ }^{16}$ such derivatives should present great adaptability to special binding sites and probably interact via dynamic processes. ${ }^{39}$

\section{Experimental Section}

Chemistry. General Methods. The purity of each compound was checked by thin-layer chromatography on TLC plastic sheets (silica gel 60F 254, layer thickness $0.2 \mathrm{~mm}$ ) from Merck. Column chromatography purification was carried out on silica gel 60 (particle size $0.063-0.200 \mathrm{~mm}$ ) from Merck, without any special treatment. All melting points were determined in a digital melting point apparatus (Electrothermal) and are uncorrected. The structures of all compounds were confirmed by IR and ${ }^{1} \mathrm{H}$ NMR spectra. IR spectra were obtained with an ATI Mattson Genesis Series FTIR infrared spectrometer, and ${ }^{1} \mathrm{H}$ NMR spectra were recorded in $\mathrm{CDCl}_{3}$ on a Brucker AC 200 spectrometer or a J EOL PMX60SI NMR spectrometer using hexamethyldisiloxane (HMDS) as an internal standard. All elemental analyses were within $\pm 0.4 \%$ of theoretical values.

Preparation of Alkyl and Benzyl Ester Intermediates $2 a-g, 7 a-d$, and 8a-c (Scheme 1). Ethyl 1,4-Diisopropylpiperazine-2-carboxylate Dihydrochloride (2a). A suspension of $1 \cdot 2 \mathrm{HCl}(23.1 \mathrm{~g}, 0.1 \mathrm{~mol})$ and dry $\mathrm{K}_{2} \mathrm{CO}_{3}(40 \mathrm{~g})$ in $200 \mathrm{~mL}$ of acetonitrile was stirred for $1 \mathrm{~h}$ at room temper-

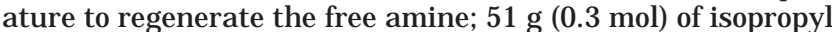
iodide was added, and the mixture refluxed for $24 \mathrm{~h}$. The reaction mixture was cooled and filtered and the filtrate diluted with ether. The organic layer was washed with water and dried over $\mathrm{MgSO}_{4}$, and the solvents were removed in vacuo. The crude product was dissolved in $\mathrm{CH}_{2} \mathrm{Cl}_{2}$, and after the product was cooled in an ice bath, $\mathrm{EtOH}$ saturated with $\mathrm{HCl}$ gas was added until acidic $\mathrm{pH}$. The solvents were evaporated and the dihydrochloride salt recrystallized from $\mathrm{CH}_{2} \mathrm{Cl}_{2}$-acetone-ether to afford $22 \mathrm{~g}(72 \%)$ of $2 \mathrm{a} \cdot 2 \mathrm{HCl}$ : $\mathrm{mp}$ $94-95^{\circ} \mathrm{C}$. Usual treatment of this salt gave free amine $\mathbf{2 a}$ as a colorless oil: IR (film, $\left.\mathrm{cm}^{-1}\right) v 1755(\mathrm{C}=\mathrm{O}) ;{ }^{1 \mathrm{H}} \mathrm{NMR} \delta 4.16$ 
$\left(2 \mathrm{H}, \mathrm{q}, \mathrm{J}=6.5 \mathrm{~Hz}, \mathrm{H}_{2} \mathrm{C}-\mathrm{O}\right), 3.40(1 \mathrm{H}, \mathrm{dd}, \mathrm{J}=4.3$ and $5.2 \mathrm{~Hz}$, $\mathrm{HC}-\mathrm{N}), 2.95-2.38\left(8 \mathrm{H}\right.$, ma, three $\mathrm{H}_{2} \mathrm{C}-\mathrm{N}$ and two $\left.\mathrm{HC}\left(\mathrm{CH}_{3}\right)_{2}\right)$, $1.21\left(3 \mathrm{H}, \mathrm{t}, \mathrm{J}=6.5 \mathrm{~Hz}, \mathrm{H}_{3} \mathrm{C}-\mathrm{CH}_{2} \mathrm{O}\right), 1.09,0.96,0.95,0.90$ $\left(12 \mathrm{H}, 4 \mathrm{~d}, \mathrm{~J}=6.5 \mathrm{~Hz}\right.$, two $\left.\left(\mathrm{H}_{3} \mathrm{C}\right)_{2} \mathrm{CH}\right)$.

Compounds $\mathbf{2} \mathbf{b}-\mathbf{g}$ (free amines as oils) were prepared by the same procedure using acetone as solvent instead of acetonitrile, catalytic amount of $\mathrm{KI}$, and the corresponding chloro or bromo derivative.

Ethyl 1,4-diisobutylpiperazine-2-carboxylate (2b): ${ }^{1} \mathrm{H}$ NMR $\delta$ 4.17-4.01 $\left(2 \mathrm{H}, \mathrm{m}, \mathrm{H}_{2} \mathrm{C}-\mathrm{O}\right), 3.16(1 \mathrm{H}, \mathrm{dd}, \mathrm{J}=3.42$ and $5.72 \mathrm{~Hz}, \mathrm{HC}-\mathrm{N}$ ), 3.08-3.0, 2.73-2.64, 2.43-2.22 (7H, 3m, three $\mathrm{H}_{2} \mathrm{C}-\mathrm{N}$ and $\left.\mathrm{H}-\mathrm{CH}-\mathrm{N}_{1}\right), 2.12(1 \mathrm{H}, \mathrm{dd}, \mathrm{J}=6.42$ and 12.46 $\left.\mathrm{Hz}, \mathrm{H}-\mathrm{CH}-\mathrm{N}_{1}\right), 1.97\left(2 \mathrm{H}, \mathrm{d}, \mathrm{J}=7.66 \mathrm{~Hz}, \mathrm{H}_{2} \mathrm{C}-\mathrm{N}_{4}\right), 1.73-1.56$ $\left(2 \mathrm{H}, \mathrm{m}\right.$, two $\left.\mathrm{HC}\left(\mathrm{CH}_{3}\right)_{2}\right), 1.19\left(3 \mathrm{H}, \mathrm{t}, \mathrm{J}=7.12 \mathrm{~Hz}, \mathrm{H}_{3} \mathrm{C}-\mathrm{CH}_{2} \mathrm{O}\right)$, 0.82 and $0.80\left(12 \mathrm{H}, 2 \mathrm{~d}\right.$ in $1: 3$ ratio, two $\left.\left(\mathrm{H}_{3} \mathrm{C}\right)_{2} \mathrm{CH}\right)$.

Ethyl 1,4-dicyclopentylpiperazine-2-carboxylate (2c): ${ }^{1} \mathrm{H}$ NMR $\delta 4.19-4.05\left(2 \mathrm{H}, \mathrm{m}, \mathrm{H}_{2} \mathrm{C}-\mathrm{O}\right), 3.42(1 \mathrm{H}, \mathrm{dd}, \mathrm{J}$ $=3.56$ and $5.8 \mathrm{~Hz}, \mathrm{HC}-\mathrm{N}), 3.18-3.01,2.81-2.73,2.55-2.36$, 1.78-1.27 $\left(24 \mathrm{H}, 4 \mathrm{~m}\right.$, in ratio $2: 1: 5: 16$, three $\mathrm{H}_{2} \mathrm{C}-\mathrm{N}$ and $\mathrm{H}$ cyclopentyl), $1.21\left(3 \mathrm{H}, \mathrm{t}, \mathrm{J}=7.1 \mathrm{~Hz}, \mathrm{H}_{3} \mathrm{C}-\mathrm{CH}_{2} \mathrm{O}\right)$.

Ethyl 1,4-di(2'-propen-1'-yl)piperazine-2-carboxylate (2d): ${ }^{1} \mathrm{H}$ NMR $\delta 5.90-5.55(2 \mathrm{H}, \mathrm{m}$, two $\mathrm{HC}=), 5.3-5.0(4 \mathrm{H}$, $\left.\mathrm{m}, \mathrm{H}_{2} \mathrm{C}=\right), 4.17\left(2 \mathrm{H}, \mathrm{q}, \mathrm{J}=7.2 \mathrm{~Hz}, \mathrm{H}_{2} \mathrm{C}-\mathrm{O}\right), 3.62-2.0(11 \mathrm{H}$, $\mathrm{m}, \mathrm{H}$ piperazine and two $\left.\mathrm{H}_{2} \mathrm{C}-\mathrm{CH}=\right), 1.23(3 \mathrm{H}, \mathrm{t}, \mathrm{J}=7.2 \mathrm{~Hz}$, $\mathrm{H}_{3} \mathrm{C}-\mathrm{CH}_{2} \mathrm{O}$ ).

Ethyl 1,4-di(2'-methyl-2' -propen-1'-yl)pi perazine-2-carboxylate (2e): ${ }^{1 \mathrm{H}} \mathrm{NMR} \delta 4.85-4.46\left(4 \mathrm{H}\right.$, m, two $\left.\mathrm{H}_{2} \mathrm{C}=\right), 4.15-$ $4.02\left(2 \mathrm{H}, \mathrm{m}, \mathrm{H}_{2} \mathrm{C}-\mathrm{O}\right), 3.22-2.22(11 \mathrm{H}, \mathrm{m}, \mathrm{H}$ piperazine and two $\left.\mathrm{H}_{2} \mathrm{C}-\mathrm{C}=\mathrm{C}\right), 1.66$ and $1.63\left(6 \mathrm{H}, 2 \mathrm{~s}\right.$, two $\left.\mathrm{H}_{3} \mathrm{C}-\mathrm{C}=\right), 1.20$ $\left(3 \mathrm{H}, \mathrm{t}, \mathrm{J}=7.1 \mathrm{~Hz}, \mathrm{H}_{3} \mathrm{C}-\mathrm{CH}_{2} \mathrm{O}\right)$.

Ethyl 1,4-di( 2 -methylbutyl)piperazine-2-carboxylate (2f): ${ }^{1} \mathrm{H} N M R \delta 4.15-4.02\left(2 \mathrm{H}, \mathrm{m}, \mathrm{H}_{2} \mathrm{C}-\mathrm{O}\right), 3.18-1.91(9 \mathrm{H}$, $\mathrm{m}, \mathrm{H}$ piperazine and two $\mathrm{HC}-\mathrm{N}), 1.48-1.29\left(4 \mathrm{H}, \mathrm{m}, \mathrm{H}_{2} \mathrm{C}-\right.$ $\left.\mathrm{CH}_{3}\right), 1.20\left(3 \mathrm{H}, \mathrm{t}, \mathrm{J}=7.15 \mathrm{~Hz}, \mathrm{H}_{3} \mathrm{C}-\mathrm{CH}_{2} \mathrm{O}\right), 0.80(6 \mathrm{H}, \mathrm{t}, \mathrm{J}=$ $6.87 \mathrm{~Hz}$, two $\left.\mathrm{H}_{3} \mathrm{C}-\mathrm{CH}_{2}\right), 0.81$ and $0.79(6 \mathrm{H}, 2 \mathrm{~d}, \mathrm{~J}=6.87 \mathrm{~Hz}$, two $\mathrm{H}_{3} \mathrm{C}-\mathrm{CH}$ ).

Ethyl 1,4-dineopentylpiperazine-2-carboxylate (2g): ${ }^{1} \mathrm{H}$ NMR $\delta$ 4.15-4.05 (2H, m, $\left.\mathrm{H}_{2} \mathrm{C}-\mathrm{O}\right), 3.22-2.5(7 \mathrm{H}, \mathrm{m}, \mathrm{H}$ piperazine), $1.9\left(4 \mathrm{H}\right.$, s, two $\left.\mathrm{H}_{2} \mathrm{C}-\mathrm{C}\left(\mathrm{CH}_{3}\right)_{3}\right), 1.2(3 \mathrm{H}$, t, J $=7.17$ $\left.\mathrm{Hz}, \mathrm{H}_{3} \mathrm{C}-\mathrm{CH}_{2} \mathrm{O}\right), 0.75\left(18 \mathrm{H}, \mathrm{s},\left(\mathrm{H}_{3} \mathrm{C}\right)_{3}-\mathrm{C}\right)$.

Ethyl 4-(2'-Propen-1'-yl)piperazine-2-carboxylate (4a). A suspension of 1 ( $23.1 \mathrm{~g}, 0.1 \mathrm{~mol})$, dry $\mathrm{K}_{2} \mathrm{CO}_{3}(40 \mathrm{~g})$, and $\mathrm{KI}$ $(4 \mathrm{~g})$ in DMF $(200 \mathrm{~mL})$ was stirred vigorously and heated at $40{ }^{\circ} \mathrm{C}$. After the mixture cooled, 1-bromo-2-propene (12.1 g, $0.1 \mathrm{~mol})$ in DMF $(80 \mathrm{~mL}$ ) was added dropwise and the mixture stirred at room temperature for $24 \mathrm{~h}$. The solid material was filtered and the filtrate diluted with ether and water. The aqueous layer was extracted with ether. The organic layer was dried over $\mathrm{MgSO}_{4}$ and concentrated. The crude product was purified by column chromatography using petroleum ether/ ether (first 60:40 then 50:50, v/v) as eluent to give $6.1 \mathrm{~g} \mathrm{(31 \% )}$ of 4 a as a yellow oil: IR (film, $\left.\mathrm{cm}^{-1}\right) v 3320(\mathrm{~N}-\mathrm{H}), 1740(\mathrm{C}=$ $0) ;{ }^{1} \mathrm{H}$ NMR $\delta$ 5.85-5.68 $(1 \mathrm{H}, \mathrm{m}, \mathrm{HC}=), 5.18-5.09(2 \mathrm{H}, \mathrm{m}$, $\left.\mathrm{H}_{2} \mathrm{C}=\right), 4.13\left(2 \mathrm{H}, \mathrm{q}, \mathrm{J}=7.1 \mathrm{~Hz}, \mathrm{H}_{2} \mathrm{C}-\mathrm{O}\right), 3.66-2.10(9 \mathrm{H}, \mathrm{m}$, $\mathrm{H}$ piperazine and $\left.\mathrm{H}_{2} \mathrm{C}-\mathrm{C}=\right), 1.97\left(1 \mathrm{H}, \mathrm{S}, \mathrm{D}_{2} \mathrm{O}\right.$ exchange, $\left.\mathrm{H}-\mathrm{N}\right)$, $1.20\left(3 \mathrm{H}, \mathrm{t}, \mathrm{J}=7.1 \mathrm{~Hz}, \mathrm{H}_{3} \mathrm{C}-\mathrm{CH}_{2} \mathrm{O}\right)$.

Compounds $\mathbf{4 b}$ and $\mathbf{4} \mathbf{c}$ were prepared by the same procedure using the corresponding bromo derivative.

Ethyl 1-I sobutyl-4-(triphenylmethyl)piperazine-2-carboxylate (5a). A mixture of $3^{16}(40 \mathrm{~g}, 0.1 \mathrm{~mol})$, dry $\mathrm{K}_{2} \mathrm{CO}_{3}(40$ g), KI (4 g), and isobutyl bromide $(16.4 \mathrm{~g}, 0.12 \mathrm{~mol})$ in acetonitrile $(400 \mathrm{~mL})$ was heated at $80^{\circ} \mathrm{C}$ with stirring for 15 h. After filtration of solid material, the filtrate was diluted with ether and washed with water. The aqueous layer was extracted with ether, and the combined organic layers were dried over $\mathrm{MgSO}_{4}$. Solvents were removed in vacuo, and this crude $5 \mathbf{a}$ was used in the next step without purification.

Compounds $\mathbf{5 b} \mathbf{-}-\mathbf{d}$ were prepared using the corresponding chloro derivatives.

Ethyl 1-I sobutylpiperazine-2-carboxylate (6a). Crude 5 a was dissolved in acetone $(600 \mathrm{~mL})$ containing $12 \mathrm{M} \mathrm{HCl}$ (25 mL). After $3 \mathrm{~h}$ stirring at room temperature, the solvent was removed in vacuo and the residue was partitioned between ether and water. The aqueous layer was treated with a saturated $\mathrm{NaHCO}_{3}$ solution until basic $\mathrm{pH}$ and extracted with ether. The organic phase was dried over $\mathrm{MgSO}_{4}$ and the solvent evaporated under vacuo. The crude product was purified by column chromatography using first petroleum ether/ether (30:70, v/v) and then ether to afford $17 \mathrm{~g}(80 \%)$ of 6a as a colorless oil: IR (film, $\left.\mathrm{cm}^{-1}\right) v 3340(\mathrm{~N}-\mathrm{H}), 1740(\mathrm{C}=$ O); ${ }^{1} \mathrm{H}$ NMR $\delta 4.15\left(2 \mathrm{H}, \mathrm{q}, \mathrm{J}=7.1 \mathrm{~Hz}, \mathrm{H}_{2} \mathrm{C}-\mathrm{O}\right), 3.19-1.99$ (7H, $\mathrm{m}, \mathrm{H}$ piperazine), $1.96\left(2 \mathrm{H}, \mathrm{d}, \mathrm{J}=7.68 \mathrm{~Hz}, \mathrm{H}_{2} \mathrm{C}-\mathrm{CH}\right)$, 1.73-1.56 $\left(1 \mathrm{H}, \mathrm{m}, \mathrm{HC}\left(\mathrm{CH}_{3}\right)_{2}\right), 1.5\left(1 \mathrm{H}, \mathrm{br} \mathrm{s}, \mathrm{D}_{2} \mathrm{O}\right.$ exchange, $\mathrm{H}-\mathrm{N}), 1.23\left(3 \mathrm{H}, \mathrm{t}, \mathrm{J}=7.1 \mathrm{~Hz}, \mathrm{H}_{3} \mathrm{C}-\mathrm{CH}_{2} \mathrm{O}\right), 0.82(6 \mathrm{H}, \mathrm{d}, \mathrm{J}=$ $\left.6.4 \mathrm{~Hz},\left(\mathrm{H}_{3} \mathrm{C}\right)_{2} \mathrm{CH}\right)$.

Compounds $\mathbf{6 b}-\mathbf{d}$ were prepared using the same procedure.

Ethyl 1-I sobutyl-4-methylpiperazine-2-carboxylate (7a). A mixture of $6 \mathbf{a}(17 \mathrm{~g}, 0.08 \mathrm{~mol}), 37 \%$ formal dehyde $(10 \mathrm{~mL}$, $0.13 \mathrm{~mol}$ ), and formic acid (10 mL, $0.25 \mathrm{~mol}$ ) in $\mathrm{MeOH}$ (110 $\mathrm{mL}$ ) was refluxed for $20 \mathrm{~h}$. After evaporation of the solvent, the residue was taken up in ether and washed with saturated $\mathrm{NaHCO}_{3}$ solution until basic $\mathrm{pH}$. The organic layer was washed with water and dried over $\mathrm{MgSO}_{4}$, and the solvent was removed in vacuo. The crude product was purified by crystallization of the hydrochloride salt from ethanol-ether. Usual treatment of this salt afforded $15.5 \mathrm{~g}(85 \%)$ of $7 \mathrm{a}$ as a colorless oil: IR (film, $\left.\mathrm{cm}^{-1}\right) v 1745(\mathrm{C}=\mathrm{O})$; ${ }^{1} \mathrm{H}$ NMR $\delta 4.15(2 \mathrm{H}, \mathrm{q}$, J $=$ $\left.7.10 \mathrm{~Hz}, \mathrm{H}_{2} \mathrm{C}-\mathrm{O}\right), 3.07-2.20(7 \mathrm{H}, \mathrm{m}, \mathrm{H}$ piperazine), $2.27(3 \mathrm{H}$, S, $\left.\mathrm{H}_{3} \mathrm{C}-\mathrm{N}\right), 2.02\left(2 \mathrm{H}, \mathrm{d}, \mathrm{J}=7.29 \mathrm{~Hz}, \mathrm{H}_{2} \mathrm{C}-\mathrm{CH}\right), 1.79-1.59$ $\left(1 \mathrm{H}, \mathrm{m}, \mathrm{HC}\left(\mathrm{CH}_{3}\right)_{2}\right), 1.22\left(3 \mathrm{H}, \mathrm{t}, \mathrm{J}=7.10 \mathrm{~Hz}, \mathrm{H}_{3} \mathrm{C}-\mathrm{CH}_{2} \mathrm{O}\right), 0.81$ $\left(6 \mathrm{H}, \mathrm{d}, \mathrm{J}=6.33 \mathrm{~Hz},\left(\mathrm{H}_{3} \mathrm{C}\right)_{2} \mathrm{CH}\right)$.

Compounds $\mathbf{7 b}-\mathbf{d}$ were prepared using the same procedure.

Ethyl 1-(2',4'-dichlorobenzyl)-4-methylpiperazine-2carboxylate (7b): ${ }^{1} \mathrm{H}$ NMR $\delta 7.38-7.11(3 \mathrm{H}, \mathrm{m}, \mathrm{Ar}-\mathrm{H}), 4.06$ $\left(2 \mathrm{H}, \mathrm{q}, \mathrm{J}=7.09 \mathrm{~Hz}, \mathrm{H}_{2} \mathrm{C}-\mathrm{O}\right), 3.75$ and $3.44(2 \mathrm{H}, \mathrm{AB}$ spectrum, $\mathrm{J}=14.76 \mathrm{~Hz}, \mathrm{H}_{2} \mathrm{C}-\mathrm{Ar}$ ), 3.6-2.24 (7H, m, $\mathrm{H}$ piperazine), 2.19 $\left(3 \mathrm{H}, \mathrm{s}, \mathrm{H}_{3} \mathrm{C}-\mathrm{N}\right), 1.16\left(3 \mathrm{H}, \mathrm{t}, \mathrm{J}=7.09 \mathrm{~Hz}, \mathrm{H}_{3} \mathrm{C}-\mathrm{CH}_{2} \mathrm{O}\right)$.

Ethyl 1-(2'-chlorobenzyl)-4-methylpiperazine-2-carboxylate (7c) and ethyl 1-(2'-methoxybenzyl)-4-methylpiperazine-2-carboxylate (7d): ${ }^{1} \mathrm{H}$ NMR spectra were the same as for 7b; particular signal for $\mathbf{7 d} \delta 6.69\left(3 \mathrm{H}, \mathrm{s}, \mathrm{H}_{3} \mathrm{C}-\right.$ O).

Ethyl 1-Isobutyl-4-(2'-propen-1'-yl)piperazine-2-carboxylate (8a). This compound was prepared following the procedure described for $5 \mathbf{a}$, starting from $\mathbf{4 a}(19.8 \mathrm{~g}, 0.1 \mathrm{~mol})$ and isobutyl bromide $(16.4 \mathrm{~g}, 0.12 \mathrm{~mol})$. After treatment the crude product was purified by column chromatography using petroleum ether/ether (first 70:30 then 50:50, v/v) as eluent to afford $18 \mathrm{~g}(71 \%)$ of $\mathbf{8 a}$ as a colorless oil: IR (film, $\left.\mathrm{cm}^{-1}\right)$ v $1745(\mathrm{C}=\mathrm{O}) ;{ }^{1 \mathrm{H}} \mathrm{NMR} \delta 5.79-5.75(\mathrm{H}, \mathrm{m}, \mathrm{HC}=), 5.24-5.14$ $\left(2 \mathrm{H}, \mathrm{m}, \mathrm{H}_{2} \mathrm{C}=\right), 4.12\left(2 \mathrm{H}, \mathrm{q}\right.$, J $\left.=7.2 \mathrm{~Hz}, \mathrm{H}_{2} \mathrm{C}-\mathrm{O}\right), 3.10-2.24$ $\left(1 \mathrm{H}, \mathrm{m}, \mathrm{H}\right.$ piperazine, $\mathrm{H}_{2} \mathrm{C}-\mathrm{C}=$ and $\left.\mathrm{H}_{2} \mathrm{C}-\mathrm{CH}\left(\mathrm{CH}_{3}\right)_{2}\right), 1.72-$ $1.62\left(\mathrm{H}, \mathrm{m}, \mathrm{H}-\mathrm{C}\left(\mathrm{CH}_{3}\right)_{2}, 1.19\left(3 \mathrm{H}, \mathrm{t}, \mathrm{J}=7.2 \mathrm{~Hz}, \mathrm{H}_{3} \mathrm{C}-\mathrm{CH}_{2} \mathrm{O}\right)\right.$, 0.82 and $0.79\left(6 \mathrm{H}, 2 \mathrm{~d}, \mathrm{~J}=6.2 \mathrm{~Hz},\left(\mathrm{H}_{3} \mathrm{C}\right)_{2} \mathrm{CH}\right)$.

Ethyl 1-isobutyl-4-(2'-methyl-2'-propen-1'-yl)piperazine2-carboxylate (8b): prepared like compound 8a starting from 4b; ${ }^{1} \mathrm{H}$ NMR $\delta 4.77\left(2 \mathrm{H}, \mathrm{br} \mathrm{s}, \mathrm{H}_{2} \mathrm{C}=\right), 4.45-4.15\left(2 \mathrm{H}, \mathrm{m}, \mathrm{H}_{2} \mathrm{C}-\right.$ O), 3.20-2.08 $\left(11 \mathrm{H}, \mathrm{H}\right.$ piperazine, $\mathrm{H}_{2} \mathrm{C}-\mathrm{N}_{1}$ and $\left.\mathrm{H}_{2} \mathrm{C}-\mathrm{N}_{4}\right), 1.63$ $\left(3 \mathrm{H}, \mathrm{s}, \mathrm{H}_{3} \mathrm{C}-\mathrm{C}=\right), 1.20\left(3 \mathrm{H}, \mathrm{t}, \mathrm{J}=7.13 \mathrm{~Hz}, \mathrm{H}_{3} \mathrm{C}-\mathrm{CH}_{2} \mathrm{O}\right), 0.82$ and $0.79\left(6 \mathrm{H}, 2 \mathrm{~d}, \mathrm{~J}=6.35 \mathrm{~Hz},\left(\mathrm{H}_{3} \mathrm{C}\right)_{2} \mathrm{CH}\right)$.

Ethyl 1-methyl-4-isobutylpiperazine-2-carboxylate (8c): obtained as described for 7a starting from 4c; ${ }^{1} \mathrm{H}$ NMR $\delta 4.14$ $\left(2 \mathrm{H}, \mathrm{q}, \mathrm{J}=7.1 \mathrm{~Hz}, \mathrm{H}_{2} \mathrm{C}-\mathrm{O}\right), 3.71-2.12(7 \mathrm{H}, \mathrm{m}, \mathrm{H}$ piperazine), $2.27\left(3 \mathrm{H}, \mathrm{s}, \mathrm{H}_{3} \mathrm{C}-\mathrm{N}\right), 2.02\left(2 \mathrm{H}, \mathrm{d}, \mathrm{J}=7.37 \mathrm{~Hz}, \mathrm{H}_{2} \mathrm{C}-\mathrm{N}\right), 1.79$ $1.59\left(1 \mathrm{H}, \mathrm{m}, \mathrm{HC}\left(\mathrm{CH}_{3}\right)_{2}\right), 1.22\left(3 \mathrm{H}, \mathrm{t}, \mathrm{J}=7.10 \mathrm{~Hz}, \mathrm{H}_{3} \mathrm{C}-\mathrm{CH}_{2} \mathrm{O}\right)$, $0.81\left(6 \mathrm{H}, \mathrm{d}, \mathrm{J}=7.37 \mathrm{~Hz},\left(\mathrm{H}_{3} \mathrm{C}\right)_{2} \mathrm{CH}\right)$.

Preparation of Dicyclopropylmethyl Ester Intermediates 18 and 19 (Scheme 2). N-Benzyl-N-methylethanolamine (9). This compound was prepared following the same procedure as for $7 a$. The crude product was purified by distillation $\left(\mathrm{E}_{15}=140-142{ }^{\circ} \mathrm{C}\right) ; 151 \mathrm{~g}(1 \mathrm{~mol})$ of N-benzylethanolamine afforded $138 \mathrm{~g}$ (84\%) of 9: IR (film, cm $\left.{ }^{-1}\right) v 3500$ $(\mathrm{OH}), 1590(\mathrm{C}=\mathrm{C})$; ${ }^{1} \mathrm{H}$ NMR $\delta 7.20(5 \mathrm{H}, \mathrm{s}, \mathrm{Ar}-\mathrm{H}), 3.80(1 \mathrm{H}, \mathrm{br}$ $\mathrm{s}, \mathrm{D}_{2} \mathrm{O}$ exchange, $\left.\mathrm{H}-\mathrm{O}\right), 3.54\left(2 \mathrm{H}, \mathrm{t}, \mathrm{J}=5.6 \mathrm{~Hz}, \mathrm{H}_{2} \mathrm{C}-\mathrm{O}\right), 3.49$ $\left(2 \mathrm{H}, \mathrm{s}, \mathrm{H}_{2} \mathrm{C}-\mathrm{Ar}\right), 2.47\left(2 \mathrm{H}, \mathrm{t}, \mathrm{J}=5.6 \mathrm{~Hz}, \mathrm{H}_{2} \mathrm{C}-\mathrm{N}\right), 2.13(3 \mathrm{H}$, $\left.\mathrm{S}, \mathrm{J}=7.2 \mathrm{~Hz}, \mathrm{H}_{3} \mathrm{C}-\mathrm{N}\right)$. 
2-Chloro-N-benzyl-N-methylethylamine Hydrochloride (10). To $130 \mathrm{~g}(0.79 \mathrm{~mole})$ of 9 in $\mathrm{CHCl}_{3}(400 \mathrm{~mL})$ was added dropwise $70 \mathrm{~mL}$ of $\mathrm{SOCl}_{2}$ in $\mathrm{CHCl}_{3}(70 \mathrm{~mL})$. After $15 \mathrm{~h}$ stirring at room temperature, the solvent was removed in vacuo. The residue was crystallized from acetone/ $\mathrm{MeOH}(80$ : 20, v/v) to give $146 \mathrm{~g}(84 \%)$ of 10 as a white powder: $\mathrm{mp} 140$ $141{ }^{\circ} \mathrm{C}$; I R (free base, film, $\mathrm{cm}^{-1}$ ) $1595 v(\mathrm{C}=\mathrm{C})$; ${ }^{1} \mathrm{H}$ NMR (free base) $\delta 7.24(5 \mathrm{H}, \mathrm{m}, \mathrm{Ar}-\mathrm{H}), 3.54\left(2 \mathrm{H}, \mathrm{s}, \mathrm{H}_{2} \mathrm{C}-\mathrm{Ar}\right), 3.53(2 \mathrm{H}, \mathrm{t}$, $\left.\mathrm{J}=6.8 \mathrm{~Hz}, \mathrm{H}_{2} \mathrm{C}-\mathrm{Cl}\right), 2.69\left(2 \mathrm{H}, \mathrm{t}, \mathrm{J}=6.8 \mathrm{~Hz}, \mathrm{H}_{2} \mathrm{C}-\mathrm{N}\right), 2.21$ $\left(3 \mathrm{H}, \mathrm{s}, \mathrm{H}_{3} \mathrm{C}-\mathrm{N}\right)$.

N-Benzyl-N-methylethylenediamine (11). 10 (110 g, 0.5 mol) was solubilized in a $28 \%$ aqueous ammonia solution (1 $L$ ) and stirred for 3 days at room temperature. The water was partially removed in vacuo, and $28 \mathrm{~g}$ of $\mathrm{KOH}$ pellets was added. The aqueous layer was extracted with $\mathrm{CH}_{2} \mathrm{Cl}_{2}$, and the organic layer was dried over $\mathrm{MgSO}_{4}$ and concentrated. The crude product was purified by distillation $\left(\mathrm{E}_{15}=152-154^{\circ} \mathrm{C}\right)$ to give $49 \mathrm{~g}(60 \%)$ of 11: IR (film, cm $\left.{ }^{-1}\right) v 3410$ and $3405\left(\mathrm{NH}_{2}\right), 1590$ $(\mathrm{C}=\mathrm{C}) ;{ }^{1} \mathrm{H}$ NMR $(60 \mathrm{MHz}) \delta 7.18(5 \mathrm{H}, \mathrm{s}, \mathrm{Ar}-\mathrm{H}), 3.41(2 \mathrm{H}, \mathrm{s}$, $\left.\mathrm{H}_{2} \mathrm{C}-\mathrm{Ar}\right), 2.80-2.20\left(4 \mathrm{H}, \mathrm{m}\right.$, two $\left.\mathrm{H}_{2} \mathrm{C}-\mathrm{N}\right), 2.10\left(3 \mathrm{H}, \mathrm{s}, \mathrm{H}_{3} \mathrm{C}-\right.$ $\mathrm{N}), 1.12\left(2 \mathrm{H}\right.$, br $\mathrm{S}, \mathrm{D}_{2} \mathrm{O}$ exchange, $\left.\mathrm{H}_{2} \mathrm{~N}\right)$.

N-Benzyl-N-methyl-N'-(dicyclopropylmethyl)ethylenediamine (15). A mixture of $8.2 \mathrm{~g}(0.05 \mathrm{~mol})$ of $\mathbf{1 1}$ and $5.5 \mathrm{~g}$ $(0.05 \mathrm{~mol})$ of dicyclopropyl ketone in benzene $(50 \mathrm{~mL})$ was refluxed for 15 days using a Dean-Stark apparatus. Advancement of the reaction was followed by IR. The solvent was evaporated, and the residue was diluted in dry and cold $\mathrm{MeOH}$ $(50 \mathrm{~mL})$; then $1.9 \mathrm{~g}(0.05 \mathrm{~mol})$ of $\mathrm{NaBH}_{4}$ was added portionwise. After $15 \mathrm{~h}$ stirring at room temperature, the mixture was poured into water containing $2 \mathrm{~g}$ of $\mathrm{NaOH}$, saturated with $\mathrm{NaCl}$, and extracted with hexane. The organic layer was dried over $\mathrm{MgSO}_{4}$ and concentrated. The crude product was purified by column chromatography using $\mathrm{CH}_{2} \mathrm{Cl}_{2}$ and then $\mathrm{CH}_{2} \mathrm{Cl}_{2}$ l $\mathrm{MeOH}(97: 3, \mathrm{v} / \mathrm{v})$ as eluents to give $5.2 \mathrm{~g}(40 \%)$ of 15: IR (film, $\left.\mathrm{cm}^{-1}\right)$ v $3380(\mathrm{NH}), 3100,3080$ (cycl opropyl), $1580(\mathrm{C}=\mathrm{C}) ;{ }^{1} \mathrm{H}$ NMR $(60 \mathrm{MHz}) \delta 7.19(5 \mathrm{H}, \mathrm{s}, \mathrm{Ar}-\mathrm{H}), 3.45\left(2 \mathrm{H}, \mathrm{s}, \mathrm{H}_{2} \mathrm{C}-\mathrm{Ar}\right)$, 2.95-2.67 $\left(4 \mathrm{H}, \mathrm{m}\right.$, two $\left.\mathrm{H}_{2} \mathrm{C}-\mathrm{N}\right), 1.90\left(1 \mathrm{H}, \mathrm{s}, \mathrm{D}_{2} \mathrm{O}\right.$ exchange, $\mathrm{H}-\mathrm{N}), 1.35-0.48(1 \mathrm{H}, \mathrm{m}, \mathrm{HC}-$ dicyclopropyl and $\mathrm{H}$ cyclopropyl).

N-Methyl-N' -(dicyclopropylmethyl)ethylenediamine (17). A shaken suspension of $\mathbf{1 5}(23 \mathrm{~g}, 0.09 \mathrm{~mol})$ and $10 \% \mathrm{Pd} / \mathrm{C}$ $(300 \mathrm{mg})$ in anhydrous ethanol $(120 \mathrm{~mL})$ was heated at $40^{\circ} \mathrm{C}$ under $\mathrm{H}_{2}$ atmosphere for $3 \mathrm{~h}$. The reaction mixture was filtered through Celite and concentrated. The crude product was purified by distillation $\left(\mathrm{E}_{0.05}=48-52{ }^{\circ} \mathrm{C}\right)$ to give $12.8 \mathrm{~g}(85 \%)$ of 17 as a colorless oil: IR (film, $\left.\mathrm{cm}^{-1}\right) v 3400(\mathrm{NH}), 3100,3080$ (cyclopropyl); ${ }^{1 H} \mathrm{HMR}(60 \mathrm{MHz}) \delta 2.95-2.50$ (4H, m, two $\left.\mathrm{H}_{2} \mathrm{C}-\mathrm{N}\right), 1.75\left(2 \mathrm{H}, \mathrm{S}, \mathrm{D}_{2} \mathrm{O}\right.$ exchange, two $\left.\mathrm{H}-\mathrm{N}\right), 1.35-0.45$ (11H, m, HC-dicyclopropyl and H cyclopropyl).

Ethyl 1-(Dicyclopropylmethyl)-4-methylpiperazine-2carboxylate (18). To a hot $\left(80^{\circ} \mathrm{C}\right)$ stirred solution of $\mathbf{1 7}(12$ $\mathrm{g}, 0.07 \mathrm{~mol})$ and triethylamine $(24 \mathrm{~mL}, 0.17 \mathrm{~mol})$ in toluene (100 mL) was added dropwise, but rapidly, ethyl 2,3-dibromopropionate $(18.3 \mathrm{~g}, 0.071 \mathrm{~mol})$ in toluene $(100 \mathrm{~mL})$. After the addition, the reaction mixture was stirred at $80{ }^{\circ} \mathrm{C}$ for 3 $\mathrm{h}$, then cooled, and filtered. The filtrate was washed with saturated aqueous $\mathrm{NaHCO}_{3}(100 \mathrm{~mL})$. The organic layer was dried over $\mathrm{MgSO}_{4}$ and the solvent removed in vacuo. The crude product was purified by column chromatography using petroleum ether/ether (80:20, v/v) as eluent to afford $9.5 \mathrm{~g}(54 \%)$ of 18 as a paleyellow oil: IR (film, $\left.\mathrm{cm}^{-1}\right) v 3100,3080$ (cyclopropyl), $1745(\mathrm{C}=\mathrm{O})$; ${ }^{1} \mathrm{H}$ NMR $\delta 4.08\left(2 \mathrm{H}, \mathrm{q}, \mathrm{J}=7.2 \mathrm{~Hz}, \mathrm{H}_{2} \mathrm{C}-\right.$ O), $4.03(1 \mathrm{H}, \mathrm{t}, \mathrm{J}=6.3 \mathrm{~Hz}, \mathrm{HC}-\mathrm{N}), 3.23-3.04,2.74-2.70$, 2.60-2.38 $\left(6 \mathrm{H}, 3 \mathrm{~m}\right.$, three $\left.\mathrm{H}_{2} \mathrm{C}-\mathrm{N}\right), 2.25(3 \mathrm{H}, \mathrm{s}, \mathrm{J}=7.2 \mathrm{~Hz}$, $\left.\mathrm{H}_{3} \mathrm{C}-\mathrm{N}\right), 1.49(1 \mathrm{H}, \mathrm{t}, \mathrm{J}=9 \mathrm{~Hz}, \mathrm{HC}$-dicyclopropyl $), 1.26(3 \mathrm{H}, \mathrm{t}$, $\left.\mathrm{J}=7.2 \mathrm{~Hz}, \mathrm{H}_{3} \mathrm{C}-\mathrm{CH}_{2} \mathrm{O}\right), 0.9-0.76,0.56-0.1(10 \mathrm{H}, 2 \mathrm{~m}, \mathrm{H}$ cyclopropyl).

Ethyl 1,4-Bis(dicyclopropylmethyl)piperazine-2-carboxylate (19). Compound 19 was obtai ned similarly, starting with disubstituted ethylenediamine 16: ${ }^{1} \mathrm{H}$ NMR $\delta 4.15-3.95$ $\left(3 \mathrm{H}, \mathrm{m}, \mathrm{H}_{2} \mathrm{C}-\mathrm{O}\right.$ and $\left.\mathrm{HC}-\mathrm{N}\right), 3.15-2.73\left(6 \mathrm{H}, \mathrm{m}\right.$, three $\mathrm{H}_{2} \mathrm{C}-$ N), $1.45(1 \mathrm{H}, \mathrm{t}, \mathrm{J}=9 \mathrm{~Hz}, \mathrm{HC}$-dicyclopropyl), $1.06(1 \mathrm{H}, \mathrm{t}, \mathrm{J}=$ $8.5 \mathrm{~Hz}, \mathrm{HC}$-dicyclopropyl), $1.18\left(3 \mathrm{H}, \mathrm{t}, \mathrm{J}=7.1 \mathrm{~Hz}, \mathrm{H}_{3} \mathrm{C}-\mathrm{CH}_{2} \mathrm{O}\right)$, $0.8-0.69,0.47-0.08$ (20H, 2m, H cyclopropyl).
Preparation of 1-Phenyl-4-alkyl Ester Intermediates 24a, 29a,b, and 35b (Scheme 3). N-Benzoylaniline (20). To a cold solution of $150 \mathrm{~mL}$ (1.65 mol) of aniline in $\mathrm{CH}_{2} \mathrm{Cl}_{2}$ $(400 \mathrm{~mL})$ was added dropwise $90 \mathrm{~mL}(0.776 \mathrm{~mol})$ of benzoyl chloride in $\mathrm{CH}_{2} \mathrm{Cl}_{2}(200 \mathrm{~mL})$. After $2 \mathrm{~h}$ stirring at room temperature, water $(300 \mathrm{~mL})$ and concentrated $\mathrm{HCl}(20 \mathrm{~mL}$ at $37 \%$ ) were added. The mixture was filtered and the solid product washed with water and then with acetone to afford $120 \mathrm{~g}$ of $\mathbf{2 0}$. The filtrate was concentrated to provide another $28 \mathrm{~g}$ of $\mathbf{2 0}$ (global yield $97 \%$ ): $\mathrm{mp} 162-164{ }^{\circ} \mathrm{C}$; IR (film, $\mathrm{cm}^{-1}$ ) $v 3399(\mathrm{NH}), 1642(\mathrm{C}=\mathrm{O}) ;{ }^{1} \mathrm{H}$ NMR $\delta 7.82\left(1 \mathrm{H}, \mathrm{br} \mathrm{S}, \mathrm{D}_{2} \mathrm{O}\right.$ exchange, $\mathrm{H}-\mathrm{N}), 7.80-7.04(10 \mathrm{H}, \mathrm{m}, \mathrm{Ar}-\mathrm{H})$.

$\mathbf{N}$-Benzoyl-N-phenyl-N'-benzyl-N'-methylethylenediamine (21). To a stirred cold suspension of $\mathrm{NaH}(25 \mathrm{~g}, 0.625$ $\mathrm{mol})$ in DMF (100 mL) was added dropwise the amide 20 (118 $\mathrm{g}, 0.6 \mathrm{~mol}$ ) in DMF (500 mL). The mixture was stirred for $1 \mathrm{~h}$ at room temperature, and then $105 \mathrm{~g}(0.57 \mathrm{~mol})$ of 2-chloro$\mathrm{N}$-benzyl-N-methylethylamine dissolved in DMF (100 mL) was added. The solution was stirred and heated for $3 \mathrm{~h}$ at $60^{\circ} \mathrm{C}$, and after the solution had cooled in an ice bath, water (500 $\mathrm{mL}$ ) was added. The aqueous layer was extracted several times with ether and the etheral layer washed with aqueous $\mathrm{HCl}$ until acidic $\mathrm{pH}$. The aqueous layer was extracted with $\mathrm{CH}_{2-}$ $\mathrm{Cl}_{2}$ (the hydrochloride salt of compound $\mathbf{2 1}$ is very soluble in $\mathrm{CH}_{2} \mathrm{Cl}_{2}$ ) and the organic layer washed with aqueous $\mathrm{Na}_{2} \mathrm{CO}_{3}$ until basic $\mathrm{pH}$. The dichloromethane phase was dried over $\mathrm{MgSO}_{4}$ and concentrated. The crude product was crystallized from pentane/ether (90:10, v/v) to give $120 \mathrm{~g}(58 \%)$ of $\mathbf{2 1}$ as a

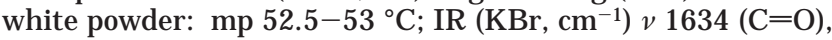
$1594(\mathrm{C}=\mathrm{C}) ;{ }^{1} \mathrm{H}$ NMR $\delta$ 7.22-6.92 $(15 \mathrm{H}, \mathrm{ma}, \mathrm{Ar}-\mathrm{H}), 4.00(2 \mathrm{H}$, $\left.\mathrm{t}, \mathrm{J}=6.8 \mathrm{~Hz}, \mathrm{H}_{2} \mathrm{C}-\mathrm{N}\right), 3.46\left(2 \mathrm{H}, \mathrm{s}, \mathrm{H}_{2} \mathrm{C}-\mathrm{Ar}\right), 2.62(2 \mathrm{H}, \mathrm{t}, \mathrm{J}=$ $\left.6.8 \mathrm{~Hz}, \mathrm{H}_{2} \mathrm{C}-\mathrm{N}^{\prime}\right), 2.14\left(3 \mathrm{H}, \mathrm{s}, \mathrm{H}_{3} \mathrm{C}-\mathrm{N}^{\prime}\right)$.

N-Phenyl-N'-benzyl-N'-methylethylenediamine (22). 21 (120 g, $0.35 \mathrm{~mol}$ ) was solubilized in $1 \mathrm{~L}$ of $\mathrm{HCl}(6 \mathrm{M})$ and refluxed for $24 \mathrm{~h}$. After cooling in an ice bath and filtration of benzoic acid, the water was partially evaporated. The aqueous solution was extracted twice with $\mathrm{CH}_{2} \mathrm{Cl}_{2}$, treated with $\mathrm{Na}_{2}-$ $\mathrm{CO}_{3}$ until basic $\mathrm{pH}$, and then re-extracted with $\mathrm{CH}_{2} \mathrm{Cl}_{2}$. The organic layer was dried over $\mathrm{MgSO}_{4}$ and concentrated to afford $81 \mathrm{~g}(96 \%)$ of 22 as a colorless oil: IR (film, $\left.\mathrm{cm}^{-1}\right) v 3389(\mathrm{NH})$, $1603(\mathrm{C}=\mathrm{C}) ;{ }^{1} \mathrm{H}$ NMR $\delta 7.23-6.52(10 \mathrm{H}, \mathrm{m}, \mathrm{Ar}-\mathrm{H}), 4.18(1 \mathrm{H}$, br $\mathrm{S}, \mathrm{D}_{2} \mathrm{O}$ exchange, $\left.\mathrm{H}-\mathrm{N}\right), 3.45\left(2 \mathrm{H}, \mathrm{S}, \mathrm{H}_{2} \mathrm{C}-\mathrm{Ar}\right), 3.09(2 \mathrm{H}, \mathrm{t}$, $\left.\mathrm{J}=5.6 \mathrm{~Hz}, \mathrm{H}_{2} \mathrm{C}-\mathrm{N}\right), 2.58\left(2 \mathrm{H}, \mathrm{t}, \mathrm{J}=5.6 \mathrm{~Hz}, \mathrm{H}_{2} \mathrm{C}-\mathrm{N}^{\prime}\right), 2.13$ $\left(3 \mathrm{H}, \mathrm{S}, \mathrm{H}_{3} \mathrm{C}-\mathrm{N}^{\prime}\right)$.

N-Phenyl-N'-methylethylenediamine Dihydrochloride (23). A shaken suspension of $\mathbf{2 2}(80 \mathrm{~g}, 0.33 \mathrm{~mol})$ and $10 \% \mathrm{Pd} / \mathrm{C}$ $(600 \mathrm{mg})$ in anhydrous ethanol $(300 \mathrm{~mL})$ was kept under an $\mathrm{H}_{2}$ atmosphere for $24 \mathrm{~h}$ at room temperature. The solution was filtered; the filtrate was diluted with $\mathrm{EtOH} / \mathrm{HCl}$ and then concentrated; $65.5 \mathrm{~g}$ (89\%) of $\mathbf{2 3}$ was obtained as a white powder: $\mathrm{mp} 153-168^{\circ} \mathrm{C}$ dec; I R (free base, film, $\mathrm{cm}^{-1}$ ) $v 3391$ $(\mathrm{NH}), 1603(\mathrm{C}=\mathrm{C})$; ${ }^{1} \mathrm{H}$ NMR (free base) $\delta 7.15-7.05$, 6.65$6.52(5 \mathrm{H}, 2 \mathrm{~m}, \mathrm{Ar}-\mathrm{H}), 4.16\left(1 \mathrm{H}\right.$, br $\mathrm{s}, \mathrm{D}_{2} \mathrm{O}$ exchange $\left.\mathrm{H}-\mathrm{N}\right), 3.11$ $\left(2 \mathrm{H}, \mathrm{t}, \mathrm{J}=6.1 \mathrm{~Hz}, \mathrm{H}_{2} \mathrm{C}-\mathrm{N}\right), 2.73\left(2 \mathrm{H}, \mathrm{t}, \mathrm{J}=6.1 \mathrm{~Hz}, \mathrm{H}_{2} \mathrm{C}-\mathrm{N}^{\prime}\right)$, $2.34\left(3 \mathrm{H}, \mathrm{s}, \mathrm{H}_{3} \mathrm{C}-\mathrm{N}^{\prime}\right), 1.55\left(1 \mathrm{H}\right.$, br S, $\mathrm{D}_{2} \mathrm{O}$ exchange, $\left.\mathrm{H}-\mathrm{N}^{\prime}\right)$.

Ethyl 1-Phenyl-4-methylpiperazine-2-carboxylate (24a). The title compound was prepared according to the procedure used for 18, starting from $65 \mathrm{~g}(0.29 \mathrm{~mol})$ of $\mathbf{2 3}$ dihydrochl oride salt (the free base was regenerated in situ). The crude product was purified by column chromatography using petroleum ether/ether (first 80:20 then 70:30, v/v) as eluent, to afford 27 $\mathrm{g}(\mathbf{3 9} \%)$ of the two isomers $\mathbf{2 4 a}$ and $\mathbf{2 4 b}$. The pure isomer $\mathbf{2 4 a}$ was obtained by crystallization of the dihydrochloride salt from acetone-ether and then recrystallized from acetone/ethanol (90:10, v/v): $\mathrm{mp} 159^{\circ} \mathrm{C}$. The mother liquor was concentrated, and the residue, after alkalization, gave a paleyellow oil, mixture of the two isomers $\mathbf{2 4 a}$ and $\mathbf{2 4 \mathbf { b }}$ in the ratio $\mathbf{1 : 1}$; IR (free base, film, $\left.\mathrm{cm}^{-1}\right)$ of 24a: $v 1743(\mathrm{C}=\mathrm{O}), 1599(\mathrm{C}=\mathrm{C}) ;{ }^{1} \mathrm{H}$ NMR $\delta$ 7.18-7.10, 6.77-6.67 (5H, 2m, Ar-H), $4.36(1 \mathrm{H}, \mathrm{t}, \mathrm{J}$ $=3.3 \mathrm{~Hz}, \mathrm{H}-\mathrm{N})^{*}, 4.00\left(2 \mathrm{H}, \mathrm{dq}, \mathrm{J}=6.5\right.$ and $\left.1.8 \mathrm{~Hz}, \mathrm{H}_{2} \mathrm{C}-\mathrm{O}\right)$, 3.46-2.04 (6H, 3m, three $\left.\mathrm{H}_{2} \mathrm{C}-\mathrm{N}\right), 2.20\left(3 \mathrm{H}, \mathrm{s}, \mathrm{H}_{3} \mathrm{C}-\mathrm{N}\right), 1.05$ $\left(3 \mathrm{H}, \mathrm{t}, \mathrm{J}=6.5 \mathrm{~Hz}, \mathrm{H}_{3} \mathrm{C}-\mathrm{CH}_{2} \mathrm{O}\right)$. *This signal allowed to determine the ratio of the isomers. It presents $0.5 \mathrm{H}$ in the mixture obtained from the mother liquor. 
N-Benzyl-2-anilinoethanol (25). To $175.5 \mathrm{~g}$ (1.28 mol) of 2-anilinoethanol in benzene $(200 \mathrm{~mL})$ was added $79 \mathrm{~g}(0.625$ $\mathrm{mol})$ of benzyl chloride. The solution was stirred for $48 \mathrm{~h}$ at room temperature, then water $(200 \mathrm{~mL})$ was added, and the aqueous layer was extracted with ether. The organic phase was dried over $\mathrm{MgSO}_{4}$ and concentrated. The residue was taken up in aqueous $\mathrm{HCl}$ and extracted with $\mathrm{CH}_{2} \mathrm{Cl}_{2}$ (the hydrochloride salt of $\mathbf{2 5}$ is very soluble in $\mathrm{CH}_{2} \mathrm{Cl}_{2}$ ). The organic layer was neutralized and dried over $\mathrm{MgSO}_{4}$ and the solvent evaporated. The crude product was purified by distillation $\left(\mathrm{E}_{0.05}=145-147^{\circ} \mathrm{C}\right)$ to give $80 \mathrm{~g}(56 \%)$ of 25: IR $\left(\mathrm{KBr}, \mathrm{cm}^{-1}\right)$ $v$ 3568-3531 (OH), $1598(\mathrm{C}=\mathrm{C})$; ${ }^{1} \mathrm{H}$ NMR $\delta$ 7.20-7.05, 6.70$6.60(10 \mathrm{H}, 2 \mathrm{~m}, \mathrm{Ar}-\mathrm{H}), 4.50\left(2 \mathrm{H}, \mathrm{s}, \mathrm{H}_{2} \mathrm{C}-\mathrm{Ar}\right), 3.68(2 \mathrm{H}, \mathrm{dt}, \mathrm{J}$ $=5.66$ and $\left.5.60 \mathrm{~Hz}, \mathrm{H}_{2} \mathrm{C}-\mathrm{O}\right), 3.49\left(2 \mathrm{H}, \mathrm{t}, \mathrm{J}=5.66 \mathrm{~Hz}, \mathrm{H}_{2} \mathrm{C}-\right.$ $\mathrm{N}), 1.83\left(\mathrm{H}, \mathrm{t}, \mathrm{J}=5.60 \mathrm{~Hz}, \mathrm{D}_{2} \mathrm{O}\right.$ exchange, $\left.\mathrm{H}-\mathrm{O}\right)$.

N-Benzyl-N-phenyl-2-(p-tolylsulfonyloxy)ethylamine (26). 25 (113.5 g, $0.5 \mathrm{~mol}$ ) was dissolved in chloroform (500 $\mathrm{mL})$ and cooled in a salted ice bath. $\mathrm{Et}_{3} \mathrm{~N}(83 \mathrm{~mL}, 0.6 \mathrm{~mol})$ was then added, followed by the addition of $95.2 \mathrm{~g}(0.5 \mathrm{~mol})$ of p-toluenesulfonyl chloride in one portion with constant stirring. The reaction was complete in $24 \mathrm{~h}$ at $0{ }^{\circ} \mathrm{C}$. Ether $(200 \mathrm{~mL})$ was added, and the precipitate of triethylamine hydrochloride was filtered. The filtrate was concentrated in vacuo and the residue dissolved in ether. The etheral phase was washed successively with diluted $\mathrm{HCl}$ and water. The organic layer was dried over $\mathrm{MgSO}_{4}$, and the solvent was removed under reduced pressure. The crude tosylate was purified by crystallization from hexane/ $\mathrm{CH}_{2} \mathrm{Cl}_{2}$ to give 26 (127 g, 67\%) as white crystals: $\mathrm{mp} 82-84^{\circ} \mathrm{C}$; IR $\left(\mathrm{KBr}, \mathrm{cm}^{-1}\right) v 1598(\mathrm{C}=\mathrm{C}) ;{ }^{1} \mathrm{H}$ NMR $\delta 7.64\left(2 \mathrm{H}, \mathrm{d}, \mathrm{J}=8.30 \mathrm{~Hz}, 2 \mathrm{H}\right.$ in ortho of $\left.\mathrm{Ar}-\mathrm{SO}_{2}\right), 7.25-6.52$ $(12 \mathrm{H}, \mathrm{m}, \mathrm{Ar}-\mathrm{H}), 4.41\left(2 \mathrm{H}, \mathrm{s}, \mathrm{H}_{2} \mathrm{C}-\mathrm{Ar}\right), 4.11(2 \mathrm{H}, \mathrm{t}, \mathrm{J}=6.40$ $\left.\mathrm{Hz}, \mathrm{H}_{2} \mathrm{C}-\mathrm{O}\right), 3.61\left(2 \mathrm{H}, \mathrm{t}, \mathrm{J}=6.40 \mathrm{~Hz}, \mathrm{H}_{2} \mathrm{C}-\mathrm{N}\right), 2.34(3 \mathrm{H}, \mathrm{s}$, $\mathrm{H}_{3} \mathrm{C}-\mathrm{Ar}$ ).

N-Benzyl-N-phenyl-N'-isopropylethylenediamine (27). An amount of $150 \mathrm{~mL}$ (1.74 mol) of isopropylamine was added to $114 \mathrm{~g}(0.3 \mathrm{~mol})$ of tosylate 26 in $\mathrm{CH}_{2} \mathrm{Cl}_{2}(200 \mathrm{~mL})$. After 8 days stirring at room temperature, the solvent and excess of isopropylamine were evaporated under reduced pressure. The residue was treated with ether and $2 \mathrm{M} \mathrm{NaOH}$ until basic $\mathrm{pH}$. The aqueous layer was extracted with ether, the extracts were dried over $\mathrm{MgSO}_{4}$, and the solvent was removed in vacuo. The diamine $\mathbf{2 7}$ was purified by crystallization of its hydrochloride salt from ether/ethanol. After alkylization, $57 \mathrm{~g}$ (71\%) of 27 was obtained as a pale-yellow oil: I $\mathrm{R}\left(\mathrm{KBr}, \mathrm{cm}^{-1}\right) v 3316(\mathrm{NH})$, $1598(\mathrm{C}=\mathrm{C})$; ${ }^{1} \mathrm{H}$ NMR $\delta$ 7.25-7.07, 6.70-6.57 (10H, 2m, Ar$\mathrm{H}), 4.50\left(2 \mathrm{H}, \mathrm{s}, \mathrm{H}_{2} \mathrm{C}-\mathrm{Ar}\right), 3.48\left(2 \mathrm{H}, \mathrm{t}, \mathrm{J}=6.80 \mathrm{~Hz}, \mathrm{H}_{2} \mathrm{C}-\mathrm{N}\right)$, $2.82\left(2 \mathrm{H}, \mathrm{t}, \mathrm{J}=6.80 \mathrm{~Hz}, \mathrm{H}_{2} \mathrm{C}-\mathrm{N}^{\prime}\right), 2.67(1 \mathrm{H}, \mathrm{hp}, \mathrm{J}=6.20 \mathrm{~Hz}$, $\left.\mathrm{HC}\left(\mathrm{CH}_{3}\right)_{2}\right), 1.31\left(1 \mathrm{H}\right.$, br s, $\mathrm{D}_{2} \mathrm{O}$ exchange, $\left.\mathrm{H}-\mathrm{N}\right), 0.94(6 \mathrm{H}, \mathrm{d}$, $\left.\mathrm{J}=6.20 \mathrm{~Hz},\left(\mathrm{H}_{3} \mathrm{C}\right)_{2} \mathrm{CH}\right)$.

N-Phenyl-N'-isopropylethylenediamine Dihydrochloride (28). This compound was prepared in a similar way as 17, starting from $27(53 \mathrm{~g}, 0.20 \mathrm{~mol})$. The crude product was dissolved in $\mathrm{CH}_{2} \mathrm{Cl}_{2}$, and after it had cooled in an ice bath, $\mathrm{C}_{2} \mathrm{H}_{5} \mathrm{OH}$ saturated with $\mathrm{HCl}$ gas was added until acidic $\mathrm{pH}$. The solvent was evaporated and the dihydrochloride salt recrystallized from acetone/ethanol (90:10, v/v) to afford $35 \mathrm{~g}$ (70\%) of 28 as a white powder: $\mathrm{mp} 154{ }^{\circ} \mathrm{C}$; I $\mathrm{R}\left(\mathrm{KBr}, \mathrm{cm}^{-1}\right)$ v $3371(\mathrm{NH}), 1599(\mathrm{C}=\mathrm{C})$; ${ }^{1} \mathrm{H}$ NMR (free base) $\delta$ 7.19-7.05, 6.67$6.55(4 \mathrm{H}, 2 \mathrm{~m}, \mathrm{Ar}-\mathrm{H}), 4.19\left(\mathrm{H}, \mathrm{t}, \mathrm{D}_{2} \mathrm{O}\right.$ exchange, $\left.\mathrm{H}-\mathrm{N}-\mathrm{Ar}\right)$, $3.19\left(2 \mathrm{H}, \mathrm{t}, \mathrm{J}=5.50 \mathrm{~Hz}, \mathrm{H}_{2} \mathrm{C}-\mathrm{N}\right), 2.84-2.69\left(3 \mathrm{H}, \mathrm{m}, \mathrm{H}_{2} \mathrm{C}-\mathrm{N}^{\prime}\right.$ and $\left.\mathrm{HC}\left(\mathrm{CH}_{3}\right)_{2}\right), 2.09\left(1 \mathrm{H}\right.$, br s, $\mathrm{D}_{2} \mathrm{O}$ exchange, $\left.\mathrm{H}-\mathrm{N}^{\prime}\right), 1.03(6 \mathrm{H}$, d, J $\left.=6.30 \mathrm{~Hz},\left(\mathrm{H}_{3} \mathrm{C}\right)_{2} \mathrm{CH}\right)$.

Ethyl 1-Phenyl-4-isopropylpiperazine-2-carboxylate (29a) and Ethyl 1-Isopropyl-4-phenylpiperazine-2-carboxylate (29b). The title compounds were prepared according to the procedure used to dispose 18, starting from $32 \mathrm{~g}(0.127$ $\mathrm{mol}$ ) of $\mathbf{2 8}$ dihydrochloride salt (the free base was regenerated in situ). Compounds 29a and 29b were separated by column chromatography using petroleum ether/ether (90:10, 85:15, 80: 20, v/v) as eluent. 29a: $15 \mathrm{~g}(43 \%) ; \mathrm{mp} 70-72{ }^{\circ} \mathrm{C}$ (hexane); ${ }^{1} \mathrm{H}$ NMR spectrum of this ester was similar to that of 24a; particular signal $\delta 0.97$ and $0.93\left(6 \mathrm{H}, 2 \mathrm{~d}, \mathrm{~J}=6.6 \mathrm{~Hz},\left(\mathrm{H}_{3} \mathrm{C}\right)_{2^{-}}\right.$ $\mathrm{CH}$ ). 29b: $6 \mathrm{~g}$ (17\%), pale-yellow oil (after crystallization of the dihydrochloride salt from acetone/hexane/ $\mathrm{CH}_{2} \mathrm{Cl}_{2}$ and regeneration of the free base); ${ }^{1} \mathrm{H}$ NMR $\delta 7.23-7.14,6.86-$ $6.75(5 \mathrm{H}, 2 \mathrm{~m}, \mathrm{Ar}-\mathrm{H}), 4.15\left(2 \mathrm{H}, \mathrm{q}, \mathrm{J}=7.1 \mathrm{~Hz}, \mathrm{H}_{2} \mathrm{C}-\mathrm{O}\right), 3.58$ $(1 \mathrm{H}, \mathrm{t}, \mathrm{J}=5.9 \mathrm{~Hz}, \mathrm{HC}-\mathrm{N}), 3.35-2.94\left(6 \mathrm{H}, \mathrm{m}\right.$, three $\left.\mathrm{H}_{2} \mathrm{C}-\mathrm{N}\right)$, 2.68-2.57 (1H, m, HC( $\left.\left(\mathrm{CH}_{3}\right)_{2}\right), 1.22\left(3 \mathrm{H}, \mathrm{t}, \mathrm{J}=1 \mathrm{~Hz}, \mathrm{H}_{3} \mathrm{C}-\right.$ $\left.\mathrm{CH}_{2} \mathrm{O}\right), 1.10$ and $0.94\left(6 \mathrm{H}, 2 \mathrm{~d}, \mathrm{~J}=6.5 \mathrm{~Hz},\left(\mathrm{H}_{3} \mathrm{C}\right)_{2} \mathrm{CH}\right)$.

N-Benzoyl-o-chloroaniline (30). To a cold solution of 132 $\mathrm{g}(1.035 \mathrm{~mol})$ of o-chloroaniline in $\mathrm{CH}_{2} \mathrm{Cl}_{2}(300 \mathrm{~mL})$ was added dropwise $60 \mathrm{~mL}(0.517 \mathrm{~mol})$ of benzoyl chloride in $\mathrm{CH}_{2} \mathrm{Cl}_{2}(200$ $\mathrm{mL}$ ). After $2 \mathrm{~h}$ stirring at room temperature, the hydrochloride salt of o-chloroaniline was filtered and the filtrate washed first with diluted $\mathrm{HCl}$ and then with water. The organic layer was dried over $\mathrm{MgSO}_{4}$ and concentrated in vacuo. The product crystallized from hexane to afford $108 \mathrm{~g}(90 \%)$ of 30 as a white powder: $\mathrm{mp} 163^{\circ} \mathrm{C}$; IR $\left(\mathrm{KBr}, \mathrm{cm}^{-1}\right)$ v $1642(\mathrm{C}=\mathrm{O}), 1596(\mathrm{C}=$ C); ${ }^{1} \mathrm{H}$ NMR $\delta 8.50(1 \mathrm{H}, \mathrm{d}, \mathrm{J}=7.96 \mathrm{~Hz}, \mathrm{Ar}-\mathrm{H}), 8.39(1 \mathrm{H}, \mathrm{s}$, $\mathrm{D}_{2} \mathrm{O}$ very slow exchange, $\left.\mathrm{H}-\mathrm{N}\right), 7.88-6.98(8 \mathrm{H}, \mathrm{m}, \mathrm{Ar}-\mathrm{H})$.

N-Benzoyl-N-(o-chlorophenylamino)acetonitrile (31). To a cold suspension of $\mathrm{NaH}(14 \mathrm{~g}, 0.35 \mathrm{~mol})$ in DMF (100 $\mathrm{mL}$ ) was added dropwise the amide $30(75 \mathrm{~g}, 0.324 \mathrm{~mol})$ in DMF $(300 \mathrm{~mL})$. The mixture was stirred for $2 \mathrm{~h}$ at room temperature; then $25 \mathrm{~g}(0.33 \mathrm{~mol})$ of 2-chloroacetonitrile dissolved in DMF (100 mL) was added dropwise. The solution was stirred for $15 \mathrm{~h}$ and then poured into iced water $(500 \mathrm{~mL})$. The aqueous layer was extracted several times with ether and the extract dried over $\mathrm{MgSO}_{4}$ and concentrated. The crude product crystallized from hexane/ $\mathrm{CH}_{2} \mathrm{Cl}_{2}$ to give $46 \mathrm{~g}$ of 31 as a white powder: $\mathrm{mp} 93{ }^{\circ} \mathrm{C}$. The mother liquor was concentrated and purified by column chromatography using petroleum ether/ether/ $\mathrm{CH}_{2} \mathrm{Cl}_{2}(70: 20: 10, \mathrm{v} / \mathrm{v} / \mathrm{v})$ as el uent, to give 17 $\mathrm{g}$ of 31 (total yield 72\%): IR ( $\left.\mathrm{KBr}, \mathrm{cm}^{-1}\right) v 2242$ (CN), 1642 $(\mathrm{C}=\mathrm{O}), 1596(\mathrm{C}=\mathrm{C}) ;{ }^{1} \mathrm{H}$ NMR $\delta 7.38-7.08(9 \mathrm{H}, \mathrm{m}, \mathrm{Ar}-\mathrm{H}), 5.05$ and $4.21\left(2 \mathrm{H}, 2 \mathrm{~d}, \mathrm{~J}=17.1 \mathrm{~Hz}, \mathrm{H}_{2} \mathrm{C}-\mathrm{CN}\right)$.

$\mathbf{N}$-Benzoyl-N-(o-chlorophenyl)-N'-acetylethylenediamine (32). A mixture of 31 (27 g, $0.1 \mathrm{~mol})$, dry $\mathrm{CH}_{3} \mathrm{CO}_{2} \mathrm{Na}$ $(12 \mathrm{~g})$, and Raney nickel in $200 \mathrm{~mL}$ of acetic anhydride was heated at $50{ }^{\circ} \mathrm{C}$ and hydrogenated on a Parr hydrogenator apparatus under a 40-50 psi pressure for $18 \mathrm{~h}$. The catalyst was separated by decantation and the solvent removed under vacuo. The crude product was dissolved in $\mathrm{CH}_{2} \mathrm{Cl}_{2}$, the solution washed with water and then dried over $\mathrm{MgSO}_{4}$, and the solvent removed. Addition of ether to the residue gave $22 \mathrm{~g}$ of 32. The mother liquor was concentrated and then chromatographed using $\mathrm{CH}_{2} \mathrm{Cl}_{2} / \mathrm{MeOH}(99: 1, \mathrm{v} / \mathrm{v})$ as eluent to afford 5 $\mathrm{g}$ of 32 (total yield $27 \mathrm{~g}, 85 \%$ ): $\mathrm{mp} 138.5-139{ }^{\circ} \mathrm{C}$; IR (KBr, $\left.\mathrm{cm}^{-1}\right) v 3257(\mathrm{NH}), 1650(\mathrm{C}=\mathrm{O}), 1595(\mathrm{C}=\mathrm{C}) ;{ }^{1} \mathrm{H} \mathrm{NMR} \delta 7.27-$ $7.03(9 \mathrm{H}, \mathrm{m}, \mathrm{Ar}-\mathrm{H}), 6.86\left(\mathrm{H}, \mathrm{br} \mathrm{s}, \mathrm{D}_{2} \mathrm{O}\right.$ exchange, $\left.\mathrm{H}-\mathrm{N}\right), 4.29$, 3.56 and $3.30\left(4 \mathrm{H}, 3 \mathrm{~m}\right.$ in 1:2:1 ratio, $\mathrm{H}_{2} \mathrm{C}-\mathrm{N}$ and $\left.\mathrm{H}_{2} \mathrm{C}-\mathrm{N}^{\prime}\right)$, $1.89\left(3 \mathrm{H}, \mathrm{s}, \mathrm{H}_{3} \mathrm{C}-\mathrm{C}=\mathrm{O}\right)$.

$\mathbf{N}$-(o-Chlorophenyl)-N-benzoyl-N'-acetyl-N'-methylethylenediamine (33). To a cooled $\left(0^{\circ} \mathrm{C}\right)$ suspension of $\mathrm{NaH}(3.6$ $\mathrm{g}, 0.09 \mathrm{~mol}$ ) in DMF (50 mL) was added dropwise the diamide $32(25.9 \mathrm{~g}, 0.082 \mathrm{~mol})$ in DMF $(100 \mathrm{~mL})$. The mixture was then stirred for $3 \mathrm{~h}$ at room temperature, and $13 \mathrm{~g}(0.09 \mathrm{~mole})$ of methyl iodide dissolved in DMF (30 mL) was added dropwise. The solution was stirred overnight, then poured into cold water (500 mL), and extracted with $\mathrm{CH}_{2} \mathrm{Cl}_{2}$. The organic layer was dried over $\mathrm{MgSO}_{4}$, and the solvents were evaporated in vacuo to dryness. The crude product $\mathbf{3 3}$ was used in the next step without purification.

N-(o-Chlorophenyl)-N'-methylethylenediamine Dihydrochloride (34). This compound was prepared using the procedure described to prepare compound $\mathbf{2 2}$ except the time of the reaction (48 h). The hydrochl oride salt was crystallized from acetone/ethanol (90:10, v/v) to afford $10 \mathrm{~g}$ (47\% for the two steps) of 34: $\mathrm{mp} 116^{\circ} \mathrm{C}$; IR ( $\left.\mathrm{KBr}, \mathrm{cm}^{-1}\right) v 3337(\mathrm{NH}), 1599$ $(\mathrm{C}=\mathrm{C}) ;{ }^{1} \mathrm{H}$ NMR $\delta$ 7.20-7.02, 6.63-6.51 (4H, 2m, Ar-H), 4.62 $\left(1 \mathrm{H}, \mathrm{br} \mathrm{s}, \mathrm{D}_{2} \mathrm{O}\right.$ exchange, $\left.\mathrm{H}-\mathrm{N}\right), 3.21\left(2 \mathrm{H}, \mathrm{t}, \mathrm{J}=6.1 \mathrm{~Hz}, \mathrm{H}_{2} \mathrm{C}-\right.$ $\mathrm{N}), 2.82\left(2 \mathrm{H}, \mathrm{t}, \mathrm{J}=6.1 \mathrm{~Hz}, \mathrm{H}_{2} \mathrm{C}-\mathrm{N}^{\prime}\right), 2.41\left(3 \mathrm{H}, \mathrm{s}, \mathrm{H}_{3} \mathrm{C}-\mathrm{N}^{\prime}\right)$, $2.35\left(1 \mathrm{H}, \mathrm{s}, \mathrm{D}_{2} \mathrm{O}\right.$ exchange, $\left.\mathrm{H}-\mathrm{N}^{\prime}\right)$.

Ethyl 1-Methyl-4-(2'-chlorophenyl)piperazine-2-carboxylate (35b). The title compound was prepared according to the procedure used to prepare 18 starting from $16 \mathrm{~g}(0.062$ $\mathrm{mol}$ ) of $\mathbf{3 4}$ dihydrochl oride salt (the free base was regenerated in situ). Two successive purifications by column chromatog- 
raphy using petroleum ether/ether $(85: 15, \mathrm{v} / \mathrm{v})$ as eluent afforded $3.8 \mathrm{~g}(22 \%)$ of pure $35 \mathrm{~b}$ as a pale-yell ow oil and $0.8 \mathrm{~g}$ of a mixture of the two isomers $35 \mathbf{a}$ and $\mathbf{3 5 b}$ in a $1: 1$ ratio. The ${ }^{1} \mathrm{H}$ NMR spectrum of $\mathbf{3 5 b}$ was similar to that of $\mathbf{2 9 b}$, particular signal $\delta 2.35\left(3 \mathrm{H}, \mathrm{s}, \mathrm{H}_{3} \mathrm{C}-\mathrm{N}\right)$.

Preparation of the Ester Intermediates 39 and $40 \mathrm{a}-\mathrm{C}$ (Scheme 4). 1,4-Dibenzyl-2-(hydroxymethyl)piperazine (36). A stirred suspension of $\mathrm{LiAlH}_{4}(5 \mathrm{~g}, 0.13 \mathrm{~mol})$ in dry tetrahydrofuran $(200 \mathrm{~mL})$ was cooled at $0{ }^{\circ} \mathrm{C}$, and $57 \mathrm{~g}(0.17$ $\mathrm{mol}$ ) of ethyl 1,4-dibenzyl pi perazine-2-carboxylate in tetrahydrofuran $(200 \mathrm{~mL})$ was added. The mixture was stirred for 20 $\mathrm{h}$ at room temperature, then cool ed, and treated carefully with aqueous $\mathrm{NaOH}$ (20\%). The aqueous layer was extracted with $\mathrm{CH}_{2} \mathrm{Cl}_{2}$, and the extracts were dried over $\mathrm{MgSO}_{4}$. After the solvents were removed, crystallization of the crude product afforded $47 \mathrm{~g}$ (93\%) of 36 as a white powder: $\mathrm{mp} 70-72{ }^{\circ} \mathrm{C}$; IR $\left(\mathrm{KBr}, \mathrm{cm}^{-1}\right) v 3400(\mathrm{OH}), 1600(\mathrm{C}=\mathrm{C}) ;{ }^{1} \mathrm{H} \mathrm{NMR}(500 \mathrm{MHz})$ $\delta 7.22(10 \mathrm{H}, \mathrm{m}, \mathrm{Ar}-\mathrm{H}), 4.05$ and $3.58(2 \mathrm{H}$, two dd, $\mathrm{J}=11.14$ and $\left.2.86 \mathrm{~Hz}, \mathrm{H}_{2} \mathrm{C}-\mathrm{O}\right), 3.98$ and $3.47(2 \mathrm{H}, 2 \mathrm{~d}, \mathrm{~J}=13.2 \mathrm{~Hz}$, $\left.\mathrm{H}_{2} \mathrm{C}-\mathrm{Ar}\right), 3.49\left(2 \mathrm{H}, \mathrm{s}, \mathrm{H}_{2} \mathrm{C}-\mathrm{Ar}\right), 2.56\left(1 \mathrm{H}, \mathrm{s}, \mathrm{D}_{2} \mathrm{O}\right.$ exchange, $\mathrm{H}-\mathrm{O}), 2.98-2.94(1 \mathrm{H}, \mathrm{m}, \mathrm{HC}-\mathrm{N}), 2.69-2.60,2.52-2.44$ and 2.40-2.37 (6H, 3m, $\left.\mathrm{H}_{2} \mathrm{C}-\mathrm{N}\right)$.

1,4-Dibenzyl-2-(chloromethyl)piperazine (37). Compound $\mathbf{3 7}$ was prepared according to the procedure used to dispose 10. The crude product obtained from $20 \mathrm{~g}(0.068 \mathrm{~mol})$ of $\mathbf{3 6}$ was partitioned between ether and water. The aqueous layer was treated with $\mathrm{Na}_{2} \mathrm{CO}_{3}$ and extracted with $\mathrm{CHCl}_{3}$. The organic layer was dried over $\mathrm{MgSO}_{4}$ and the solvent removed in vacuo. The residue was purified by col umn chromatography using petroleum ether/ether $(90: 10, v / v)$ as eluent, to afford $17 \mathrm{~g}(79 \%)$ of 37 as a yellow oil: IR (film, $\left.\mathrm{cm}^{-1}\right)$ v $1600(\mathrm{C}=\mathrm{C})$; ${ }^{1} \mathrm{H}$ NMR $\delta 7.23(10 \mathrm{H}$, br $\mathrm{s}, \mathrm{Ar}-\mathrm{H}), 3.97$ and $3.54(2 \mathrm{H}, \mathrm{AB}$ spectrum, $\left.\mathrm{J}=12 \mathrm{~Hz}, \mathrm{H}_{2} \mathrm{C}-\mathrm{Ar}\right), 3.50$ and $3.35(2 \mathrm{H}, \mathrm{AB}$ spectrum, J $\left.=11.8 \mathrm{~Hz}, \mathrm{H}_{2} \mathrm{C}-\mathrm{Ar}\right), 3.30-2.30(9 \mathrm{H}, \mathrm{m}, \mathrm{H}$ piperazine and $\mathrm{H}_{2} \mathrm{C}-\mathrm{Cl}$ ).

1,4-Dibenzyl-2-(cyanomethyl)pi perazine (38). To a re fluxing solution of KCN $(4.57 \mathrm{~g}, 0.07 \mathrm{~mol})$ in water $(20 \mathrm{~mL})$ was added dropwise the halide $37(17 \mathrm{~g}, 0.054 \mathrm{~mol})$ in ethanol $(20 \mathrm{~mL})$. The mixture was stirred and refluxed for $3 \mathrm{~h}$. Ethanol was evaporated, the residue was taken up in chloroform, washed with water, and dried over $\mathrm{MgSO}_{4}$, and the solvent was removed in vacuo. Crystallization from hexane/ether gave $13.2 \mathrm{~g}(80 \%)$ of 38 as a white powder: $\mathrm{mp} 80-89{ }^{\circ} \mathrm{C}$; I ( film, $\left.\mathrm{cm}^{-1}\right)$ v $2215(\mathrm{CN}), 1600(\mathrm{C}=\mathrm{C}) ;{ }^{1} \mathrm{H}$ NMR $\delta 7.21(10 \mathrm{H}, \mathrm{br} \mathrm{S}$, $\mathrm{Ar}-\mathrm{H}), 3.72$ and $3.40\left(2 \mathrm{H}, \mathrm{AB}\right.$ spectrum, J $=13.5 \mathrm{~Hz}, \mathrm{H}_{2} \mathrm{C}-$ $\mathrm{Ar}), 3.45\left(2 \mathrm{H}, \mathrm{s}, \mathrm{H}_{2} \mathrm{C}-\mathrm{Ar}\right), 3.00-2.10(9 \mathrm{H}, \mathrm{m}, \mathrm{H}$ piperazine and $\mathrm{H}_{2} \mathrm{C}-\mathrm{CN}$ )

Ethyl 1,4-Dibenzylpiperazin-2-ylacetate (39). A mixture of $13.2 \mathrm{~g}(0.043 \mathrm{~mol})$ of $38, \mathrm{H}_{2} \mathrm{SO}_{4}(10 \mathrm{~mL}$ at $95 \%)$, and ethanol $(30 \mathrm{~mL})$ was stirred and refluxed for $3 \mathrm{~h}$. Then ethanol was evaporated, and the residue was taken up in chloroform, washed with water, and dried over $\mathrm{MgSO}_{4}$. Evaporation of the organic layer gave a crude product which was purified by column chromatography using petroleum ether/ether (90:10, $\mathrm{v} / \mathrm{v})$ as eluent to give $11.4 \mathrm{~g}(75 \%)$ of $\mathbf{3 8}$ as a yellow oil: IR (film, $\left.\mathrm{cm}^{-1}\right) v 1720(\mathrm{C}=\mathrm{O}), 1600(\mathrm{C}=\mathrm{C})$; ${ }^{1} \mathrm{H}$ NMR $\delta$ 7.23-7.14 $(10 \mathrm{H}, \mathrm{m}, \mathrm{Ar}-\mathrm{H}), 4.07\left(2 \mathrm{H}, \mathrm{dq}, \mathrm{J}=6.95\right.$ and $\left.3.25 \mathrm{~Hz}, \mathrm{H}_{2} \mathrm{C}-\mathrm{O}\right)$, 3.72 and $3.34\left(2 \mathrm{H}, \mathrm{AB}\right.$ spectrum, $\left.\mathrm{J}=13.3 \mathrm{~Hz}, \mathrm{H}_{2} \mathrm{C}-\mathrm{Ar}\right), 3.47$ and $3.38\left(2 \mathrm{H}, \mathrm{AB}\right.$ spectrum, $\left.\mathrm{J}=13.1 \mathrm{~Hz}, \mathrm{H}_{2} \mathrm{C}-\mathrm{Ar}\right), 3.07-3.02$ $(1 \mathrm{H}, \mathrm{m}, \mathrm{HC}-\mathrm{N}), 2.60$ and $2.22\left(8 \mathrm{H}, \mathrm{m}\right.$, three $\mathrm{H}_{2} \mathrm{C}-\mathrm{N}$ and $\mathrm{H}_{2} \mathrm{C}-$ $\mathrm{C}=\mathrm{O}), 1.15\left(3 \mathrm{H}, \mathrm{t}, \mathrm{J}=7.10 \mathrm{~Hz}, \mathrm{H}_{3} \mathrm{C}-\mathrm{CH}_{2} \mathrm{O}\right)$.

Ethyl Piperazin-2-ylacetate Dihydrochloride (40). To a solution of $39(20 \mathrm{~g}, 0.057 \mathrm{~mol})$ in ethanol $(200 \mathrm{~mL})$ were added concentrated $\mathrm{HCl}(9 \mathrm{~mL})$ and $10 \%$ palladium on charcoal. The mixture was kept under $\mathrm{H}_{2}$ atmosphere for $5 \mathrm{~h}$ at $50{ }^{\circ} \mathrm{C}$. The catalyst was filtered and the solvent removed in vacuo. The crude product $\mathbf{4 0}$ was used in the next step without purification.

Ethyl 1,4-diisopropylpiperazin-2-ylacetate (40a): prepared like $2 \mathbf{2 a}$ starting from 40; ${ }^{1} \mathrm{H}$ NMR $\delta 4.07(2 \mathrm{H}, \mathrm{q}, \mathrm{J}=$ $\left.7.13 \mathrm{~Hz}, \mathrm{H}_{2} \mathrm{C}-\mathrm{O}\right), 3.16-2.28\left(11 \mathrm{H}, \mathrm{m}, \mathrm{H}\right.$ piperazine, $\mathrm{H}_{2} \mathrm{C}-\mathrm{CO}_{2}$, two $\left.\mathrm{HC}\left(\mathrm{CH}_{3}\right)_{2}\right), 1.22-0.90\left(15 \mathrm{H}, \mathrm{m}, \mathrm{H}_{3} \mathrm{C}-\mathrm{CH}_{2} \mathrm{O}\right.$, two $\left(\mathrm{H}_{3} \mathrm{C}\right)_{2^{-}}$ $\mathrm{CH}, \mathrm{H}_{3} \mathrm{C}$ signals overlapping).
Ethyl 1-(2',4'-dichlorobenzyl)-4-methylpiperazin-2ylacetate (40b) and ethyl 1-(2'-methoxybenzyl)-4-methylpiperazin-2-ylacetate (40c): prepared like 7b; ${ }^{1} \mathrm{H}$ NMR $\delta$ 7.38-7.11 (3H, m, H-Ar), $4.06\left(2 \mathrm{H}, \mathrm{q}\right.$, J $\left.=7.09 \mathrm{~Hz}, \mathrm{H}_{2} \mathrm{C}-\mathrm{O}\right)$, 3.75 and $3.44\left(2 \mathrm{H}, \mathrm{AB}\right.$ spectrum, $\left.\mathrm{J}=14.76 \mathrm{~Hz}, \mathrm{H}_{2} \mathrm{C}-\mathrm{Ar}\right), 3.6-$ $2.19\left(9 \mathrm{H}, \mathrm{m}, \mathrm{H}\right.$ piperazine and $\left.\mathrm{H}_{2} \mathrm{C}-\mathrm{CO}_{2}\right), 2.24\left(3 \mathrm{H}, \mathrm{s}, \mathrm{H}_{3} \mathrm{C}-\right.$ $\mathrm{N}), 1.16\left(3 \mathrm{H}, \mathrm{t}, \mathrm{J}=7.09 \mathrm{~Hz}, \mathrm{H}_{3} \mathrm{C}-\mathrm{CH}_{2} \mathrm{O}\right)$. ${ }^{1} \mathrm{H} \mathrm{NMR}$ spectrum of $\mathbf{4 0 c}$ was similar to the one of compound $\mathbf{4 0 b}$; particular signal $\delta 3.69\left(3 \mathrm{H}, \mathrm{S}, \mathrm{H}_{3} \mathrm{C}-\mathrm{O}\right)$.

Preparation of Final Imidazoline $(41 a-q, 42,60-63)$ and Tetrahydropyrimidine (43) Analogues (Scheme 5). The compounds $\mathbf{4 1 a}-\mathbf{q}, \mathbf{4 2}$, and 60-63 were prepared as described in our previous publication ${ }^{16}$ using the corresponding esters. All the ${ }^{1} \mathrm{H}$ NMR spectra were recorded from the free bases. The hydrogens of the imidazoline ring of compounds 4la, 41b, 41d, 41e, 41g, 41n, 41j, 41l, and 41m gave unresolved peaks. The corresponding signal is very broad, and the summit of this signal was a coalescence point.

1,4-Diisopropyl-2-(4',5'-dihydro-1'H-imidazol-2'-yl)piperazine (41a): ${ }^{1 \mathrm{H}} \mathrm{NMR} \delta 5.3\left(\mathrm{H}\right.$, br $\mathrm{s}, \mathrm{D}_{2} \mathrm{O}$ exchange, $\left.\mathrm{H}-\mathrm{N}\right)$, $3.52(1 \mathrm{H}, \mathrm{dd}, \mathrm{J}=3.37$ and $7.91 \mathrm{~Hz}, \mathrm{HC}-\mathrm{N}), 3.65$ and 3.49 (4H, 2 coal escence points, $\mathrm{H}$ imidazoline), $2.83-2.26(8 \mathrm{H}, \mathrm{m}$, three $\mathrm{H}_{2} \mathrm{C}-\mathrm{N}$ and two $\left.\mathrm{HC}\left(\mathrm{CH}_{3}\right)_{2}\right), 1.00,0.96,0.95$ and 0.93 $\left(12 \mathrm{H}, 4 \mathrm{~d}, \mathrm{~J}=6.35\right.$ and $6 \mathrm{~Hz}$, two $\left.\left(\mathrm{H}_{3} \mathrm{C}\right)_{2} \mathrm{CH}\right) \cdot 41 \mathrm{a} \cdot 1.5 \mathrm{HCl}: 35 \%$ yield; mp $145-147{ }^{\circ} \mathrm{C}$ (acetone/ether). Anal. $\left(\mathrm{C}_{13} \mathrm{H}_{26} \mathrm{~N}_{4} \cdot 3 \mathrm{HCl} \cdot\right.$ $\left.1.5 \mathrm{H}_{2} \mathrm{O}\right) \mathrm{C}, \mathrm{H}, \mathrm{N}$.

1,4-Diisobutyl-2-(4',5'-dihydro-1'H-imidazol-2'-yl)piperazine (41b): ${ }^{1} \mathrm{H}$ NMR $\delta 5.45\left(1 \mathrm{H}, \mathrm{br} \mathrm{s}, \mathrm{D}_{2} \mathrm{O}\right.$ exchange, $\mathrm{H}-\mathrm{N})$, 3.53-3.47 (4H, m, H imidazoline), 3.20 (1H, dd, J = 3.32 and $7.01 \mathrm{~Hz}, \mathrm{HC}-\mathrm{N}), 2.82-1.93\left(10 \mathrm{H}, \mathrm{m}\right.$, three $\mathrm{H}_{2} \mathrm{C}-\mathrm{N}$ and two $\left.\mathrm{H}_{2} \mathrm{C}-\mathrm{CH}\right), 1.81-1.62\left(2 \mathrm{H}\right.$, m, two $\left.\mathrm{HC}\left(\mathrm{CH}_{3}\right)_{2}\right), 0.61,0.79$ and $0.77\left(12 \mathrm{H}\right.$, 3d in 2:1:1 ratio, J $=6.29 \mathrm{~Hz}$, two $\left.\left(\mathrm{H}_{3} \mathrm{C}\right)_{2} \mathrm{CH}\right)$. 41b. $3 \mathrm{HCl}$ : $33 \%$ yield; $\mathrm{mp} 152-154{ }^{\circ} \mathrm{C}$ (acetone/ $\mathrm{CH}_{2} \mathrm{Cl}_{2}$ ). Anal. $\left(\mathrm{C}_{15} \mathrm{H}_{30} \mathrm{~N}_{4} \cdot 3 \mathrm{HCl} \cdot 0.75 \mathrm{H}_{2} \mathrm{O}\right) \mathrm{C}, \mathrm{H}, \mathrm{N}$.

1,4-Dicyclopentyl-2-(4',5'-dihydro-1'H-imidazol-2'-yl)piperazine (41c): ${ }^{1} \mathrm{H}$ NMR $\delta 5.1\left(1 \mathrm{H}, \mathrm{br} \mathrm{s}, \mathrm{D}_{2} \mathrm{O}\right.$ exchange, $\mathrm{H}-\mathrm{N}), 3.61-3.49,2.77-2.35$ and $2.00-1.19(29 \mathrm{H}, 3 \mathrm{~m}$ in $5: 8$ : 16 ratio). 41c. $3 \mathrm{HCl}$ : $29 \%$ yield; $\mathrm{mp} 159-161{ }^{\circ} \mathrm{C}$. Anal. $\left(\mathrm{C}_{17} \mathrm{H}_{30} \mathrm{~N}_{4} \cdot 3 \mathrm{HCl} \cdot 0.5 \mathrm{H}_{2} \mathrm{O}\right) \mathrm{C}, \mathrm{H}, \mathrm{N}$

1,4-Di(2'-propen-1'-yl)-2-(4',5'-dihydro-1'H-imidazol-2' yl)piperazine (41d): $20 \%$ yield; $\mathrm{mp} 102-104{ }^{\circ} \mathrm{C}$ (hexane); ${ }_{1 \mathrm{H}} \mathrm{NMR} \delta 5.85-5.64(2 \mathrm{H}, \mathrm{m}$, two $\mathrm{HC}=), 5.17-5.06(5 \mathrm{H}, \mathrm{m}$, two $\mathrm{H}_{2} \mathrm{C}=$ and $\left.\mathrm{H}-\mathrm{N}^{\prime}\right), 3.50(4 \mathrm{H}$, coalescence point, $\mathrm{H}$ imidazoline), $3.27(1 \mathrm{H}$, dd, J = 3.20 and $8.45 \mathrm{~Hz}, \mathrm{HC}-\mathrm{N}), 3.15-$ $2.17\left(10 \mathrm{H}, \mathrm{m}\right.$, three $\mathrm{H}_{2} \mathrm{C}-\mathrm{N}$ and two $\left.\mathrm{H}_{2} \mathrm{C}-\mathrm{C}=\right)$. Anal. $\left(\mathrm{C}_{13} \mathrm{H}_{22} \mathrm{~N}_{4}\right)$ $\mathrm{C}, \mathrm{H}, \mathrm{N}$.

1,4-Di (2'-methyl-2' -propen-1'-yl)-2-(4',5'-dihydro-1' Himidazol-2'-yl)piperazine (41e): $30 \%$ yield; mp $83-84{ }^{\circ} \mathrm{C}$ (hexane); ${ }^{1} \mathrm{H}$ NMR $\delta 5.2\left(1 \mathrm{H}\right.$, br s, $\mathrm{D}_{2} \mathrm{O}$ exchange, $\left.\mathrm{H}-\mathrm{N}\right), 4.84-$ $4.78\left(4 \mathrm{H}, \mathrm{m}\right.$, two $\left.\mathrm{H}_{2} \mathrm{C}=\right), 3.50(4 \mathrm{H}$, coalescence point, $\mathrm{H}$ imidazoline), $3.24(1 \mathrm{H}, \mathrm{dd}, \mathrm{J}=3.2$ and $7.96 \mathrm{~Hz}, \mathrm{HC}-\mathrm{N}), 2.91-$ $1.64\left(10 \mathrm{H}, \mathrm{m}\right.$, three $\mathrm{H}_{2} \mathrm{C}-\mathrm{N}$ and two $\left.\mathrm{H}_{2} \mathrm{C}-\mathrm{C}=\right), 1.65$ and 1.64 $\left(6 \mathrm{H}, 2 \mathrm{~s}\right.$, two $\left.\mathrm{H}_{3} \mathrm{C}-\mathrm{C}=\right)$. Anal. $\left(\mathrm{C}_{15} \mathrm{H}_{26} \mathrm{~N}_{4}\right) \mathrm{C}, \mathrm{H}, \mathrm{N}$.

1,4-Di(2'-methylbutyl)-2-(4',5'-dihydro-1'H-imidazol-2' yl)piperazine (41f): ${ }^{1} \mathrm{H}$ NMR $\delta 5.20(1 \mathrm{H}$, br S, H-N ), 3.503.46 and 3.26-3.19 (4H, 2m, H imdazol ine), 2.91-2.90 (11H, $\mathrm{m}, \mathrm{H}$ piperazine and two $\left.\mathrm{H}_{2} \mathrm{C}-\mathrm{CH}\right), 1.56-0.94(6 \mathrm{H}, \mathrm{m}$, two $\mathrm{H}_{2} \mathrm{C}-\mathrm{CH}_{3}$ and two $\mathrm{HC}\left(\mathrm{CH}_{3}\right), 0.85-0.74\left(12 \mathrm{H}, \mathrm{m}\right.$, two $\mathrm{H}_{3} \mathrm{C}-$ $\mathrm{CH}_{2}$ and two $\mathrm{H}_{3} \mathrm{C}-\mathrm{CH}, \mathrm{H}_{3} \mathrm{C}$ signals overlapping). $41 \mathrm{f} \cdot 3 \mathrm{HCl}$ : $30 \%$ yield; mp $160{ }^{\circ} \mathrm{C}$ dec (MeOH/acetone). Anal. $\left(\mathrm{C}_{17} \mathrm{H}_{34} \mathrm{~N}_{4}\right.$. $\left.3 \mathrm{HCl} \cdot 0.25 \mathrm{H}_{2} \mathrm{O}\right) \mathrm{C}, \mathrm{H}, \mathrm{N}$.

1,4-Dineopentyl-2-(4',5'-dihydro-1'H-imidazol-2'-yl)piperazine (41g): ${ }^{1} \mathrm{H}$ NMR $\delta 5.3\left(1 \mathrm{H}\right.$, br $\mathrm{S}, \mathrm{D}_{2} \mathrm{O}$ exchange, $\left.\mathrm{H}-\mathrm{N}\right)$, 3.60 and $3.35(4 \mathrm{H}$, coalescence point, $\mathrm{H}$ imidazoline), $3.3(1 \mathrm{H}$, $\left.\mathrm{dd}, \mathrm{J}_{1}=\mathrm{J}_{2}=3.88 \mathrm{~Hz}, \mathrm{HC}-\mathrm{N}\right), 3.08-3.10$ and $2.75-2.30(7 \mathrm{H}$, $2 \mathrm{~m}$, three $\mathrm{H}_{2} \mathrm{C}-\mathrm{N}$ and $\left.\mathrm{H}-\mathrm{CH}-\mathrm{C}\left(\mathrm{CH}_{3}\right)_{3}\right), 2.05\left(2 \mathrm{H}, \mathrm{s}, \mathrm{H}_{2} \mathrm{C}-\right.$ $\left.\mathrm{C}\left(\mathrm{CH}_{3}\right)_{3}\right), 1.93(1 \mathrm{H}$, d, part $\mathrm{B}$ of $\mathrm{AB}$ spectrum, J $=14.93 \mathrm{~Hz}$, $\left.\mathrm{H}-\mathrm{CH}-\mathrm{C}\left(\mathrm{CH}_{3}\right)_{3}\right), 0.85\left(18 \mathrm{H}\right.$, br s, two $\left.\left(\mathrm{H}_{3} \mathrm{C}\right)_{3}-\mathrm{C}\right) . \mathbf{4 1 g} \cdot 2 \mathrm{HCl}$ : $25 \%$ yield; $\mathrm{mp} 178{ }^{\circ} \mathrm{C}$ dec $\left(\mathrm{CH}_{2} \mathrm{Cl}_{2} / \mathrm{MeOH} /\right.$ hexane). Anal. $\left(\mathrm{C}_{17} \mathrm{H}_{34} \mathrm{~N}_{4} \cdot 2 \mathrm{HCl} \cdot 2 \mathrm{H}_{2} \mathrm{O}\right) \mathrm{C}, \mathrm{H}, \mathrm{N}$.

1,4-Bis(dicyclopropylmethyl)-2-(4',5'-dihydro-1'H-imidazol-2' -yl)piperazine (41h): $58 \%$ yield; $\mathrm{mp} 156{ }^{\circ} \mathrm{C}\left(\mathrm{CH}_{2^{-}}\right.$ $\mathrm{Cl}_{2}$ /ether); ${ }^{1} \mathrm{H}$ NMR $\delta 5.6\left(1 \mathrm{H}\right.$, br s, $\mathrm{D}_{2} \mathrm{O}$ exchange, $\left.\mathrm{H}-\mathrm{N}\right), 3.90$ $(1 \mathrm{H}, \mathrm{dd}, \mathrm{J}=3.37$ and $7.0 \mathrm{~Hz}, \mathrm{HC}-\mathrm{N}), 3.50(4 \mathrm{H}$, coalescence 
point, $\mathrm{H}$ imidazoline), 3.16-2.52 (6H, m, three $\left.\mathrm{H}_{2} \mathrm{C}-\mathrm{N}\right), 1.39$ and $1.05(2 \mathrm{H}, 2 \mathrm{t}, \mathrm{J}=8.3$ and $8.5 \mathrm{~Hz}$, two HC-dicyclopropyl), 0.97-0.10 (10H, m, H cyclopropyl). Anal. $\left(\mathrm{C}_{21} \mathrm{H}_{34} \mathrm{~N}_{4}\right) \mathrm{C}, \mathrm{H}, \mathrm{N}$.

1-I sobutyl-4-(2'-propen-1'-yl)-2-(4',5'-dihydro-1'H-imidazol-2'-yl)piperazine (41i): $29 \%$ yield; $\mathrm{mp} 96-98{ }^{\circ} \mathrm{C}$ (hexane); ${ }^{1} \mathrm{H}$ NMR $\delta 5.86-5.66(1 \mathrm{H}, \mathrm{m}, \mathrm{HC}=), 5.3\left(1 \mathrm{H}, \mathrm{br} \mathrm{s}, \mathrm{D}_{2} \mathrm{O}\right.$ exchange, $\mathrm{H}-\mathrm{N}), 5.15-5.06\left(2 \mathrm{H}, \mathrm{m}, \mathrm{H}_{2} \mathrm{C}=\right)$, 3.49 (4H, coalescence point, $\mathrm{H}$ imidazoline), $3.16(1 \mathrm{H}, \mathrm{dd}, \mathrm{J}=3.24$ and 8.80 $\mathrm{Hz}, \mathrm{HC}-\mathrm{N}), 3.00-2.61$ and $2.26-1.93\left(10 \mathrm{H}, 2 \mathrm{~m}\right.$, three $\mathrm{H}_{2} \mathrm{C}-$ $\mathrm{N}, \mathrm{H}_{2} \mathrm{C}-\mathrm{CH}$ and $\left.\mathrm{H}_{2} \mathrm{C}-\mathrm{C}=\right), 1.82-1.68\left(1 \mathrm{H}, \mathrm{m}, \mathrm{HC}\left(\mathrm{CH}_{3}\right)_{2}\right), 0.81$ and $0.78\left(6 \mathrm{H}, 2 \mathrm{~d}, \mathrm{~J}=6.5 \mathrm{~Hz},\left(\mathrm{H}_{3} \mathrm{C}\right)_{2} \mathrm{CH}\right)$. Anal. $\left(\mathrm{C}_{14} \mathrm{H}_{26} \mathrm{~N}_{4} \cdot 0.25\right.$ $\left.\mathrm{H}_{2} \mathrm{O}\right) \mathrm{C}, \mathrm{H}, \mathrm{N}$.

1-Isobutyl-4-(2'-methyl-2'-propen-1'-yl)-2-(4',5'-dihydro1'H-imidazol-2'-yl)piperazine (41j): 30\% yield; mp 104$106^{\circ} \mathrm{C}$ (hexane); ${ }^{1} \mathrm{H}$ NMR $\delta 5.2\left(1 \mathrm{H}\right.$, br s, $\mathrm{D}_{2} \mathrm{O}$ exchange, $\mathrm{H}-\mathrm{N}$ ), $4.78\left(2 \mathrm{H}, \mathrm{s}, \mathrm{H}_{2} \mathrm{C}=\right), 3.50$ (4H, coalescence point, $\mathrm{H}$ imidazoline), $3.20(1 \mathrm{H}, \mathrm{dd}, \mathrm{J}=3.30$ and $7.82 \mathrm{~Hz}, \mathrm{HC}-\mathrm{N}), 2.84-1.65(11 \mathrm{H}$, $\mathrm{m}$, three $\mathrm{H}_{2} \mathrm{C}-\mathrm{N}, \mathrm{H}_{2} \mathrm{C}-\mathrm{CH}, \mathrm{H}_{2} \mathrm{C}-\mathrm{C}=$ and $\left.\mathrm{HC}\left(\mathrm{CH}_{3}\right)_{2}\right), 0.81$ and $0.78\left(6 \mathrm{H}, 2 \mathrm{~d}, \mathrm{~J}=6.2 \mathrm{~Hz},\left(\mathrm{H}_{3} \mathrm{C}\right)_{2} \mathrm{CH}\right)$. Anal. $\left(\mathrm{C}_{15} \mathrm{H}_{28} \mathrm{~N}_{4}\right) \mathrm{C}, \mathrm{H}$, N.

1-Methyl-4-isobutyl-2-(4',5'-dihydro-1'H-imidazol-2'-yl)piperazine (41k): ${ }^{1} \mathrm{H}$ NMR $\delta 4.55\left(1 \mathrm{H}, \mathrm{br} \mathrm{s}, \mathrm{D}_{2} \mathrm{O}\right.$ exchange, $\mathrm{H}-\mathrm{N}), 3.60(4 \mathrm{H}, \mathrm{br} \mathrm{s}, \mathrm{H}$ imidazoline), 3.50-2.00 $(10 \mathrm{H}, \mathrm{m}, \mathrm{H}$ piperazine, $\left.\mathrm{H}_{2} \mathrm{C}-\mathrm{CH}, \mathrm{HC}\left(\mathrm{CH}_{3}\right)_{2}\right), 2.25\left(3 \mathrm{H}, \mathrm{s}, \mathrm{H}_{3} \mathrm{C}-\mathrm{N}\right)$. 41k $3 \mathrm{HCl}$ : $40 \%$ yield; $\mathrm{mp} 142{ }^{\circ} \mathrm{C}$ dec (acetone). Anal. $\left(\mathrm{C}_{12} \mathrm{H}_{24} \mathrm{~N}_{4}\right.$. $\left.3 \mathrm{HCl} \cdot \mathrm{H}_{2} \mathrm{O}\right) \mathrm{C}, \mathrm{H}, \mathrm{N}$

1-I sobutyl-4-methyl-2-(4',5'-dihydro-1' H-imidazol-2' yl)piperazine (41)): ${ }^{1} \mathrm{H}$ NMR $\delta 5.0\left(1 \mathrm{H}\right.$, br $\mathrm{s}, \mathrm{D}_{2} \mathrm{O}$ exchange, $\mathrm{H}-\mathrm{N}), 3.50(4 \mathrm{H}$, coalescence point, $\mathrm{H}$ imidazoline), $3.25(1 \mathrm{H}$, $\mathrm{dd}, \mathrm{J}=3.25$ and $7.80 \mathrm{~Hz}, \mathrm{HC}-\mathrm{N}), 2.80-2.0\left(8 \mathrm{H}\right.$, three $\mathrm{H}_{2} \mathrm{C}-\mathrm{N}$ and $\left.\mathrm{H}_{2} \mathrm{C}-\mathrm{CH}\right), 1.80-1.65\left(1 \mathrm{H}, \mathrm{m}, \mathrm{HC}\left(\mathrm{CH}_{3}\right)_{2}\right), 0.80$ and 0.78 $\left(6 \mathrm{H}, 2 \mathrm{~d}, \mathrm{~J}=6.3 \mathrm{~Hz},\left(\mathrm{H}_{3} \mathrm{C}\right)_{2} \mathrm{CH}\right) .41 \mathrm{l} \cdot 2 \mathrm{HCl}: 38 \%$ yield; $\mathrm{mp}$ 137.5-139 ${ }^{\circ} \mathrm{C}$. Anal. $\left(\mathrm{C}_{12} \mathrm{H}_{24} \mathrm{~N}_{4} \cdot 2 \mathrm{HCl} \cdot \mathrm{H}_{2} \mathrm{O}\right) \mathrm{C}, \mathrm{H}, \mathrm{N}$.

1-(Dicyclopropylmethyl)-4-methyl-2-(4',5'-dihydro-1' $\mathbf{H}$ imidazol-2 yl)piperazine (41m): $50 \%$ yield; $\mathrm{mp} 96-98{ }^{\circ} \mathrm{C}$ (ethanol/acetone); ${ }^{1} \mathrm{H}$ NMR $\delta 5.0\left(1 \mathrm{H}, \mathrm{br} \mathrm{s}, \mathrm{D}_{2} \mathrm{O}\right.$ exchange, $\mathrm{H}-\mathrm{N}), 3.88(1 \mathrm{H}$, dd, J = 3.31 and $9.1 \mathrm{~Hz}, \mathrm{HC}-\mathrm{N}), 3.46(4 \mathrm{H}$, coalescence point, $\mathrm{H}$ imidazoline), 3.06-2.97, 2.87-2.59 and 2.2-2.05 (6H, 3m, $\left.\mathrm{H}_{2} \mathrm{C}-\mathrm{N}\right), 2.2\left(3 \mathrm{H}, \mathrm{s}, \mathrm{H}_{3} \mathrm{C}-\mathrm{N}\right), 1.32(\mathrm{H}, \mathrm{t}, \mathrm{J}$ $=8.36 \mathrm{~Hz}, \mathrm{HC}$-dicyclopropyl), 0.88-0.05 (10H, m, H cyclopropyl). Anal. $\left(\mathrm{C}_{15} \mathrm{H}_{26} \mathrm{~N}_{4}\right) \mathrm{C}, \mathrm{H}, \mathrm{N}$.

1-Phenyl-4-methyl-2-(4',5'-dihydro-1' $\mathrm{H}$-imidazol-2'-yl)piperazine (41n): $10 \%$ yield; $\mathrm{mp} 106-108{ }^{\circ} \mathrm{C}$ (hexane); ${ }^{1} \mathrm{H}$ NMR $\delta$ 7.23-7.16, 6.97-6.93 and 6.83-6.76 (5H, 3m, Ar-H), $4.41\left(1 \mathrm{H}\right.$, dd, J $\left.{ }_{1}=\mathrm{J}_{2}=4.0 \mathrm{~Hz}, \mathrm{HC}-\mathrm{N}\right), 3.40(4 \mathrm{H}, \mathrm{br} \mathrm{s}, \mathrm{H}$ imidazoline), 3.33-3.27, 2.87-2.79, 2.71-2.64, 2.57-2.49 and 2.37-2.31 (6H, 5m, three $\left.\mathrm{H}_{2} \mathrm{C}-\mathrm{N}\right), 2.23\left(3 \mathrm{H}, \mathrm{s}, \mathrm{H}_{3} \mathrm{C}-\mathrm{N}\right)$. Anal . $\left(\mathrm{C}_{14} \mathrm{H}_{20} \mathrm{~N}_{4}\right) \mathrm{C}, \mathrm{H}, \mathrm{N}$.

1-I sopropyl-4-phenyl-2-(4',5'-di hydro-1' H-imidazol-2' yl)piperazine (410): $25 \%$ yield; $\mathrm{mp} 98-100{ }^{\circ} \mathrm{C}$ (ether/ hexane); ${ }^{1} \mathrm{H}$ NMR $\delta$ 7.22-7.06 and 6.87-6.75 (5H, 2m, Ar$\mathrm{H}), 4.25\left(1 \mathrm{H}\right.$, br $\mathrm{s}, \mathrm{D}_{2} \mathrm{O}$ exchange, $\left.\mathrm{H}-\mathrm{N}\right), 3.66-3.35,2.93-2.76$ and $2.59-2.47(12 \mathrm{H}, 3 \mathrm{~m}, \mathrm{H}$ imidazoline, $\mathrm{H}$ piperazine and $\mathrm{HC}$ $\left.\left(\mathrm{CH}_{3}\right)_{2}\right), 1.05$ and $0.93\left(6 \mathrm{H}, 2 \mathrm{~d}, \mathrm{~J}=6.53 \mathrm{~Hz},\left(\mathrm{H}_{3} \mathrm{C}\right)_{2} \mathrm{CH}\right)$. Anal. $\left(\mathrm{C}_{14} \mathrm{H}_{24} \mathrm{~N}_{4}\right) \mathrm{C}, \mathrm{H}, \mathrm{N}$.

1-Methyl-4-(2'-chlorophenyl)-2-(4',5'-di hydro-1' H-imidazol-2'-yl)piperazine (41p): $12 \%$ yield; $\mathrm{mp}$ (free base) $115-$ $117{ }^{\circ} \mathrm{C}$ (acetone/ether); ${ }^{1 \mathrm{H}} \mathrm{NMR} \delta 7.32-6.90(4 \mathrm{H}, \mathrm{m}, \mathrm{Ar}-\mathrm{H})$, $4.25\left(1 \mathrm{H}\right.$, br $\mathrm{s}, \mathrm{D}_{2} \mathrm{O}$ exchange, $\left.\mathrm{H}-\mathrm{N}\right), 3.54(4 \mathrm{H}$, br $\mathrm{s}, \mathrm{H}$ imi dazoline), 3.36-3.26, 3.06-2.88 and $2.60-2.51$ (7H, 3m, $\mathrm{H}$ piperazine), $2.27\left(3 \mathrm{H}, \mathrm{S}, \mathrm{H}_{3} \mathrm{C}-\mathrm{N}\right)$. Anal. $\left(\mathrm{C}_{14} \mathrm{H}_{19} \mathrm{ClN}_{4}\right) \mathrm{C}, \mathrm{H}, \mathrm{N}$.

1-Phenyl-4-isopropyl-2-(4',5'-dihydro-1'H-imidazol-2' yl)piperazine (41q): $15 \%$ yield; mp $120-122{ }^{\circ} \mathrm{C}$ (acetone/ ether); ${ }^{1} \mathrm{H}$ NMR $\delta$ 7.22-7.14, 7.0-6.96 and 6.82-6.74 (5H, 3m, $\mathrm{Ar}-\mathrm{H}), 4.99\left(1 \mathrm{H}, \mathrm{br} \mathrm{s}, \mathrm{D}_{2} \mathrm{O}\right.$ exchange, $\left.\mathrm{H}-\mathrm{N}\right), 4.41\left(1 \mathrm{H}, \mathrm{dd}, \mathrm{J}_{1}\right.$ $\left.=\mathrm{J}_{2}=4.02 \mathrm{~Hz}, \mathrm{HC}-\mathrm{N}\right), 3.36(4 \mathrm{H}, \mathrm{s}, \mathrm{H}$ imidazoline), 3.313.26 and $2.84-2.67\left(6 \mathrm{H}, 2 \mathrm{~m}\right.$, three $\left.\mathrm{H}_{2} \mathrm{C}-\mathrm{N}\right), 2.63-2.47(1 \mathrm{H}$, $\left.\mathrm{m}, \mathrm{HC}\left(\mathrm{CH}_{3}\right)_{2}\right), 1.02$ and $1.01\left(6 \mathrm{H}, 2 \mathrm{~d}, \mathrm{~J}=6.5 \mathrm{~Hz},\left(\mathrm{H}_{3} \mathrm{C}\right)_{2} \mathrm{CH}\right)$. Anal. $\left(\mathrm{C}_{16} \mathrm{H}_{24} \mathrm{~N}_{4}\right) \mathrm{C}, \mathrm{H}, \mathrm{N}$.

1-(2',4'-Dichlorobenzyl)-4-methyl-2-(4',5'-dihydro-1'methylimidazol-2'-yl)piperazine (42): ${ }^{1} \mathrm{H}$ NMR $\delta$ 7.52-7.0 $(3 \mathrm{H}, \mathrm{m}, \mathrm{Ar}-\mathrm{H}), 3.9-2.0\left(13 \mathrm{H}, \mathrm{m}, \mathrm{H}_{2} \mathrm{C}-\mathrm{Ar}, \mathrm{H}\right.$ piperazine and $\mathrm{H}$ imidazoline), 2.95 ( $\left.3 \mathrm{H}, \mathrm{s}, \mathrm{H}_{3} \mathrm{C}-\mathrm{N}-\mathrm{C}=\right), 2.27\left(3 \mathrm{H}, \mathrm{s}, \mathrm{H}_{3} \mathrm{C}-\right.$
$\mathrm{N}) . \mathbf{4 2} \cdot 3 \mathrm{HCl}$ : $40 \%$ yield; $\mathrm{mp} 160-162{ }^{\circ} \mathrm{C}$ (acetone/ethanol). Anal. $\left(\mathrm{C}_{16} \mathrm{H}_{22} \mathrm{Cl}_{2} \mathrm{~N}_{4} \cdot 3 \mathrm{HCl} \cdot 2.5 \mathrm{H}_{2} \mathrm{O}\right) \mathrm{C}, \mathrm{H}, \mathrm{N}$.

1-(2', 4' -Dichlorobenzyl)-4-methyl-2-(1', 4', 5', 6'-tetrahydro-1'H-pyrimidin-2'-yl)piperazine (43): ' ${ }^{1} \mathrm{H}$ NMR $\delta$ 7.29$7.19(3 \mathrm{H}, \mathrm{m}, \mathrm{Ar}-\mathrm{H}), 5.52(\mathrm{H}, \mathrm{br} \mathrm{s}, \mathrm{H}-\mathrm{N}), 3.68-3.40,2.80-$ 2.10 and $1.89-1.68\left(15 \mathrm{H}, 3 \mathrm{~m}, \mathrm{H}_{2} \mathrm{C}-\mathrm{Ar}, \mathrm{H}\right.$ piperazine and $\mathrm{H}$ tetrahydropyrimidine), $2.25\left(3 \mathrm{H}, \mathrm{s}, \mathrm{H}_{3} \mathrm{C}-\mathrm{N}\right) .43 \cdot 3 \mathrm{HCl}: 39 \%$ yield; $\mathrm{mp} 175-177{ }^{\circ} \mathrm{C}$ (methanol/acetone). Anal. $\left(\mathrm{C}_{16} \mathrm{H}_{22} \mathrm{Cl}_{2} \mathrm{~N}_{4}\right.$. $\left.3 \mathrm{HCl} \cdot \mathrm{H}_{2} \mathrm{O}\right) \mathrm{C}, \mathrm{H}, \mathrm{N}$.

1,4-Di isopropyl-2-(4',5'-dihydro-1' H-imidazol-2' -yl)methylpiperazine (60): 32\% yield; mp $197{ }^{\circ} \mathrm{C}$ (hexane/ ether); ${ }^{1} \mathrm{H} N M R \quad \delta 4.45\left(2 \mathrm{H}\right.$, br s, $\mathrm{D}_{2} \mathrm{O}$ exchange, $\mathrm{H}-\mathrm{N}$ and 0.5 $\left.\mathrm{H}_{2} \mathrm{O}\right)$, 3.53-2.03 $(15 \mathrm{H}, \mathrm{m}, \mathrm{H}$ imidazoline, $\mathrm{H}$ piperazine, two $\mathrm{HC}\left(\mathrm{CH}_{3}\right)_{2}$ and $\left.\mathrm{H}_{2} \mathrm{C}-\mathrm{C}=\mathrm{N}\right), 1.06,0.96$ and $0.88(12 \mathrm{H}, 3 \mathrm{~d}$ in 1:2:1 ratio, J $=6.50 \mathrm{~Hz}$, two $\left.\left(\mathrm{H}_{3} \mathrm{C}\right)_{2} \mathrm{CH}\right)$. Anal. $\left(\mathrm{C}_{14} \mathrm{H}_{28} \mathrm{~N}_{4} \cdot 3 \mathrm{HCl} \cdot\right.$ $\left.3 \mathrm{H}_{2} \mathrm{O}\right) \mathrm{C}, \mathrm{H}, \mathrm{N}$.

1,4-Dibenzyl-2-(4',5'-dihydro-1'H-imidazol-2' -yl)-methylpiperazine (61): ${ }^{1} \mathrm{H}$ NMR $\delta$ 7.35-7.15 $(10 \mathrm{H}, \mathrm{m}, \mathrm{Ar}-\mathrm{H})$, $3.95(1 \mathrm{H}$, part $A$ of $A B$ spectrum, J $=12.7 \mathrm{~Hz}, \mathrm{HCH}-\mathrm{Ar})$, 3.55-3.20 (7H, m, $\mathrm{H}$ imidazoline, $\mathrm{H}_{2} \mathrm{C}-\mathrm{Ar}$ and $\left.\mathrm{HCH}-\mathrm{Ar}\right)$, 2.85-2.10 $\left(9 \mathrm{H}, \mathrm{m}, \mathrm{H}\right.$ piperazine, $\left.\mathrm{H}_{2} \mathrm{C}-\mathrm{C}=\mathrm{N}\right) .61 \cdot 3 \mathrm{HCl}: 70 \%$ yield; mp $176-178{ }^{\circ} \mathrm{C}$ (ether/hexane). Anal. $\left(\mathrm{C}_{22} \mathrm{H}_{28} \mathrm{~N}_{4} \cdot 3 \mathrm{HCl}\right.$. $\left.2 \mathrm{H}_{2} \mathrm{O}\right) \mathrm{C}, \mathrm{H}, \mathrm{N}$.

1-(2-Methoxybenzyl)-4-methyl-2-(4',5'-dihydro-1'H-imidazol-2'-yl)methylpiperazine (62): ${ }^{1} \mathrm{H}$ NMR spectrum similar to compound 61, particular signal $\delta 3.88\left(3 \mathrm{H}, \mathrm{s}, \mathrm{H}_{3} \mathrm{C}-\mathrm{O}\right)$. 62.3HCl: $40 \%$ yield; $\mathrm{mp} 160-162{ }^{\circ} \mathrm{C}$ (ethanol/acetone). Anal. $\left(\mathrm{C}_{17} \mathrm{H}_{26} \mathrm{~N}_{4} \mathrm{O} \cdot 3 \mathrm{HCl} \cdot 2 \mathrm{H}_{2} \mathrm{O}\right) \mathrm{C}, \mathrm{H}, \mathrm{N}$.

1-(2', ,' -Dichlorobenzyl)-4-methyl-2-(4',5'-dihydro-1' $\mathbf{H}$ imidazol-2'-yl)methylpiperazine (63): ${ }^{1} \mathrm{H}$ NMR $\delta$ 7.35$7.13(3 \mathrm{H}, \mathrm{m}, \mathrm{Ar}-\mathrm{H}), 3.88$ and $3.48(2 \mathrm{H}, \mathrm{AB}$ spectrum, $\mathrm{J}=14.2$ $\mathrm{Hz}, \mathrm{H}_{2} \mathrm{C}-\mathrm{Ar}$ ), 3.47 (4H, br s, $\mathrm{H}$ imdazoline), 2.86-2.2 (9H, m, $\mathrm{H}$ piperazine, $\left.\mathrm{H}_{2} \mathrm{C}-\mathrm{C}=\mathrm{N}\right), 2.17\left(3 \mathrm{H}, \mathrm{s}, \mathrm{H}_{3} \mathrm{C}-\mathrm{N}\right) \cdot 63 \cdot 2 \mathrm{HCl}: 70 \%$ yield; $\mathrm{mp} 160-162{ }^{\circ} \mathrm{C}$ (ether/hexane). Anal. $\left(\mathrm{C}_{16} \mathrm{H}_{22} \mathrm{Cl}_{2} \mathrm{~N}_{4}\right.$. $\left.2 \mathrm{HCl} \cdot \mathrm{H}_{2} \mathrm{O}\right) \mathrm{C}, \mathrm{H}, \mathrm{N}$

Preparation of Oxazoline Analogue 50 (Scheme 6). N,N-Dibenzylethanolamine Hydrochloride (44). To $18 \mathrm{~mL}$ $(0.3 \mathrm{~mol})$ of ethanolamine in absolute $\mathrm{EtOH}(400 \mathrm{~mL})$ and $\mathrm{Et}_{3} \mathrm{~N}$ $(100 \mathrm{~mL})$ was added $69 \mathrm{~mL}(0.6 \mathrm{~mol})$ of benzyl chloride in absolute $\mathrm{EtOH}(70 \mathrm{~mL})$. The solution was refluxed overnight; then the ethanol was evaporated and the residue taken up in a saturated $\mathrm{Na}_{2} \mathrm{CO}_{3}$ solution and ether. The organic layer was washed with diluted $\mathrm{HCl}$; the aqueous layer was neutralized with $\mathrm{Na}_{2} \mathrm{CO}_{3}$ and extracted with ether. After drying over $\mathrm{MgSO}_{4}$ the solvent was evaporated and the residue purified by crystallization of the hydrochloride salt from ethanol/ether to afford $46 \mathrm{~g} \mathrm{(55 \% )}$ of $\mathbf{4 4}$ as a white powder: $\mathrm{mp} 149.5^{\circ} \mathrm{C}$; IR (film, $\left.\mathrm{cm}^{-1}\right) v 3550-3525(\mathrm{OH}), 1599(\mathrm{C}=\mathrm{C}) ;{ }^{1} \mathrm{H}$ NMR $\delta$ 7.30$7.01(10 \mathrm{H}, \mathrm{m}, \mathrm{Ar}-\mathrm{H}), 3.68\left(4 \mathrm{H}, \mathrm{s}\right.$, two $\left.\mathrm{H}_{2} \mathrm{C}-\mathrm{Ar}\right), 3.50(1 \mathrm{H}, \mathrm{s}$, $\mathrm{D}_{2} \mathrm{O}$ exchange, $\left.\mathrm{H}-\mathrm{O}\right), 3.45\left(2 \mathrm{H}, \mathrm{t}, \mathrm{J}=6.8 \mathrm{~Hz}, \mathrm{H}_{2} \mathrm{C}-\mathrm{O}\right), 2.54$ $\left(2 \mathrm{H}, \mathrm{t}, \mathrm{J}=6.8 \mathrm{~Hz}, \mathrm{H}_{2} \mathrm{C}-\mathrm{N}\right)$.

Tetrahydropyran-2-yloxyethylamine (46). A total of 50 $\mathrm{mL}(0.56 \mathrm{~mol})$ of dihydropyran was added dropwise to $78 \mathrm{~g}$ $(0.28 \mathrm{~mol})$ of 44 in $\mathrm{CH}_{2} \mathrm{Cl}_{2}(500 \mathrm{~mL})$. The solution was stirred at room temperature for 2 days and then poured into a molar solution of $\mathrm{Na}_{2} \mathrm{CO}_{3}(300 \mathrm{~mL})$. The aqueous layer was extracted with $\mathrm{CH}_{2} \mathrm{Cl}_{2}$. The organic layer was dried over $\mathrm{MgSO}_{4}$ and concentrated to give $\mathbf{4 5}$ which was used in the next step without purification. A shaken suspension of $10 \% \mathrm{Pd} / \mathrm{C}(300$ $\mathrm{mg})$ and $45(50 \mathrm{~g}, 0.21 \mathrm{~mol})$ in anhydrous ethanol $(300 \mathrm{~mL})$ was kept under an $\mathrm{H}_{2}$ atmosphere for $12 \mathrm{~h}$ at room temperature. The solution was filtered through Celite, and the filtrate was concentrated. The crude $\mathbf{4 6}$ was purified by distillation $\left(E_{15}=102-104{ }^{\circ} \mathrm{C}\right)$ to give $32 \mathrm{~g}(79 \%)$ of the title compound: IR $\left(\mathrm{KBr}, \mathrm{Cm}^{-1}\right) v 3380-3369(\mathrm{NH}){ }^{1}{ }^{1} \mathrm{H}$ NMR $\delta 4.53(\mathrm{H}, \mathrm{t}, \mathrm{J}=$ $3.19 \mathrm{~Hz}, \mathrm{HC}-\mathrm{O}), 3.84-3.63$ and $3.47-3.30\left(4 \mathrm{H}, 2 \mathrm{~m}\right.$, two $\mathrm{H}_{2} \mathrm{C}-$ O), $2.79\left(2 \mathrm{H}, \mathrm{t}, \mathrm{J}=5.32 \mathrm{~Hz}, \mathrm{H}_{2} \mathrm{C}-\mathrm{N}\right), 2.02\left(2 \mathrm{H}, \mathrm{br} \mathrm{s}, \mathrm{D}_{2} \mathrm{O}\right.$ exchange, $\left.\mathrm{H}_{2} \mathrm{~N}\right), 1.78-1.46\left(6 \mathrm{H}, \mathrm{m}, \mathrm{H}_{2} \mathrm{C}-\mathrm{C}\right)$.

1-(2'-Chlorobenzyl)-4-methyl-2-[((tetrahydropyran-2yloxy)ethylamino)carbonyl]piperazine (47). 46 (7.3 g, 0.05 $\mathrm{mol}$ ) in toluene ( $25 \mathrm{~mL}$ ) was added dropwise to a stirred and cooled solution of $25 \mathrm{~mL}$ of $\mathrm{Al}\left(\mathrm{CH}_{3}\right)_{2}(0.05 \mathrm{~mol})$ in toluene at 0 ${ }^{\circ} \mathrm{C}$, so that the temperature did not exceed $10{ }^{\circ} \mathrm{C}$. After $1 \mathrm{~h}$, $10 \mathrm{~g}(0.038 \mathrm{~mol})$ of $7 \mathrm{c}$ dissolved in toluene $(20 \mathrm{~mL})$ was added 
gradually at room temperature. The reaction mixture was refluxed for $4 \mathrm{~h}$ (argon atmosphere) and stirred one night at room temperature. The mixture was then cooled again and treated dropwise with $100 \mathrm{~mL}$ of water/MeOH $(20: 80, \mathrm{v} / \mathrm{v})$. After filtration and solvent evaporation, the residue was suspended in methylene chloride $(200 \mathrm{~mL})$. The organic layer was washed with water and dried over $\mathrm{MgSO}_{4}$ and the solvent removed in vacuo. The crude product $\mathbf{4 7}$ was used in the next step without purification.

1-(2'-Chlorobenzyl)-4-methyl-2-[(hydroxyethylamino)carbonyl]piperazine (48). 47 (11 g) was solubilized in $\mathrm{MeOH}$ saturated with $\mathrm{HCl}(75 \mathrm{~mL})$ and stirred for $2 \mathrm{~h}$. The solvent was removed in vacuo, and the residue was taken up in water. The aqueous solution was extracted with $\mathrm{CH}_{2} \mathrm{Cl}_{2}$ and then neutralized with $\mathrm{Na}_{2} \mathrm{CO}_{3}$. The organic layer was dried over $\mathrm{MgSO}_{4}$ and concentrated to afford $7.3 \mathrm{~g}(62 \%)$ of 48: IR (film, $\left.\mathrm{cm}^{-1}\right) v 3400(\mathrm{NH}$ and $\mathrm{OH}), 1660(\mathrm{C}=\mathrm{O}) ;{ }^{1} \mathrm{H} \mathrm{NMR} \delta 7.66(1 \mathrm{H}$, br $\mathrm{S}, \mathrm{D}_{2} \mathrm{O}$ exchange, $\left.\mathrm{H}-\mathrm{N}\right), 7.38-7.11(4 \mathrm{H}, \mathrm{ma}, \mathrm{Ar}-\mathrm{H}), 3.80$ and $3.48\left(2 \mathrm{H}, \mathrm{AB}\right.$ spectrum, $\left.\mathrm{J}=13.9 \mathrm{~Hz}, \mathrm{H}_{2} \mathrm{C}-\mathrm{Ar}\right), 3.70-3.55$ $\left(2 \mathrm{H}, \mathrm{m}, \mathrm{H}_{2} \mathrm{C}-\mathrm{O}\right), 3.38-3.33\left(2 \mathrm{H}, \mathrm{m}, \mathrm{H}_{2} \mathrm{C}-\mathrm{N}-\mathrm{C}=\mathrm{O}\right), 3.15(1 \mathrm{H}$, $\mathrm{dd}, \mathrm{J}=3.6$ and $8 \mathrm{~Hz}, \mathrm{HC}-\mathrm{N}), 2.89-2.70$ and $2.51-2.11(6 \mathrm{H}$, $2 \mathrm{~m}$, three $\left.\mathrm{H}_{2} \mathrm{C}-\mathrm{N}\right), 2.21\left(3 \mathrm{H}, \mathrm{s}, \mathrm{H}_{3} \mathrm{C}-\mathrm{N}\right), 1.87\left(1 \mathrm{H}\right.$, br s, $\mathrm{D}_{2} \mathrm{O}$ exchange, $\mathrm{H}-\mathrm{O})$.

1-(2'-Chlorobenzyl)-4-methyl-2-[(chloroethylamino)carbonyl]pi perazine (49). To $48(7 \mathrm{~g}, 0.022 \mathrm{~mol})$ in ice bathcooled chloroform $(50 \mathrm{~mL})$ was added dropwise $2.7 \mathrm{~mL}(0.037$ $\mathrm{mol})$ of freshly distilled thionyl chloride in $\mathrm{CHCl}_{3}(10 \mathrm{~mL})$. The mixture was stirred $12 \mathrm{~h}$ in ice bath and then poured in a molar solution of $\mathrm{Na}_{2} \mathrm{CO}_{3}(60 \mathrm{~mL})$. The organic layer was dried over $\mathrm{MgSO}_{4}$ and concentrated. The crude product was purified by column chromatography using ether/petroleum ether ( 50 : $50, \mathrm{v} / \mathrm{v})$ as eluent to give $4.5 \mathrm{~g}(61 \%)$ of 49 as white crystals:

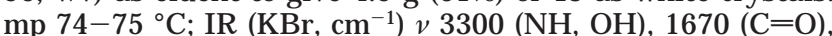
$1600(\mathrm{C}=\mathrm{C}) ;{ }^{1} \mathrm{H} N M R \delta 7.80(\mathrm{H}, \mathrm{s}, \mathrm{HN}-\mathrm{C}=\mathrm{O}), 7.38-7.10(4 \mathrm{H}$, $\mathrm{m}, \mathrm{Ar}-\mathrm{H}), 3.70$ and $3.55\left(2 \mathrm{H}, \mathrm{AB}\right.$ spectrum, $\mathrm{J}=14.5 \mathrm{~Hz}, \mathrm{H}_{2} \mathrm{C}-$ Ar), $3.54\left(4 \mathrm{H}, \mathrm{s}, \mathrm{H}_{2} \mathrm{C}-\mathrm{N}-\mathrm{C}=\mathrm{O}\right.$ and $\left.\mathrm{H}_{2} \mathrm{C}-\mathrm{Cl}\right), 3.18-3.10,2.82-$ 2.69 and $2.50-2.20$ (7H, 3m, $\mathrm{H}$ piperazine), $2.23\left(3 \mathrm{H}, \mathrm{s}, \mathrm{H}_{3} \mathrm{C}-\right.$ N).

1-(2-Chlorobenzyl)-4-methyl-2-(4',5'-dihydro-1',3-oxazol$\mathbf{2}$-yl)piperazine (50). To $2.2 \mathrm{~g}(6.7 \mathrm{mmol})$ of $\mathbf{4 9}$ in EtOH (15 $\mathrm{mL})$ was added rapidly $0.26 \mathrm{~g}(6.5 \mathrm{mmol})$ of $\mathrm{NaOH}$ in hot $\mathrm{EtOH}$ at $80 \%(6 \mathrm{~mL})$. The mixture was stirred overnight at room temperature, then filtered, and concentrated. The residue was taken up in ether and washed with water. The organic layer was dried over $\mathrm{MgSO}_{4}$ and the ether removed in vacuo; $1.7 \mathrm{~g}$ (85\%) of $\mathbf{5 1}$ as white crystals was obtained after addition of hexane: $\mathrm{mp} 97^{\circ} \mathrm{C}$; IR $\left(\mathrm{KBr}, \mathrm{cm}^{-1}\right)$ v $1680(\mathrm{C}=\mathrm{N}), 1590(\mathrm{C}=\mathrm{C})$ $\mathrm{cm}^{-1}$; ${ }^{1} \mathrm{H}$ NMR $\delta$ 7.41-7.46 and 7.35-7.05 $(4 \mathrm{H}, 2 \mathrm{~m}, \mathrm{Ar}-\mathrm{H})$, 4.25-4.03 and 3.88-3.72 (4H, $2 \mathrm{~m}, \mathrm{H}$ oxazoline), 3.76 and 3.64 ( $2 \mathrm{H}, \mathrm{AB}$ spectrum, $\mathrm{J}=17 \mathrm{~Hz}, \mathrm{H}_{2} \mathrm{C}-\mathrm{Ar}$ ), $3.43(1 \mathrm{H}, \mathrm{dd}, \mathrm{J}=3.5$ and $8.5 \mathrm{~Hz}, \mathrm{HC}-\mathrm{N}), 2.93-2.82,2.72-2.65$ and $2.54-2.21(6 \mathrm{H}$, $3 \mathrm{~m}$, three $\left.\mathrm{H}_{2} \mathrm{C}-\mathrm{N}\right), 2.21\left(3 \mathrm{H}, \mathrm{s}, \mathrm{H}_{3} \mathrm{C}-\mathrm{N}\right)$. Anal. $\left(\mathrm{C}_{15} \mathrm{H}_{20} \mathrm{CIN}{ }_{3} \mathrm{O}\right)$ $\mathrm{C}, \mathrm{H}, \mathrm{N}$.

Preparation of Amidine Analogues 52a, 52b, and 56 (Scheme 7). 1,4-Dibenzyl-2-cyanopiperazine Dihydrochloride (51). To a hot $\left(80^{\circ} \mathrm{C}\right)$ stirred solution of $\mathrm{N}, \mathrm{N}^{\prime}$ dibenzylethylenediamine $(72 \mathrm{~g}, 0.3 \mathrm{~mol})$ and triethylamine $(100 \mathrm{~mL}, 0.72 \mathrm{~mol})$ in toluene $(300 \mathrm{~mL})$ was added dropwise, but rapidly, freshly distilled 2,3-dibromopropionitrile (70 g, 0.3 $\mathrm{mol})$ in toluene $(300 \mathrm{~mL})$. After the addition, the reaction mixture was stirred at $80^{\circ} \mathrm{C}$ for $3 \mathrm{~h}$, then cooled, and filtered. The filtrate was washed with saturated aqueous $\mathrm{NaHCO}_{3}(200$ $\mathrm{mL}$ ). The organic layer was dried over $\mathrm{MgSO}_{4}$ and the solvent removed in vacuo. The crude product was dissolved in anhydrous $\mathrm{EtOH}(400 \mathrm{~mL})$ and saturated with $\mathrm{HCl}$ gas. The addition of ether gave a precipitate of $51(65.5 \mathrm{~g}, 60 \%)$ as a white powder: $\mathrm{mp} 152-154{ }^{\circ} \mathrm{C}$; IR (free base, film, $\mathrm{cm}^{-1}$ ) $v$ $2200(\mathrm{CN}), 1600(\mathrm{C}=\mathrm{C}) ;{ }^{1} \mathrm{H}$ NMR $\delta$ 7.40-7.10 $(10 \mathrm{H}, \mathrm{m}, \mathrm{Ar}-$ $\mathrm{H}), 3.38-3.88\left(4 \mathrm{H}, \mathrm{m}, \mathrm{H}_{2} \mathrm{C}-\mathrm{Ar}\right), 3.32-3.21,3.05-2.95$ and 2.69-2.27 (7H, 3m, H piperazine).

1,4-Dibenzyl-2-amidinopiperazine Hydrochloride (52a). A total of $50 \mathrm{~mL}$ of a solution of $\mathrm{Al}\left(\mathrm{CH}_{3}\right)_{3}(2 \mathrm{M})$ in toluene was added dropwise to a cold and stirred suspension of $\mathrm{NH}_{4} \mathrm{Cl}(5.35$ $\mathrm{g}, 0.1 \mathrm{~mol}$ ) in $50 \mathrm{~mL}$ of toluene according to Levin et al. procedure. ${ }^{25}$ The mixture was stirred $1 \mathrm{~h}$ at room temperature: then $10 \mathrm{~g}(0.034 \mathrm{~mol})$ of $\mathbf{5 1}$ dissolved in toluene $(50 \mathrm{~mL})$ was added dropwise. The solution was heated at $80-90{ }^{\circ} \mathrm{C}$ overnight. After cooling in an ice bath, $\mathrm{MeOH} / \mathrm{H}_{2} \mathrm{O}(80: 20$, v/v) was added carefully and the mixture filtered. The salts were washed with $\mathrm{CHCl}_{3}$, and the filtrate was acidified. The solvents were evaporated to dryness; the residue was taken up in $\mathrm{CHCl}_{3}$ and filtered again. After evaporation of $\mathrm{CHCl}_{3}$, the crude product was purified by col umn chromatography using $\mathrm{CHCl}_{3} /$ $\mathrm{MeOH}$ (95: 5, v/v) as eluent to give $4.2 \mathrm{~g}(36 \%)$ of $\mathbf{5 2 a}$ as a white powder: $\mathrm{mp} 175-177^{\circ} \mathrm{C}\left(\mathrm{CH}_{2} \mathrm{Cl}_{2} /\right.$ ether); IR (film, cm $\left.{ }^{-1}\right)$ $v$ 3420-3390 (NH), $1615(\mathrm{C}=\mathrm{N}), 1595(\mathrm{C}=\mathrm{C})$; ${ }^{1} \mathrm{H}$ NMR (free base) $\delta 7.28-7.13(10 \mathrm{H}, \mathrm{m}, \mathrm{Ar}-\mathrm{H}), 4.56\left(5 \mathrm{H}, \mathrm{br} \mathrm{s}, \mathrm{D}_{2} \mathrm{O}\right.$ exchange, $\mathrm{H}_{2} \mathrm{~N}, \mathrm{HN}=$ and $\left.1 \mathrm{H}_{2} \mathrm{O}\right), 3.77$ and $3.18(2 \mathrm{H}, \mathrm{AB}$ spectrum, J $\left.=13.37 \mathrm{~Hz}, \mathrm{H}_{2} \mathrm{C}-\mathrm{Ar}\right), 3.39\left(2 \mathrm{H}, \mathrm{s}, \mathrm{H}_{2} \mathrm{C}-\mathrm{Ar}\right), 3.05$ $(1 \mathrm{H}, \mathrm{dd}, \mathrm{J}=3.3$ and $8.7 \mathrm{~Hz}, \mathrm{HC}-\mathrm{N}), 2.85-2.51$ and $2.32-$ $2.10\left(6 \mathrm{H}, 2 \mathrm{~m}\right.$, three $\left.\mathrm{H}_{2} \mathrm{C}-\mathrm{N}\right)$. Anal. $\left(\mathrm{C}_{19} \mathrm{H}_{24} \mathrm{~N}_{4} \cdot 0.75 \mathrm{HCl}\right) \mathrm{C}, \mathrm{H}$, $\mathrm{N}$

1,4-Dibenzyl-2-(N-methylamidino)piperazine Hydrochloride (52b). It was prepared by the same procedure as above using the corresponding nitrile $\mathbf{5 1}$ derivative and methylamine hydrochloride salt: $52 \% ; \mathrm{mp} 221-223{ }^{\circ} \mathrm{C}$ dec $\left(\mathrm{CH}_{2} \mathrm{Cl}_{2}\right.$ /acetone); this compound gave ${ }^{1} \mathrm{H} \mathrm{NMR}$ spectrum similar to that of $\mathbf{5 2 a}$, particular signal $\delta \mathrm{ppm} 2.31(3 \mathrm{H}, \mathrm{s}$, $\left.\mathrm{H}_{3} \mathrm{C}-\mathrm{N}=\right)$. Anal. $\left(\mathrm{C}_{20} \mathrm{H}_{26} \mathrm{~N}_{4} \cdot 1 \mathrm{HCl}\right) \mathrm{C}, \mathrm{H}, \mathrm{N}$.

$\mathbf{N}, \mathbf{N}^{\prime}$-Dibenzyl-N,N'-diisopropylethylenediamine (53). A total of $38 \mathrm{~g}(0.223 \mathrm{~mol})$ of isopropyl iodide was added to a suspension of $24 \mathrm{~g}(0.1 \mathrm{~mol})$ of $\mathrm{N}, \mathrm{N}^{\prime}$-dibenzylethylenediamine and $35 \mathrm{~g}$ of dry $\mathrm{K}_{2} \mathrm{CO}_{3}$ in $100 \mathrm{~mL}$ of acetonitrile. The reaction mixture was refluxed for $48 \mathrm{~h}$. After cooling and filtration, the solvent was removed in vacuo. The residue was dissolved in $\mathrm{CH}_{2} \mathrm{Cl}_{2}$, the solution washed with water and then dried over $\mathrm{MgSO}_{4}$, and the solvent evaporated. The crude product was purified by column chromatography using petroleum ether/ ether $(80: 20,70: 30$ then $50: 50, v / v)$ as eluent to give $29 \mathrm{~g}(89 \%)$ of 53 as a col orless oil: IR (film, $\left.\mathrm{cm}^{-1}\right) v 1590(\mathrm{C}=\mathrm{C})$; ${ }^{1} \mathrm{H}$ NMR $\delta$ 7.25-7.09 (10H, m, Ar-H ), $3.44\left(4 \mathrm{H}, \mathrm{s}\right.$, two $\left.\mathrm{H}_{2} \mathrm{C}-\mathrm{Ar}\right), 2.88-$ $2.70\left(2 \mathrm{H}, \mathrm{m}\right.$, two $\left.\mathrm{HC}\left(\mathrm{CH}_{3}\right)_{2}\right), 2.33\left(4 \mathrm{H}, \mathrm{s}\right.$, two $\left.\mathrm{H}_{2} \mathrm{C}-\mathrm{N}\right), 0.87$ $\left(12 \mathrm{H}, \mathrm{d}, \mathrm{j}=6.6 \mathrm{~Hz}\right.$, two $\left.\left(\mathrm{H}_{3} \mathrm{C}\right)_{2} \mathrm{CH}\right)$.

$\mathbf{N}, \mathbf{N}^{\prime}$-Diisopropylethylenediamine (54). The procedure was the same as the one used for the preparation of $\mathbf{1 7}$ starting from $28 \mathrm{~g}(0.086 \mathrm{~mol})$ of 53 . The crude product was purified by distillation $\left(\mathrm{E}_{15}=60{ }^{\circ} \mathrm{C}\right)$ yielding $9 \mathrm{~g}(70 \%)$ of 54 as a colorless oil: IR (film, $\left.\mathrm{cm}^{-1}\right)$ v $3300(\mathrm{NH}), 1590(\mathrm{C}=\mathrm{C}) ;{ }^{1} \mathrm{H}$ NMR $\delta 2.89\left(1 \mathrm{H}\right.$, br s, $\mathrm{D}_{2} \mathrm{O}$ exchange, two $\left.\mathrm{HN}\right), 2.80(2 \mathrm{H}$, sept, J = $6.3 \mathrm{~Hz}$, two HC- $\left.\left(\mathrm{CH}_{3}\right)_{2}\right), 2.73\left(4 \mathrm{H}, \mathrm{s}\right.$, two $\left.\mathrm{H}_{2} \mathrm{C}-\mathrm{N}\right), 1.05(12 \mathrm{H}$, $\mathrm{d}, \mathrm{J}=6.4 \mathrm{~Hz}$, two $\left.\left(\mathrm{H}_{3} \mathrm{C}\right)_{2} \mathrm{CH}\right)$.

1,4-Diisopropyl-2-cyanopiperazine (55). The procedure was the same as for the preparation of 51 using $7 \mathrm{~g}(0.05 \mathrm{~mol})$ of 54. The crude product was purified by distillation $\left(\mathrm{E}_{0.05}=\right.$ $76-82{ }^{\circ} \mathrm{C}$ ) yielding $5 \mathrm{~g} \mathrm{(51 \% )}$ of $\mathbf{5 5}$ as a yellow oil: IR (film, $\left.\mathrm{cm}^{-1}\right) v 2200(\mathrm{C}=\mathrm{N}) ;{ }^{1} \mathrm{H}$ NMR $\delta 3.90(1 \mathrm{H}, \mathrm{br} \mathrm{s}, \mathrm{HC}-\mathrm{N}), 2.91-$ $2.25\left(8 \mathrm{H}, \mathrm{m}\right.$, three $\mathrm{H}_{2} \mathrm{C}-\mathrm{N}$ and two $\left.\mathrm{HC}\left(\mathrm{CH}_{3}\right)_{2}\right), 1.09-0.92(12 \mathrm{H}$, $\mathrm{m}$, two $\left(\mathrm{H}_{3} \mathrm{C}\right)_{2} \mathrm{CH}$, the $\mathrm{CH}_{3}$ groups were nonequivalents and the doublets overlapped).

1,4-Diisopropyl-2-(N-methylamidino)piperazine hydrochloride (56): $55 \% ; \mathrm{mp} \mathrm{208-210}{ }^{\circ} \mathrm{C}$ (acetone); ${ }^{1 \mathrm{H}} \mathrm{NMR}$ $\delta 5.65\left(4 \mathrm{H}\right.$, br $\mathrm{s}, \mathrm{D}_{2} \mathrm{O}$ exchange, $\mathrm{H}-\mathrm{N}, \mathrm{HN}=$ and $\left.\mathrm{IH}_{2} \mathrm{O}\right), 3.54$ $(1 \mathrm{H}, \mathrm{dd}, \mathrm{J}=3.30$ and $7.44 \mathrm{~Hz}, \mathrm{HC}-\mathrm{N}), 2.92\left(3 \mathrm{H}, \mathrm{s}, \mathrm{H}_{3} \mathrm{C}-\mathrm{N}\right)$, 2.97-2.27 (8H, m, three $\mathrm{H}_{2} \mathrm{C}-\mathrm{N}$ and two $\left.\mathrm{HC}\left(\mathrm{CH}_{3}\right)_{2}\right), 0.99,0.95$ and $0.86(2 \mathrm{H}, 3 \mathrm{~d}$ in $1: 2: 1$ ratio, $\mathrm{J}=7.0$ and $6.54 \mathrm{~Hz}$, two $\left.\left(\mathrm{H}_{3} \mathrm{C}\right)_{2}-\mathrm{CH}\right)$. Anal. $\left(\mathrm{C}_{12} \mathrm{H}_{26} \mathrm{~N}_{4} \cdot 2 \mathrm{HCl}\right) \mathrm{C}, \mathrm{H}, \mathrm{N}$.

Preparation of Imidazole Analogue 56 (Scheme 8). 1-(2 , 4'-Dichlorobenzyl)-4-methyl-2-(hydroxymethyl)piperazine (57). This compound was prepared from ethyl 1-(2',4'dichlorobenzyl)-4-methylpiperazine-2-carboxylate ${ }^{16}$ using the same procedure as for derivative 36: IR (film, $\left.\mathrm{cm}^{-1}\right)$ v 3400 $(\mathrm{OH}), 1600(\mathrm{C}=\mathrm{C})$; ${ }^{1} \mathrm{H}$ NMR $\delta 7.50-7.05(3 \mathrm{H}, \mathrm{m}, \mathrm{Ar}-\mathrm{H}), 5.20$ (1H, br s, $\mathrm{D}_{2} \mathrm{O}$ exchange, $\left.\mathrm{H}-\mathrm{O}\right), 4.20-3.40\left(5 \mathrm{H}, \mathrm{m}, \mathrm{H}_{2} \mathrm{C}-\mathrm{Ar}\right.$, $\mathrm{H}_{2} \mathrm{C}-\mathrm{O}$ and $\left.\mathrm{HC}-\mathrm{N}\right), 3.05-2.30\left(6 \mathrm{H}, \mathrm{m}\right.$, three $\left.\mathrm{H}_{2} \mathrm{C}-\mathrm{N}\right), 2.20$ $\left(3 \mathrm{H}, \mathrm{s}, \mathrm{H}_{3} \mathrm{C}-\mathrm{N}\right)$.

1-(2', 4'-Dichlorobenzyl)-4-methyl-2-formylpiperazine (58). To a solution of DMSO $(20 \mathrm{~mL})$ in $\operatorname{dry~} \mathrm{CH}_{2} \mathrm{Cl}_{2}(140 \mathrm{~mL})$ was added dropwise for $10 \mathrm{~min}$ at $-60{ }^{\circ} \mathrm{C}$ freshly distilled 
oxalyl chloride (30 mL) in dry $\mathrm{CH}_{2} \mathrm{Cl}_{2}(60 \mathrm{~mL})$ with stirring under nitrogen atmosphere. After 15 min, $15 \mathrm{~g}$ of $\mathbf{5 7}$ in dry $\mathrm{CH}_{2} \mathrm{Cl}_{2}(250 \mathrm{~mL})$ was added dropwise to the solution mixture while the temperature was maintained at $-60{ }^{\circ} \mathrm{C}$. After stirring $90 \mathrm{~min}$, triethylamine $(56 \mathrm{~mL})$ was added quickly and the reaction mixture was allowed to warm to $-30{ }^{\circ} \mathrm{C}$. After stirring for $2 \mathrm{~h}$, the solution mixture was all owed to warm to room temperature and concentrated. The residue was taken up in chloroform; the organic layer was washed with water and dried over $\mathrm{MgSO}_{4}$. After evaporation the residue was purified by column chromatography using ether as eluent to afford 58 as a viscous oil (6.76 g, 35\%): IR (film, $\left.\mathrm{cm}^{-1}\right) v 1740$ $(\mathrm{C}=\mathrm{O}), 1600(\mathrm{C}=\mathrm{C}) ;{ }^{1} \mathrm{H} N M R \delta 9.70(\mathrm{H}, \mathrm{d}, \mathrm{J}=2.4 \mathrm{~Hz}, \mathrm{HC}=$ O), 7.45-7.10 ( $3 \mathrm{H}, \mathrm{m}, \mathrm{Ar}-\mathrm{H}), 3.90$ and $3.82(2 \mathrm{H}, \mathrm{AB}$ spectrum, $\mathrm{J}=14 \mathrm{~Hz}, \mathrm{H}_{2} \mathrm{C}-\mathrm{Ar}$ ), 3.55-2.12 (7H, m, $\mathrm{H}$ piperazine), 2.20 $\left(3 \mathrm{H}, \mathrm{S}, \mathrm{H}_{3} \mathrm{C}-\mathrm{N}\right)$.

1-(2',4'-Dichlorobenzyl)-4-methyl-2-(imidazol-2'-yl)piperazine (59). To a stirred solution of $58(5.5 \mathrm{~g}, 0.019 \mathrm{~mol})$ and glyoxal $(2 \mathrm{~g})$ in $\mathrm{MeOH}(100 \mathrm{~mL})$ was added dropwise anhydrous ammonia at $-10^{\circ} \mathrm{C}$. This temperature was maintained for $2 \mathrm{~h}$; then the solution was allowed to warm to room temperature. The addition of water $(200 \mathrm{~mL})$ gave a precipitate of 59 as a white powder (3.41 g, 55\%): mp (free base)152$154{ }^{\circ} \mathrm{C} ;{ }^{1} \mathrm{H} N M R \delta 10.95\left(1 \mathrm{H}\right.$, br s, $\mathrm{D}_{2} \mathrm{O}$ exchange, $\left.\mathrm{H}-\mathrm{N}\right), 7.45-$ $7.02(3 \mathrm{H}, \mathrm{m}, \mathrm{Ar}-\mathrm{H}), 6.95(2 \mathrm{H}, \mathrm{s}, \mathrm{two} \mathrm{HC}=), 3.98(1 \mathrm{H}, \mathrm{t}, \mathrm{J}=$ $3.7 \mathrm{~Hz}, \mathrm{HC}-\mathrm{N}), 3.63$ and $3.16(2 \mathrm{H}, \mathrm{AB}$ spectrum, $\mathrm{J}=13.7$ $\mathrm{Hz}, \mathrm{H}_{2} \mathrm{C}-\mathrm{Ar}$ ), 2.71-2.30 (6H, m, three $\left.\mathrm{H}_{2} \mathrm{C}-\mathrm{N}\right), 2.24(3 \mathrm{H}, \mathrm{s}$, $\mathrm{H}_{3} \mathrm{C}-\mathrm{N}$ ). Anal. $\left(\mathrm{C}_{15} \mathrm{H}_{18} \mathrm{Cl}_{2} \mathrm{~N}_{4} \cdot 2 \mathrm{HCl}\right) \mathrm{C}, \mathrm{H}, \mathrm{N}$.

Pharmacology. Animals and Treatments. Three monthold male Wistar rats (I ffa-Credo, France) weighing about 250 $\mathrm{g}$ were used in all the experiments. The animals were housed in wire-bottomed cages and maintained at $21 \pm 2{ }^{\circ} \mathrm{C}$ in a room with a 12-h fixed light-dark schedule. Water and standard laboratory chow (UAR, Villemoison-sur-Orge, France) were freely available.

M oderate diabetes were obtained by a single iv injection of a low dose ( $35 \mathrm{mg} / \mathrm{kg}$ ) of streptozotocin (STZ) dissolved in a citrate buffer ${ }^{28}$ under ketamine hydrochloride anesthesia (75 $\mathrm{mg} / \mathrm{kg}$ ip; I mal gene, Mérieux, France). These rats were called STZ rats. Control rats received an injection of the vehide under the same conditions.

Glucose homeostasis and insulin secretion were assessed by glucose tolerance tests performed 2 weeks after STZ injection.

Intravenous Glucose Tolerance Tests (IVGTT). Glucose was dissolved in $0.9 \%$ sal ine and given by the saphenous vein route $(0.5 \mathrm{~g} / \mathrm{kg})$ in rats under pentobarbital anesthesia $(60 \mathrm{mg} /$ kg ip; Clin-Midy, France). Blood samples were collected sequentially from the tail vessels before and $5,10,15,20$, and $30 \mathrm{~min}$ after the injection of glucose. They were then centrifuged, and the plasma was separated. Plasma glucose concentration was immediately determined in a $10-\mu \mathrm{L}$ aliquot, and the plasma left was kept at $-20^{\circ} \mathrm{C}$ until radioimmunoassay of insulin.

Drug Administration and Antidiabetic Activity. The 2-(4',5'-dihydro-1'H-imidazol-2'-yl)piperazine derivatives were tested by a single ip injection of $100 \mu \mathrm{mol} / \mathrm{kg}$ in the STZ rat $20 \mathrm{~min}$ before the IVGTT. All the compounds were used in the form of hydrochloride salts and were water-soluble. Antidiabetic activity of the compounds was evaluated using two parameters: $\Delta \mathrm{G}$, which represents the increase in glycemia over baseline integrated over a period of $30 \mathrm{~min}$ (IVGTT) following the glucose load, and $\mathrm{K}$, which is the rate of glucose disappearance between 5 and $30 \mathrm{~min}$ (in the case of IVGTT), after glucose administration. The K coefficient was calculated only during IVGTT.

Tissue and Membrane Preparation. Cerebral cortex was obtained from whole bovine brains and homogenized in 20 volumes of ice-cold $50 \mathrm{mM}$ Tris- $\mathrm{HCl}$ buffer $(\mathrm{pH}$ 7.4). The homogenate was centrifuged twice at $48000 \mathrm{~g}$ for $25 \mathrm{~min}$ at 4 ${ }^{\circ} \mathrm{C}$. The pellet (used for $\alpha_{2}$ binding assays) was resuspended in a phosphate buffer ( $\mathrm{pH} 7.4$ ), flash-frozen, and stored at -80 ${ }^{\circ} \mathrm{C}$ until $\alpha_{2}$ binding assays.

Reticular nucleus from calf's bulbis was homogenized in icecold $50 \mathrm{mM}$ Tris- $\mathrm{HCl}$ buffer ( $\mathrm{pH}$ 7.7) containing $5 \mathrm{mM}$ EDTA.
The homogenate was centrifuged at $500 \mathrm{~g}$ for $10 \mathrm{~min}$ at $4{ }^{\circ} \mathrm{C}$. The pellet (P1) was resuspended in the same buffer and centrifuged again. The combined supernatants were centrifuged at $50000 \mathrm{~g}$ for $25 \mathrm{~min}$ at $4{ }^{\circ} \mathrm{C}$. The resulting pellet (P2) was resuspended in $50 \mathrm{mM}$ Tris- $\mathrm{HCl}$ buffer $(\mathrm{pH} 7.7)$ containing $0.1 \mathrm{mM}$ p-methanesulfonyl fluoride, incubated for $30 \mathrm{~min}$ at $25^{\circ} \mathrm{C}$, then centrifuged again in the same conditions, resuspended in $50 \mathrm{mM}$ Tris- $\mathrm{HCl}$ (pH 7.7), flash-frozen, and stored at $-80^{\circ} \mathrm{C}$ until $\mathrm{I}_{1}$-imidazoline binding assays.

Renal cortex was obtained from male New Zealand white rabbits and homogenized in ice-cold preparation buffer $(20 \mathrm{mM}$ $\left.\mathrm{NaHCO}_{3}\right) .42$ The homogenate was centrifuged at $40000 \mathrm{~g}$ for $30 \mathrm{~min}$ at $4{ }^{\circ} \mathrm{C}$. The pellet was resuspended in $50 \mathrm{mM}$ Tris$\mathrm{HCl}$ buffer containing $0.5 \mathrm{mM}$ EDTA (pH 7.4), centrifuged again, resuspended in the same buffer, flash-frozen, and stored at $-80^{\circ} \mathrm{C}$ until $\mathrm{I}_{2}$-imidazoline binding assays.

Binding Assays. [ $\left.{ }^{3} \mathrm{H}\right] \mathrm{RX} 821002$ (48 Ci/mmol), [ $\left.{ }^{3} \mathrm{H}\right]-\mathrm{p}-$ aminocl onidine $(50 \mathrm{Ci} / \mathrm{mmol})$, and $\left[{ }^{3} \mathrm{H}\right]$ idazoxan $(42 \mathrm{Ci} / \mathrm{mmol})$ were obtained from Amersham (Buckinghamshire, U.K.), and phentolamine, guanabenz, tolazoline, idazoxan, yohimbine, clonidine, naphazoline, and amiloride were from Sigma (St Louis, MO). Radioligand binding assays with [ $\left.{ }^{3} \mathrm{H}\right] \mathrm{RX} 821002$, $\left[{ }^{3} \mathrm{H}\right]$-p-aminoclonidine, or $\left[{ }^{3} \mathrm{H}\right]$ idazoxan for determination of specific binding to $\alpha_{2}$ adrenoceptors, I ${ }_{1}$-PBS, and I $I_{2}$-PBS, respectively, were performed by a modification of methods previously described. ${ }^{43,44} \mathrm{Membranes}$ were sl owly thawed and diluted to a concentration of $0.4 \mathrm{mg}$ of protein $/ \mathrm{mL}$ for renal and cerebral cortex and $0.7 \mathrm{mg}$ of protein $/ \mathrm{mL}$ for calf's bulbis. Assays were conducted in a total volume of $525 \mu \mathrm{L}$ in polypropylene tubes, and each tube contained $500 \mu \mathrm{L}$ of membrane suspension, $20 \mu \mathrm{L}$ of radioligand, and $5 \mu \mathrm{L}$ of drug. Incubation was initiated by the addition of membrane and was carried out for $45 \mathrm{~min}$ at $25{ }^{\circ} \mathrm{C}$. Nonspecific binding was defined in the presence of yohimbine $(10 \mu \mathrm{M})$ in $\left[{ }^{3} \mathrm{H}\right] \mathrm{RX} 821002$ binding assays, either phentolamine $(10 \mu \mathrm{M})$ or guanabenz (5 $\mu \mathrm{M})$ in $\left[{ }^{3} \mathrm{H}\right]-p$-aminoclonidine binding assays, and either tolazoline $(10 \mu \mathrm{M})$ or amiloride $(10 \mu \mathrm{M})$ in $\left[{ }^{3} \mathrm{H}\right]$ ]idazoxan binding assays. For each drug, six concentrations from $10^{-4}$ to $10^{-11}$ $M$ were used in triplicate. Incubations were terminated by vacuum filtration over Whatman GF/B glass fi ber filters using a cell harvester. The filters were washed three times with the buffer, placed in scintillation vials, covered with $2 \mathrm{~mL}$ of scintillation cocktail (Pico-Fluor, Packard Instrument), and counted (Packard 2000 CA). Protein was assayed by a Bradford method.

Binding results were analyzed by linear regression, and the curves were obtained with Graph PAD program (I nstitute for Scientific Information, Philadel phia, PA). $K_{i}$ was calculated with the Cheng-Prusoff equation.

Analytical Methods. Plasma glucose was determined using a glucose analyzer (Beckman Inc., Fullerton, CA). Plasma immunoreactive insulin (IRI) concentration was de termined with a radioimmunoassay kit (CEA, Gif-sur-Y vette, France). The lower limit of the assay was $19.5 \mathrm{pmol} / \mathrm{L}$ with a coefficient of variation within and between assays of $6 \%$.

Statistics. Results of Tables $1-3$ are expressed as a mean \pm SEM. The significance of differences between means was evaluated by one-way analysis of variance (ANOVA), and differences were considered significant at $p<0.05$.

Partition Coefficients. Log $P$ of bases was calculated according to Rekker's method ${ }^{40}$ and from Hansch's data bank. ${ }^{41}$ $\mathrm{f}(1,2,4$-trisubstituted-piperazinyl $)=\log P($ piperazine $)-(2 f(H$ neg) $+\mathrm{f}(\mathrm{H}))=-1.50-1.124=-2.624$. $\mathrm{f}(2$-substitutedimidazolinyl) $=\log \mathrm{P}($ tolazoline or 2-benzylimidazoline) $f($ benzyl $)=2.65-2.359=+0.291$. Controlled via another way: $f(2$-imidazolinyl $)=f(2$-imidazolyl $)+2 f(H)=-0.080+$ $0.364=+0.284(|\Delta|=0.007)$. f(1,4-disubstituted-2-(4',5'dihydro-1'H-imidazolyl-2'-yl)pi perazine) $=-2.333$.

The hydrophobic fragmental constants of the 1,4-substituents of pi perazine were added to this last value.

Acknowledgment. We extend our thanks to Drs. F. Heymans and C. Z. Dong for helpful suggestions for 
manuscript preparation. This work was supported in part by the Bel gian Programme on I nteruniversity Poles of Attraction initiated by the Belgian State, Prime Minister's Office, Services Fédéraux des Affaires Scientifiques, Techniques et Culturelles (PAI No. 9), and the Fonds de la Recherche Médicale (Contract No. 3.4531.92). Georges Dive is Chercheur Qualifié of the FNRS, Brussels.

\section{References}

(1) Schmid-Antomarchi, H. S.; De Weille, J .; Fosset, M.; Lazdunski, $M$. The receptor for Antidiabetic Sulfonylureas Controls the Activity of the ATP-modulated $\mathrm{K}^{+}$Channel in Insulin-Secreting Cells. J. Biol. Chem. 1987, 262, 15840-15844.

(2) Bailey, C. J .; Nattrass, M. Treatment - Metformin. Bailiere's Clin. Endocrinol. Metab. 1988, 2, 455-476.

(3) J ackson, R. A.; Mawa, M. I.; J aspan, J . B.; Sim, B. M.; Di Silvio, L.; Featherbe, D.; Kurtz, A. B. Mechanisms of Metformin Action in Non-Insulin-Dependent Diabetes. Diabetes 1987, 36, 632640.

(4) Hermann, L. S.; Melander, A. Biguanides: Basic aspects and clinical uses. In International Textbook of Diabetes Mellitus; Alberti, K. G. M. M., De Fronzo, R. A., Keen, H., Zimmet, P., Eds.: J ohn Wiley \& Sons Ltd.: New York, 1992; pp 773-795.

(5) Campbell, I. W. In Sulphonylureas and Metformin: Efficacy and Inadequacy in New Antidiabetic Drugs; Bailey, C. J ., Flatt, P. R., Eds.; Smith-Gordon: London, 1990; pp 33-51.

(6) Berger, W. Incidence des effets secondaires sévères sous traitement par des sulfonylurées et des biguanides. J ournée de Diabétol ogieHôtel-Dieu; Flammarion: Paris, 1986; pp 243-253.

(7) Kameda, K.; Ono, S.; Aboko, Y. Hypoglycemic Action of 2-[2$\left(4^{\prime}, 5^{\prime}\right.$-Dihydro-1'H-imidazol-2'-yl)]-1-phenylethylpyridine dihydrochloride Sesquihydrate (DG-5128), a New Hypoglycaemic Agent. Arzneim. Forsch. Drug Res. 1982, 32, 39-44.

(8) Kashiwagi, A.; Harano, Y.; Susuki, M.; Kojima, H.; Harada, M.; Nishio, Y.; Shiegeta, Y. New $\alpha_{2}$-Adrenergic Blocker (DG-5128) improves Insulin Secretion and in vivo Glucose Disposal in NIDDM Patients. Diabetes 1986, 35, 1085-1089.

(9) Use of Pyrrolo [3,2,1-hi] indole Derivatives in the Manufacture of a Medicament for the Treatment of Diabetes. EP 0311467; Synthelabo.

(10) Annu. Drug Data Rep. 1992, 995.

(11) J onas, J . C.; Garcia-Banado, M. J .; Angel, I.; Henquin, J . C. The I midazol ine SL 84.0148 shows Stereoselectivity in Blocking $\alpha_{2}$ Adrenoceptors but not ATP-sensitive $\mathrm{K}^{+}$Channels in Pancreatic B-cells. Eur. J . Pharmacol. 1994, 264, 81-84.

(12) Berritge, T. L.; Doxey, J . C.; Roach, A. G. Comparison of the Effects of Efaroxan and Glibenclamide on Plasma Glucose and Insulin Levels in Rats. Eur. J . Pharmacol. 1992, 213, 213-218.

(13) Östenson, C. G.; Cattaneo, A. G.; Doxey, J . C.; Efendic, S. AlphaAdrenoceptors and Insulin Release from Pancreatic Islets of Normal and Diabetic Rats. Am. J . Physiol. 1989, 257, E439E443.

(14) Chan, S. L. F. Role of Alpha-2 Adrenoceptors and I midazolineBinding Sites in the Control of Insulin Secretion. Clin. Sci. 1993, 85, 671-677.

(15) Schultz, A.; Hasselblatt, A. An Insulin-Releasing Property of I midazoline Derivatives is not limited to Compounds that block $\alpha$-Adrenoceptors. Naunyn-Schmiedeberg's Arch. Pharmacol. 1989, 340, 321-327.

(16) Rondu, F.; Le Bihan, G.; Wang, X.; Lamouri, A.; Touboul, E.; Dive, G.; Bellahsene, T.; Pfeiffer, B.; Renard, P.; GuardiolaLemaître, B.; Manéchez, D.; Penicaud, L.; Ktorza, A.; Godfroid, J .-J . Design and Synthesis of I midazoline Derivatives Active on Glucose Homeostasis in a Rat model of Type II Diabetes. 1. Sybthesis and Biological Activity of N-benzyl-N'-alkyl-2-(4', $5^{\prime}$ dihydro-1'H-imidazol-2'-yl)piperazines. J . Med. Chem. 1997, 40, 3793-3803.

(17) Wang, X.; Rondu, F.; Lamouri, A.; Dokhan, R.; Touboul, E.; Pfeiffer, B.; Manéchez, D.; Renard, P.; Guardiola-Lemaître, B.; Godfroid, J. . .; Ktorza, A.; Pénicaud, L. Effects of S-21663 (PMS 812), an Imidazoline Derivative, on Glucose Tolerance and Insulin Secretion in Rat Model of Type II Diabetes. J . Pharmacol. Exp. Ther. 1996, 278, 82-89

(18) Le Brigand, L.; Virsolvy, A.; Peyrollier, K.; Manéchez, D. Godfroid, J .-J .; Guardiola-Lemaître, B.; Bataille, D. Stimulation of Insulin Release from the MIN6 Cell Line by a New Imidazoline Compound S-21663 (PMS 812). Evidence for the Existence of a Novel Imidazoline Site in $\beta$ Cells. Br. J . Pharmacol. 1997, 122, 786-791.
(19) J erzy, L.; Pietraseiwick, M.; Duszynska, B.; Cegla, M. T Structure-Activity Relationship Studies of Central Nervous System Agents. Effect of the Hydrocarbon Chain on the Affinity of 4-Substituted 1-(3-Chlorophenyl)piperazines for 5-HT $1 \mathrm{~A}$ Re ceptor Site. J. Med. Chem. 1992, 35, 2369-2374.

(20) Clarke, H. T.; Gillespie, H. B.; Weisshans, S. Z. The Action of Formaldehyde on Amines and Amino acids. J. Am. Chem. Soc. 1933, 55, 4571-4587.

(21) Le Bihan, G. Synthèses et études structure activité d'hétérocycles azotés actifs sur le diabète noninsulino dépendant. Ph.D. Thesis, University of Paris 5-René Descartes, 1997. The thesis is available in French librairies (microfilm). The results will be published elsewhere.

(22) Neef, G.; E der, U.; Sauer, G. One Step Conversions of Esters to 2-Imidazolines, Benzimidazoles and Benzothiazoles by Aluminium Organic Reagents. J . Org. Chem. 1981, 46, 2824-2826.

(23) Aebischer, B.; Frey, P.; Haerter, H. P.; Herrling, P. L.; Mueller, W.; Olverman, H. J.; Watkins, J. C. Synthesis and NMDA Antagonistic Properties of the Enantiomers of 4-(3-Phosphonopropyl)piperazine-2-carboxylic acid (CPP) and Insaturated Analogue (E)-4-(3-Phosphonoprop-2-enyl)piperazine-2-carboxylic acid (CPP-ene). Helv. Chim. Acta 1989, 72, 1043-1051.

(24) Garigipati, S. An Efficient Conversion of Nitriles to Amidines. Tetrahedron Lett. 1990, 31, 1969-1972.

(25) Levin, J . I.; Turos, E.; Weinreb, S. M. An Alternative Procedure for the Aluminium-mediated Conversion of Esters to Amides. Synth. Commun. 1982, 12, 989-993.

(26) Ramachandra, G. N.; Kattige, S. L.; Bhat, S. V.; Alreja, B.; De Sousa, N. J .; Rupp, R. H. An Antiinflammatory Cum Immunomodulatory Piperidinyl benzopyranone: I solation, Structure and Total Synthesis. Tetrahedron 1988, 44, 2081-2086.

(27) Rothenberg, A. S.; Dauplaise, D. L.; Panser, H. P. A Simple Route to 2-Vinyl-imidazole. Angew. Chem., Int. Ed. Engl. 1983, 22, 560-561.

(28) Thibault, C.; Laury, M. C.; Bailbe, D.; Ktorza, A.; Portha, B. Effect of Prolonged in vivo Glucose I nfusion on I nsulin Secretion in Rats with Previous Glucose Intolerance. Endocrinol ogy 1992, 130, 2521-2527.

(29) Chan, S. L. F.; Brown, C. A.; Morgan, N. G. Stimulation of Insulin Secretion by the Imidazoline alpha-2 Adrenoceptor Antagonist Efaroxan is Mediated by a Novel, Stereoselective, Binding Site. Eur. J . Pharmacol. 1993, 230, 375-378.

(30) PeléTounian, A.; Wang, X.; Rondu, F.; Lamouri, A.; Touboul E.; Marc, S.; Dokhan, R.; Pfeiffer, B.; Manéchez, D.; Renard, P.; Guardiola-Lemaître, B.; Godfroid, J .-J .; Pénicaud, L.; Ktorza, A. Potent Antihyperglyceamic Property of a New Imidazoline Derivative S-22068 (PMS 847) in a Rat Model NIDDM. Br. J . Pharmacol. 1998, 124, 1591-1596.

(31) Chan, S. L. F.; Brown, C. A.; Scarpello, K. E.; Morgan, N. G. Pancreatic $\beta$-Cells express an I midazoline Binding Site which is Distinct from $I_{1}$ and $I_{2}$-Sites. Proc. 2 nd I nt. Symp. I midazoline Receptors 1994, P3.

(32) Chan, S. L. F.; Dunne, M. J .; Stillings, M. R.; Morgan, N. G. The al pha-2 Adrenoceptor Antagonist Efaroxan modulates $\mathrm{K}^{+}$. ATP Channels in Insulin-secreting Cells. Eur. J . Pharmacol. 1991, 204, 41-48.

(33) Chan, S. L. F.; Hurst, R. D.; Morgan, N. G. Effects of alpha-2 Adrenergic Antagonists on Insulin Secretion from Rat Pancreatic Islets. Biochem. Soc. Trans. 1988, 16, 1005-1006.

(34) Chan, S. L. F.; Morgan, N. G. Stimulation of Insulin Secretion by Efaroxan may Involve Interaction with Potassium Channels. Eur. J . Pharmacol. 1990, 176, 97-101.

(35) Chan, S. L. F.; Stillings, M. R.; Morgan, N. G. Mechanisms involved in Stimulation of I nsulin Secretion by the Hypoglycemic al pha-Adrenergic Antagonist,DG-5128. Biochem. Biophys. Res. Commun. 1991, 176, 1545-1551.

(36) Olmos, G.; Kulkarni, T. N.; Haque, M.; MacDermot, J . I midazolines stimulate Release of Insulin from RIN-5AH Cells inde pendently from $I_{1}$ and $I_{2}$ Receptors. Eur. J . Pharmacol. 1994, $262,41-48$

(37) Brown, C. A.; Lowett, A. C.; Smith, S. A.; Morgan, N. G. Stimulation of Insulin Secretion by I midazoline Compounds is not due to I nteraction with non-Adrenoceptor I dazoxan Binding Sites. Br. J. Pharmacol. 1993, 108, 312-317.

(38) Renouard, A.; Widdowson, P. S.; Cordi, A. [ $\left.{ }^{3} \mathrm{H}\right]$ ] dazoxan Binding to Rabbit Cortex Recognizes Multiple I midazoline I 2 -type Receptors. Pharmacological Characterization and Relationship to Monoamine Oxidase. Br. J . Pharmacol. 1993, 109, 625-631.

(39) Several publications are in preparation in this field concerning other molecules which are structurally different from this series. They will be submitted to $\mathrm{J}$. Med. Chem.

(40) Rekker, R. F.; De Koort, M. M. The Hydrophobic Fragmental Constant; Extension to a 1000 Data Points Set. Eur. J. Med. Chem. Chim. Ther. 1979, 14, 479-488.

(41) Exploring QSAR. Hydrophobic, Electronic and Steric Constants; Hansch, C., Leo, A., Hoekman, D., Eds.; ACS Professionnal 
Reference Book; American Chemical Society: Washington, DC, 1995.

(42) Coupry, I.; Podevin, R. A.; Dausse, J . P.; Parini, A. Evidence for Imidazoline Binding Sites in Basolateral Membranes from Rabbit Kidney. Biochem. Biophys. Res. Commun. 1987, 147, 1055-1060.

(43) Reis, D. J .; Reunathan, S.; Meeley, P. M. P. Imidazoline Receptors and Clonidine-displacing Substance: Implication in
Regulation of Arterial Pressure, Neuroprotection and Medulloadrenal Secretion. Am. J. Hyper. 1992, 5, 45S-46S.

(44) Uhlen, S.; Wikberg, J . Delineation of Rat Kidney al pha-2A and al pha-2B Adrenoceptors with [ $\left.{ }^{3} \mathrm{H}\right] \mathrm{R} \times 821002$ Radioligand Binding: Computer Modelling reveals that Guanfacine is an al pha2A Selective Compound. Eur. J . Pharmacol . 1991, 202, 235-243.

J M981099B 